\title{
Functional Impairments of College Students with Attention Deficit/ Hyperactivity Disorder and Necessary Modifications for Higher Education
}

Sylvia A. Wright

West Virginia University

Follow this and additional works at: https://researchrepository.wvu.edu/etd

\section{Recommended Citation}

Wright, Sylvia A., "Functional Impairments of College Students with Attention Deficit/ Hyperactivity Disorder and Necessary Modifications for Higher Education" (2011). Graduate Theses, Dissertations, and Problem Reports. 3043.

https://researchrepository.wvu.edu/etd/3043

This Dissertation is protected by copyright and/or related rights. It has been brought to you by the The Research Repository @ WVU with permission from the rights-holder(s). You are free to use this Dissertation in any way that is permitted by the copyright and related rights legislation that applies to your use. For other uses you must obtain permission from the rights-holder(s) directly, unless additional rights are indicated by a Creative Commons license in the record and/ or on the work itself. This Dissertation has been accepted for inclusion in WVU Graduate Theses, Dissertations, and Problem Reports collection by an authorized administrator of The Research Repository @ WVU.

For more information, please contact researchrepository@mail.wvu.edu. 
Functional Impairments of College Students with Attention Deficit/ Hyperactivity Disorder and Necessary Modifications for Higher Education

\author{
Sylvia A. Wright
}

\begin{abstract}
Dissertation submitted to the College of Human Resources \& Education at West Virginia University in partial fulfillment of the requirements for the degree of
\end{abstract}

\author{
Doctor of Education \\ in \\ Curriculum and Instruction \\ Patricia Obenauf, Ed.D., Chairperson \\ Robert Rubenstein, Ed. D. \\ Nega Debela, Ed. D. \\ Ron Iannone, Ed. D. \\ Jeffrey Carver, Ed. D. \\ Joy Faini-Saab, Ed. D. \\ College of Human Resources and Education
}

Morgantown, West Virginia

2011

Keywords: Attention Deficit/Hyperactivity Disorder; Functional Impairments; Higher Education

Copyright 2011 Sylvia A. Wright 


\title{
ABSTRACT
Functional Impairments of College Students with Attention Deficit/ Hyperactivity Disorder and Necessary Modifications for Higher Education

\author{
Sylvia A. Wright
}

This study examines the impact of Attention Deficit/Hyperactivity Disorder (AD/HD) on college age students 18-25 years old. Qualitative research methods, including semi-structured interviews with students and significant others, writing samples and transcript documents, examine functional impairments of students with $\mathrm{AD} / \mathrm{HD}$ as well as functional impairment impact on relationships, academics and work. This qualitative research, grounded theory, provides a model for future research studies confirming existing theory and provides a basis for new theory.

The conclusion was that functional impairments continue to exist in college age adults with impairments with issues in concentration, organization, time related issues, time management/scheduling and hyperactivity. These in addition to issues with communication impact relationships with family and academic authority figures and significant other relationships as well as academic performance.

The research provides knowledge that contributes to planning for community agency services and academic interventions to ensure the success of students in higher education and future careers. 


\section{Acknowledgements}

The author wishes to express appreciation to the various contributors whose assistance with the research created a successful endeavor.

In memory of my father, Roy Carl Farley, who died in 2005 in the middle of my doctoral studies. Though he did not complete high school he and my mother made many financial sacrifices to see that all of their children were educated. To my mother, Dora A. Farley, whom at 81 years is my strongest supporter always keeping me in her thoughts and prayer and inspiring me with her deep faith.

To my committee members: Dr. Patrician Obenauf, Chairperson. Without your encouragement, support and expertise I could not have completed the doctorate. Thank you for being a role model in education and mentor to me as an older student. Dr. Robert Rubenstein, Minor Chairperson. Thank you for being a mentor, supporter and role model for me as a Licensed Professional Counselor as well as all Licensed Professional Counselors. Dr. Nega Debela. Thank you for inspiring me to pursue qualitative research. To my esteemed committee members: Dr. Ron Iannone, Dr. Jeffrey Carver and Dr. Joy Faini-Saab. Thank you for your gifts of time, expertise and guidance.

To my husband, Stephen and children, Adrianne and Jonathan, who are now teenagers and have grown up while I pursued the doctorate. It is my hope that I have inspired you not to give up on your dreams when the challenge is difficult.

To Karen Farmer, who struggles with her own Attention Deficit/Hyperactivity Disorder: You have helped me so much with technical assistance of typing, transcribing and coding. The experience I gained from our working relationship though challenging and frustrating at times 
has provided me insight and experience that will be invaluable to me as a Licensed Professional Counselor and employer who works with those with disabilities. It is my hope that you have gained enough confidence, growth, awareness and insight into $\mathrm{AD} / \mathrm{HD}$ that you will pursue a doctorate. You are a talented writer and excel with technology.

To the Director of Support Services, your staff and the students and their significant others, thank you for taking the time to support my research.

Finally, to all of my clients who initially inspired me to do research in the field of Attention Deficit/Hyperactivity Disorder. It is my hope that you will benefit from this research and that I have become a better educator and Licensed Professional Counselor as a result of this study. 


\section{Table of Contents}

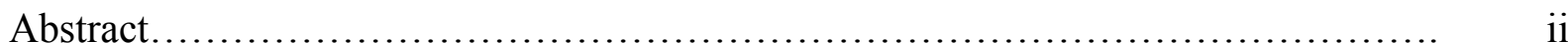

Acknowledgements.......................................................

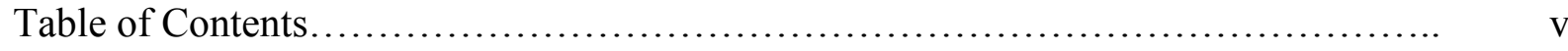

CHAPTER ONE - Introduction.......................................... 1

A Historical Perspective............................................. 1

Problem Statement................................................ 7

Major Purposes and Questions....................................... 7

Justification and Significance...................................... 8

Limitations....................................................... 9

Definitions $/$ Terms ................................................. 10

CHAPTER TWO - Literature Review................................... 14

Attention Deficit/ Hyperactivity Disorder.............................. 14

Preschool and Elementary School Years................................ 16

Recommended Academic and/or Community Agency Treatment............... 18

AD/HD Adolescent Literature Reviews............................... 28

Functional Impairments.................................... 28

Adolescent Community Agency Treatment and Academic Services............. 29

Young Adults AD/HD Literature Reviews.............................. 31

Functional Impairments.................................... 31

Adult Community Agency Services and Academic Services................. 38

Qualitative Research and Grounded Theory ............................. 39 
CHAPTER THREE - Introduction............................................ 41

Participants.......................................................... 42

Procedures.................................................................. 43

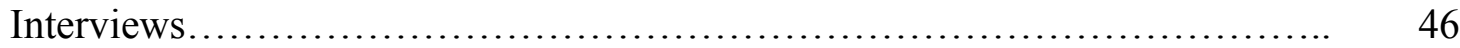

Student Interview Questions..................................... 46

Significant Others Semi-structured Interviews....................... 49

Written Student Interview Questions.............................. $\quad 50$

Methods.................................................................. 51

Data Analysis................................................ 52

Table 1 Participants........................................................... 53

Table 2 Information Sources Used to Answer Major Purposes and Research Questions.. 54

CHAPTER FOUR - Analysis................................................ 55

Functional Impairments............................................... 56

Individual Student Analysis of Overall Functional Impairments......... $\quad 58$

Table 3 Functional Impairments in College...................................... 74

Relationship Functional Impairments................................... $\quad 75$

Individual Student Analysis of Relationship Functional Impairments.... $\quad 75$

Table 4 A Relationship Functional Impairments at College with Authority Figures...... 94

Table 4 B Relationship Functional Impairments at College with Peers.................. 95

Table 4 C Relationship Functional Impairments with Family Authority Figures........ 96

Table 4 D Relationship Functional Impairments with Family Peers.................... 97

Table 4 E Relationship Functional Impairments with Significant Others............... 98 
Table 4 F Relationship Functional Impairments at Work........................ 99

Academic Functional Impairments and Writing Sample Issues............... 100

Individual Student Analysis of Academic Functional Impairments...... 100

Analysis of Writing Sample Issues.............................. 100

Table 5 Academic Functional Impairments.................................... 109

Table 6 Writing Sample Analysis......................................... 108

Work Functional Impairments...................................... 109

Individual Student Analysis of Work Functional Impairments......... 109

Table 7 Work Functional Impairments.................................... 116

Academic community Agency Services.............................. 117

History, Current Services and Requested Services.................. 117

CHAPTER FIVE - Summary of Results.................................. 124

Summary of Overall Functional Impairments........................... 125

Summary of Relationship Functional Impairments...................... 127

College University Relationship............................... 127

Family Relationships....................................... 129

Work Relationships....................................... 132

Summary of Academic Functional Impairments.......................... 133

Summary of Work Functional Impairments............................ 135

Discussion: Agreement or Disagreement with the Literature Review.......... 136

Overall Functional Impairments.............................. 138

Relationship Functional Impairments........................... 138 
College University Relationships........................... 138

Family Relationship Impairments........................... 137

Work Relationship Impairments............................... 139

Academic Functional Impairments................................. 143

Work Functional Impairments.................................... 144

Implications for Education............................................. 145

Further Research........................................................ 149

References..................................................................... 152

Appendix A - IRB Approval Document........................................ 157

Appendix B - Student Cover Letter.............................................. 159

Appendix C - Sample Student and Significant Other Interview...................... 161

Appendix D - Writing Samples............................................. 182

Appendix E - Observation Memos.............................................. 186

Appendix F - Vita....................................................... 216 


\section{CHAPTER ONE}

Introduction

\section{A Historical Perspective}

What functional impairments affect college age students with attention-deficit/ hyperactivity disorder (AD/HD)? Given the factors that affect college age students with AD/HD what changes, continuation or modifications of treatment services or academic strategies may be necessary to assist this population in universities? The historical perspective supporting functional impairments that individuals with $\mathrm{AD} / \mathrm{HD}$ have had during the elementary and high school years will serve three functions: 1) There must be a definition of AD/HD. 2) The functional impairments will provide a historical reference to document the existence of symptoms that verify the diagnosis of $\mathrm{AD} / \mathrm{HD}$, as individuals with a diagnosis of $\mathrm{AD} / \mathrm{HD}$ must have documentation of symptoms that occur prior to the age of seven. 3) Since there are few studies in the literature review for young adults, the elementary and high school studies will provide comparative baseline data as a reference for a starting point. Most of the previous studies only infer that functional impairments continue into adulthood. Only the Milwaukee study continues to study individuals ages 18-25 into young adulthood (Barkley, Fisher, Smallish \& Fletcher, 2002).

A grounded theory qualitative study will be used to 1) verify existing theory about $\mathrm{AD} / \mathrm{HD}$ and 2) develop new theory as very few studies have been done on young adults who are attending universities. Given this situation the research that is conducted will serve as a model of a qualitative research, more specifically grounded theory, as it will be impossible to reach the 
point of theoretical saturation or exploration of the data until no additional new information is found.

The literature supports that $3-7 \%$ of school age children are affected by $\mathrm{AD} / \mathrm{HD}$ (Diagnostic Statistical Manual of Mental Disorders, Fourth Edition, Revised (DSM-IV-TR, 2000). The most prominently used diagnostic assessment for Attention Deficit/Hyperactivity Disorder is the American Psychiatric Association: Diagnostic and Statistical Manual of Mental Disorders, Fourth Edition, Text Revision (DSM-IV-TR, 2000). This instrument is primarily referenced to children and is currently also used to assess adults. Attention deficit hyperactivity disorder includes symptoms of inattention, distractibility, impulsivity including failure to pay attention to details, careless mistakes in schoolwork or the workplace, difficulty sustaining attention when working or playing, not listening, inability to follow directions, incompletion of school or work tasks, avoiding tasks that require sustained mental effort, losing items required to do tasks, forgetfulness, fidgeting, leaving the seat when there is a need to remain seated, climbing excessively when inappropriate, difficulty playing or engaging in tasks quietly, driven behavior as by a motor, excessive talking, blurting out answers, not waiting for one's turn and interrupting (DSM-IV-TR, 2000).

Diagnosing adults is problematic with current criteria, as it is not developmentally referenced for adults and they may have outgrown the standard criteria (Barkley et al., 2002). There may be a need for changes to diagnostic instruments that reflect the different issues adults with AD/HD have. Problems associated with the research (Barkley et al., 2002) include limited samples; inconsistencies in the use of instruments for confirmation of the diagnosis; continual changes in the DSM criteria, which do not take into account symptoms that may be apparent in 
adults; and lack of longitudinal studies into adulthood. There is often discrepancy in the perception of continued symptoms of AD/HD into adulthood between the individual and significant others.

As many as $1-6 \%$ of adults appear to maintain debilitating symptoms of AD/HD that impact school, work performance, current and future family relationships (Wasserstein, 2001). Recent research suggests that prior beliefs that all children outgrow $\mathrm{AD} / \mathrm{HD}$ are erroneous (Nigg et al., 2002). Hallowell and Ratey (1995) support theories of a genetic cause for the disorder in terms of brain functioning with catecholamine dysfunction and impairments in serotoninergic, dopaminergic and noradrenergic systems, which impact the frontal lobe of the brain. Deficits in these areas impair memory and planning ability and cause difficulty shifting from one task to another. There is also a decrease in glucose metabolism in the basal ganglia that regulates body movement and behavior. Given the genetic problem, the assumption can be made that this is a permanent condition, which would affect adult functioning. Given the impact of $\mathrm{AD} / \mathrm{HD}$ symptoms on family, academic performance, and future careers strategies must be developed for better assessment of $\mathrm{AD} / \mathrm{HD}$, and implement treatment strategies and academic interventions that effectively deal with problems associated with AD/HD. Better longitudinal studies must be provided to assist with the understanding of the long-term impact of $\mathrm{AD} / \mathrm{HD}$, evaluate current academic strategies and assess the effectiveness of treatment strategies for AD/HD in adults. These studies are critical to planning for the needs of students in higher education.

In addition to considering the $\mathrm{AD} / \mathrm{HD}$ diagnosis, other disorders must be assessed including mood disorders, psychotic disorders, anxiety disorders, and personality disorders because half of all AD/HD cases are accompanied with co-morbid diagnoses such as conduct 
disorder and oppositional defiant disorder. Additionally, they are also accompanied by mood disorders, anxiety, substance abuse disorders, and learning disorders (DSM-IV-TR, 2000).

As a practicing Licensed Professional Counselor I have observed that many clients who reported hyperactivity as children no longer show the physical overt signs of hyperactivity as adults. However there is more cognitive restlessness in adults. This would be evident in conversations as rapid thoughts/conversation or skipping words or subjects. Part of the reason that there may be an absence of hyperactivity as defined in children is that interventions may have brought this aspect of behavior under control by adulthood particularly when counselors, parents and school officials participate in behavior management. Adults that I have seen in my clinical practice continue to have difficulty with inattention, which affects interpersonal relationships, planning, organizing, and task completion. These functional impairments have a negative impact on successful completion of work related tasks or higher education programs. Adults also have high rates of conflict in partner or marital relationships and frequent problems with employment including failure to complete tasks and high job turnover (Hallowell \& Ratey, 1995).

My personal experience with adults who have been diagnosed with AD/HD and the literature review suggests that functional impairments continue into adulthood so the question remains as to whether or not individuals will continue to need treatment interventions. If the literature implies that adults continue to have functional impairments, then what services will individuals continue to need if they attend college?

Some of the community agency interventions or academic interventions that children and adolescents used may need to be continued or modified for college age students. The following 
studies summarize what has been most successful for children and adolescents. Several studies (McGoey, Eckert, \& DePaul, 2002; Edwards, 2002) seem to substantiate that a combination of medication and psychosocial interventions are the most effective in treating AD/HD. The most common medications utilized are Ritalin and Adderall, which are stimulants, and various antidepressants. Stimulants have the ability to decrease associated behavior problems and increase the ability to pay attention. They neither improve cognition, nor do they produce longterm positive effects. They are accompanied by considerable side effects including increased blood pressure, cardiovascular effects, loss of appetite, retarded growth, decreased social interaction and depression. There is also controversy about whether or not these drugs increase the risk of substance abuse (Millberger, 1998).

The research (Edwards, 2002) suggests that therapies such as family therapy and behavior management therapy are effective because they focus on contingency management with token rewards, and consequences such as grounding, restriction, etc. Parent education, that focuses on behavior principals and problem-solving communication training, which focuses on conflict resolution skills appear to be effective. Although some of the research suggests that long-term results show less effectiveness with these treatment interventions, Robin and Foster (1989) suggest that they are beneficial because they are democratic supporting adolescent thrust toward independence, adapt for rapid change while authoritarianism resists change, and permit an orderly rational discussion of issues.

Neurofeedback appears to show promise for about $40 \%$ of individuals affected by $\mathrm{AD} / \mathrm{HD}$, but it is both costly and time consuming. It is also not covered by health insurance 
programs. Finally, some children benefit from dietary changes such as an absence of sugar or wheat products if they may have what some view to be food allergies (Hallowell \& Ratey, 1995).

Brand, Dunn, \& Greb (2002) suggest that changes in the school environment may be necessary to accommodate individuals with different needs and learning styles. Those include use of low light sources rather than bright light, afternoon classes rather than morning classes due to better performance in the afternoon, involvement of parents for these individuals, shorter study periods with breaks and kinesthetic learning. There is some indication that since work environments are not structured like classrooms collaborative small group learning could be a more effective learning style.

There are two studies that reference the need for academic services and community agency services for college age students. The first study found to address specifically collegeaged students is the Wassertein (2001) study which suggests that college students can benefit from academic services such as longer test times, student note takers, tape recorded class sessions, advanced organizers, computer technology and training sessions that teach mnemonic devices to support memorization skills.

The second study (Brand et al., 2002) suggests that AD/HD individuals with co-morbid diagnoses of conduct disorder could be more effectively managed if mental health professionals collaborated with schools to give teacher and parent trainings in behavior management strategies and conflict management skills. Though he was initially referring to school age children, he went on to suggest that college age students continue to need academic services as well as community agency treatment services. 


\section{Problem Statement}

Due to limited young adult studies with college age students I am posing the following question: "What are the functional impairments that confront college age students with AD/HD?" which is of critical importance in assessing, treating and diagnosing college age adults who have $\mathrm{AD} / \mathrm{HD}$. The literature supports the continual need for assessment, treatment and intervention well into adulthood for individuals with $\mathrm{AD} / \mathrm{HD}$ due to continued maladaptive symptoms and functional impairments. Educators and counselors must be cautious in diagnosing and labeling of individuals with $\mathrm{AD} / \mathrm{HD}$, must understand that many individuals with $\mathrm{AD} / \mathrm{HD}$ have individualized strengths and weaknesses, and that all individuals must be afforded, without repercussion, the opportunity to learn from a variety of instructional methods that meet the unique learning styles of individuals.

\section{Major Purposes and Questions}

The major purposes of this study are 1) to determine functional impairments that confront the college age students with $\mathrm{AD} / \mathrm{HD}$ and 2) to determine what changes, modifications or continued academic strategies or treatment services are needed for college age students with

\section{$\mathrm{AD} / \mathrm{HD}$.}

The following research questions will be obtained from the perspective of the interviewee, (student), significant other, observation memos, writing samples, and college transcripts to meet the major purposes. Therefore, there is a need to continue to include significant others such as parents, employers and partners when examining this topic to confirm information with similar assessment instruments.

The research questions are as follows: 
1. What functional impairments suggest that a college age student may have AD/HD?

2. How do these functional impairments affect (a) the academic function of AD/HD students in a college setting, (b) relationships with authority figures, professors, peers, and family members?

3. What is the impact of $\mathrm{AD} / \mathrm{HD}$ as the college student/young adult enters the workforce?

4. What resources, including teaching methods and other professional resources may need to be continued, be modified or be changed due to functional impairments of college age students with $\mathrm{AD} / \mathrm{HD}$ ?

5. What information from individuals with $\mathrm{AD} / \mathrm{HD}$ could be incorporated into an academic setting to ensure long-term success of students with AD/HD?

\section{Justification and Significance}

The significance of doing a qualitative study is to discover new information about college students with $\mathrm{AD} / \mathrm{HD}$, support previous assumptions about adult individuals with $\mathrm{AD} / \mathrm{HD}$, and to suggest appropriate resources, academic strategies and treatment interventions that my be necessary to prepare college age students with $\mathrm{AD} / \mathrm{HD}$. Additionally, other than a few case references from practitioners in the mental health field I found no evidence of qualitative research for adult individuals with $\mathrm{AD} / \mathrm{HD}$, nor a qualitative study of individuals in a higher education setting. It is necessary to look at factors that affect college age students with AD/HD so that teaching strategies, and treatment interventions can be changed, modified or continued to ensure the academic success of individuals with AD/HD. Some strategies that have worked in the past may need to be continued, but we must also identify new strategies for the future as well 
as provide other treatment services that will assist adults in an academic setting. Additionally, I want to focus on something that the literature does not address: Identifying and utilizing strengths and the uniqueness of individuals with $\mathrm{AD} / \mathrm{HD}$ to contribute to improvements in academic functioning.

\section{Limitations}

In order to explore this issue, a review of literature will examine early childhood onset of attention deficit hyperactivity disorder and continue with an age progression examination through adulthood.

There are some limitations in a qualitative research project of this nature. Most notably qualitative research is inductive rather than deductive. This means a much broader approach to assessing details. Without a narrow focus on a single hypothesis as in quantitative research the research sample of the number of individuals is limited due to the time consuming nature of interviews and the analysis of large amounts of information. Given this situation the research that is conducted will serve as a model of a qualitative research, more specifically grounded theory, as it will be impossible to reach the point of theoretical saturation or exploration of the data until no additional new information is found.

Other clinical issues and concerns with the study are that there is a high amount of comorbidity in individuals with $\mathrm{AD} / \mathrm{HD}$. How does having another diagnosis impact the data and its analysis? Secondly, some of the data may not reflect the diagnosis of $\mathrm{AD} / \mathrm{HD}$ because there are often accompanying diagnoses of depression, anxiety, developmental disorders, and substance abuse issues. Additionally, individuals with $\mathrm{AD} / \mathrm{HD}$ often perceive their issues and concerns as far less detrimental than those individuals who are family members or peers. Barkley 
et al. (2002) referred to the issue that self-report often reflects significantly less impairment than reports by significant others. In the comparison of longitudinal studies of individuals with $\mathrm{AD} / \mathrm{HD}$ when significant others (parents and teachers) no longer provided their input, the individuals with AD/HD estimated less impairment. Thus it is important to consider significant other observations. Finally, my role as a mental health counselor who treats individual's with $\mathrm{AD} / \mathrm{HD}$ gives me a good base of understanding the diagnosis of $\mathrm{AD} / \mathrm{HD}$, but care must be taken that my previous experiences though certainly valid do not color my judgment and limit my ability to see things in a new or different light. The use of triangulation will be important to offset the possibility of missed information and to challenge me in the ways that I view the information.

\section{Definitions/Terms}

Attention-Deficit/Hyperactivity Disorder (AD/HD) - A mental disorder with a persistent pattern of impairment of inattention and/or hyperactivity that interferes with social, academic, or work performance and is more frequently displayed than is typically noted in individuals at a comparable level of development. Symptoms must occur prior to the age of seven and impairments must occur in at least two settings i.e., home, work, or school (DSM-IV-TR. P.85).

Category - Concepts from data that stand for phenomena (Strauss \& Corbin, 1998).

Coding - The process of noting categories and properties to generate theory (Glaser \& Strauss, 1967, p.106).

1. Axial Coding - Begins the process of reassembling data fractured in open coding. It is a process of relating categories to subcategories in which coding occurs around the 
axis of a category and links categories to properties and dimensions (Strauss \& Corbin, 1998, pp. 123-124).

2. Open coding - The analytic process through which concepts are identified and their properties and dimensions are discovered in the data (Strauss \& Corbin, 1998, p.101). Phenomena - Central ideas from data that represent concepts (Strauss \& Corbin, 1998, p. 101).

Concepts - A block of theory (Strauss \& Corbin, 1998, p. 101).

Confirmability - Refers to conducting data audits, which check for potentials for biases and distortions in the trail of raw data, and looking at whether the inferences are based on the data and are logical (Lincoln and Guba, 1985, p. 323).

Credibility - Enhancement of accuracy of generating theory by use of multiple comparison groups (Glaser \& Strauss, 1970, p. 231).

Dependability - Refers to reliability. This is determined by strategies of triangulation (multiple methods of data collection) (Lincoln and Guba, 1985, page 299). Also an independent individual considers whether the emerging results are consistent in collected data.

Description - Use of words to convey a mental image of an event, a scene, experience, emotion, sensation, related from perspective of person who is depicting information (Strauss \& Corbin, 1998, p.15).

Dimensions - A range of variance in properties of a category, giving clarification and specification (Strauss \& Corbin, 1998, p.101).

Grounded theory - The process of generating theory with a well-coded set of propositions, using conceptual categories and their properties (Glaser \& Strauss, 1967, p. 31). 
Memo writing - Comments written on field notes to illustrate ideas for enhancing coding (Glaser \& Strauss, 1967, p.108).

Properties - Characteristics of a category that define and give meaning (Strauss \& Corbin, 1998, p. 101).

Sampling - There are three types of sampling: Typical cases which are the norm for those being studied, deviant or extreme cases with unusual manifestations of phenomena and negative disconfirming cases that are exceptions to the rule (Devers \& Frankel, 2000, pp. 263272).

Subcategories - Concepts of a category that give further clarification and specification (Strauss \& Corbin, 1998, p. 101).

Theoretical Sampling - A process of using samples to discover categories and their properties and to suggest the interrelationships into a theory (Glaser \& Strauss, 1067, p. 62).

Theoretical Saturation - Criterion for judging when to stop sampling different groups pertinent to a category. Saturation refers to the concept that no additional data is found whereby one can develop properties of the category (Glaser \& Strauss, 1070, p. 61).

Theory - A set of well-developed concepts related by statements of relations that constitute an integrated framework for explaining or predicting phenomena (Strauss \& Corbin, 1998, pp. 15, 19, 20).

Transferability (or generalizability) - The degree to which qualitative research can be transferred or generalized to other contexts or settings Guba and Lincoln (1981) (as cited in Merriam, 1995, p.58) 
Triangulation - The consideration of multiple viewpoints of persons, places, events and times (Strauss \& Corbin, 1998, pp. 42-46).

Qualitative Research - Research that produces findings, which are not arrived at by statistical means or quantification. The bulk of analysis is interpretive with the use of interviews, observation, documents, films, videotapes, and census data. Raw data is coded nonmathematically for analysis to discover concepts and relationships. (Strauss \& Corbin, 1998, pp. 10-11).

Unstructured Interviewing - Interview with initial guiding questions but no formal structured instrument. The interview explores the topic broadly without closed ended questions and the interviewer is free to move the conversation in any directions that comes up in the course of conversation with the interviewee (Denzin \& Lincoln, 1998, pp.56). 


\title{
CHAPTER TWO
}

\author{
Literature Review
}

\section{Attention Deficit/ Hyperactivity Disorder}

Because of limited adult studies for individuals with AD/HD the literature review will review studies for children and adolescents to establish baseline data for young adults. To date there are very limited studies for college age students. The pre-school/children's studies and then adolescent studies will be broken into two parts: 1) Establishment of functional impairments associated with $\mathrm{AD} / \mathrm{HD}$ and 2) a review of the research to determine the most appropriate courses of treatment for AD/HD. This was a starting point for formulating a semi-structured interview to look at functional impairments and the need for academic and community agency services in college age students with $\mathrm{AD} / \mathrm{HD}$. It is inferred in the literature that $\mathrm{AD} / \mathrm{HD}$ continues into young adulthood due to genetic causes. Therefore, the assumption is that, when an individual ages, they do not out grow $\mathrm{AD} / \mathrm{HD}$.

Hallowell \& Ratey (1995) suggests that preschoolers, children and adolescents have impairments and maladaptive symptoms with $\mathrm{AD} / \mathrm{HD}$, but so do young adults. It should be noted that it is standard practice in the counseling field to review and confirm symptoms of $\mathrm{AD} / \mathrm{HD}$ in early childhood even if the diagnosis is made as an adult. Based on the literature review, it appears that $\mathrm{AD} / \mathrm{HD}$ presents in early childhood but continues to be problematic into early adulthood. According to Hallowell and Ratey, previous research suggested that children outgrow some of these symptoms, but the majority of recent studies, if they use the most up to date clinical assessments, suggest that adults continue to have functional impairments and maladaptive symptoms into early adulthood. Though adult hyperactivity appears to be under 
control, adults continue to be distractible with cognitive restlessness, are impulsive, and are inattentive. This contributes to disorganization and resulting inability to complete tasks at school and work, and results in conflicts with significant others such as employers and spouses.

The Zametkin study (Zametkin et al., 1993) suggests impairments in the brain structure and notes deficits in glucose uptake in those with AD/HD. Fludeoxyglucose F 18 and emission tomography were used to study cerebral glucose metabolism, which was reduced in hyperactive girls by $17.6 \%$ during an auditory-attention task, when compared to normal girls. Glucose metabolism was significantly reduced in six of 60 specific regions of the brain particularly the left anterior frontal lobe. Lower metabolism was inversely correlated with symptom severity (Zametkin et al., 1993)

The Kosnestsky study of 1970 (as cited in Hallowell \& Ratey, 1995) noted that norepinephrine, dopamine and serotonin levels alter catachaloamines and neurotransmitters in brain functioning in those with AD/HD. They suggest that there are problems in maturation of the frontal lobe of the brain or regulation of the dopamine system. This genetic difference produces inhibiting behaviors where there is a relentless flow of events with thoughts running together. In addition, individuals cannot pause long enough to listen to others. Stimulant medication increases functioning in the frontal lobe of the brain (Hallowell \& Ratey, 1995).

Reeve and Schlandler (2001) did frontal lobe functioning assessments in adolescents with AD/HD. Twenty adolescents were interviewed. They were given the Conner's Parent Rating Scale, Adolescent Self Report Scale, and Peabody Picture Vocabulary Test to examine nuerocognitive status. The dependent measure consisted of the Wisconsin Card Sorting Activity Test sensitive to frontal lobe dysfunction. The Stroop Color and Word Test separated word and 
color naming stimuli. The Purdue Pegboard Test examined motor functioning as a control task. Results indicated that adolescents with $\mathrm{AD} / \mathrm{HD}$ performed significantly worse than the control group on tasks sensitive to frontal lobe dysfunction. Those with AD/HD performed much worse on color and color word tests and were much more sensitive to task irrelevant information referenced by interference scores (Reeve \& Schlander, 2001).

In summary it appears that the literature of Howell and Ratey (1995), Reeve and Schlander (2001) and Zametkin et al., (1993) support that the cause of AD/HD is biological affecting the frontal lobe functioning. Howell and Ratey further specify that there is a deficit in glucose affecting the reuptake inhibitor affecting chemical messengers of norepinephrine, dopamine and serotonin. The review of studies suggests that there is a genetic cause of frontal lobe problems in the brain, which contributes to the diagnosis of AD/HD. This implies a permanent condition, which would not change as children with $\mathrm{AD} / \mathrm{HD}$ mature into young adults.

Preschool and Elementary School Years:

Literature Review of Studies with Children with AD/HD Functional Impairments Hallowell and Ratey (1995) discussed two early childhood case studies of children with $\mathrm{AD} / \mathrm{HD}$. The following are descriptive narratives. The first case, adopted twins, age three, came from an unstable home and had a history of insufficient nourishment. Both were described as very active children with behavior problems in day care. The authors indicate that they were misdiagnosed as children with behavioral problems. When the diagnosis was revised to $\mathrm{AD} / \mathrm{HD}$ and the children were treated with Ritalin the symptoms abated. 
In a second case study (Hallowell \& Ratey, 1995), Will, a kindergartner, was distractible and distracted others. His performance was inconsistent with his abilities. Though he had a winning personality he had provocative behavior, forgetfulness, disorganization, indifference, underachievement, impulsivity and a search for excitement rather than discipline.

The literature supports that $3-7 \%$ of school age children are affected by $\mathrm{AD} / \mathrm{HD}$ (Diagnostic Statistical Manual of Mental Disorders, Fourth Edition, Revised (DSM-IV-TR), 2000). This is the most prominently used diagnostic assessment for Attention Deficit/Hyperactivity Disorder. This instrument is primarily referenced to children and is currently also used to assess adults. Attention deficit hyperactivity disorder includes symptoms of inattention, distractibility, impulsivity including failure to pay attention to details, careless mistakes in schoolwork or the workplace, difficulty sustaining attention when working or playing, not listening, inability to follow directions, incompletion of school or work tasks, avoiding tasks that require sustained mental effort, losing items required to do tasks, forgetfulness, fidgeting, leaving the seat when there is a need to remain seated, climbing excessively when inappropriate, difficulty playing or engaging in tasks quietly, driven behavior as by a motor, excessive talking, blurting out answers, not waiting for one's turn and interrupting (DSM-IV-TR, 2000).

Howell and Ratey (1995), McGoey's (2002) literature review of 26 experimental articles, Stage and Quiroz (1997) and Drash, Soloman, Long, and Stolberg, (1976) and McGoey and DuPaul (2000) suggest that preschoolers evidence disruptive behaviors when they have AD/HD. Strayhorn and Weidman, and Henry (as cited in McGoey et al., 2002), Pisterman et al. and Drash et al. all indicated problems with compliance. Reeve and Schlander (2001) along with Howell 
and Ratey indicate poor performance or under achievement as problematic for preschoolers. Howell and Ratey further indicate additional symptoms of forgetfulness, disorganization, and indifference as behavioral symptoms of preschoolers. Finally the Campbell study (as cited in McGoey et al., 2002) indicates difficulty with carelessness, disorganization and inability to cooperate or remain seated in the classroom. Many of these symptoms are reflective of the two main identified symptoms of compliance and disruption. The resulting poor performance and under achievement comes from the inability to pay attention and distractibility (DSM-IV-TR, 2000). The DSM-IV-TR, 2000 also indicates a high co-morbidity of other diagnoses such as oppositional defiant disorder, conduct disorders, mood disorders, depression and anxiety and substance abuse disorders in individuals with AD/HD.

Recommended Academic and/or Community Agency Treatment

In a literature review of 26 experimental articles McGoey et al. (2002) evaluated the efficacy of pharmacological intervention, parent training and behavior interventions designed to manage disruptive behaviors of preschool children with AD/HD. Campbell's study of 1990 (as cited in McGoey et al., 2002) notes that preschool children with AD/HD require highly structured environments with specific clear directions and demands. They must have routines. They have difficulty adapting to changes. Preschoolers are often described as careless, disorganized, carefree, non-reflective, have difficulty remaining in their seats and can be defiant and non-compliant to the commands of authority figures. This sums up to a lack of ability to cooperate and be productive in preschool settings.

The authors, DuPaul and Eckert, 1997 provided a meta-analysis of the effectiveness of school based intervention in 63 studies. Most of the participants were between the ages of 5 and 
10 years old. They looked at whether or not school-based interventions for AD/HD were effective in changing disruptive, off-task behavior and academic performance in elementary students. DuPaul and Eckert found that school based interventions were significantly effective at managing classroom behaviors with students with AD/HD. Additionally they wanted to know which interventions (specifically, academic, contingency management or cognitive-behavioral strategies) were more effective. Students with AD/HD showed improvements in behavior after participating in any one of the three types of interventions. However, they found that contingency management techniques and academic interventions were more effective than cognitive behavior interventions. Finally, all of the interventions had a greater effect on behavior than academic performance though academics were also enhanced. In other words, the recommendations of contingency management or providing positive reinforcement for desirable behavior and penalties for undesirable behavior, and academic interventions such as peer tutoring were preferred over cognitive-behavior modification or problem solving.

The authors referred to studies by Stage and Quiroz (1997). Stage and Quiroz conducted a meta-analysis of 99 studies of instruments to reduce disruptive classroom behavior. Instruments to reduce classroom behavior consisted of behavioral, cognitive behavioral, individual counseling, and parent counseling in a multi-model approach. The intended goal was to decrease disruptive classroom behavior with interventions of behavioral, cognitive behavioral, individual counseling and parent training through a multi-model approach. When using the Interrupted Time Series Autocorrelation program, which yielded a t statistic that was transformed into an effect size of $223,78 \%$ of children decreased disruptive behaviors when behavior modification, cognitive behavioral, individual counseling and parent counseling were 
utilized in a multi-model approach. Types of behavioral interventions included social approval, disapproval and ignoring; punishment procedures such as timeout and over-correction; differential reinforcement; group contingencies such as token economies; home based contingencies; environmental control; self-management interventions; cognitive behavioral interventions; individual counseling; parent training; and multi-model interventions (coupling two or more interventions into one treatment package). It should be noted that only 55 of 5057 students had confirmed symptoms or a diagnosis of AD/HD. Eighty-one students had Learning Disabilities, 31 had mental retardation, 57 had serious emotional disorders, and 550 students were considered to have oppositional defiant or conduct disorders. It is my opinion that some of these interventions with $\mathrm{AD} / \mathrm{HD}$ students may be appropriate, but the study does not reflect a high enough sample to represent accurately students with AD/HD (Stage and Quiroz, 1997).

The Bryant, Vizzard, Willoughby, and Kupersmidt study of 1999 (as cited in McGoey et al., 2002) evaluated child training and classroom interventions for three to eight year old children and they concluded that there were only modest results.

McGoey et al. (2002) further reviewed 28 studies: 14 were relative to psychotropic medication, 9 were related to school based behavior management intervention, and 4 had parent education intervention. There was one study with a multi-component treatment approach. The studies of pharmacological interventions on problem preschoolers indicated that methylphenidate improves compliance on tests of behavior and activity levels. Results were positive with both low and high dose levels. Limitations should be noted. There was an absence of measures of parental compliance and acceptance of medication protocol and lacking direct measures or teacher measures of student behaviors. Only an analog setting was used for assessment of 
parent-child interactions and parents did not perceive that medication was helpful. Though the studies suggested that medication was beneficial in decreasing behavioral problems many participant's discontinued medication at the end of treatment.

The authors (McGoey et al., 2002) reviewed the studies done on the effectiveness of parent-child interaction training. The authors referred to the Strayhorn and Weidman study of 1989 (as cited in McGoey et al., 2002). Participants consisted of preschoolers. The instrument consisted of child behavior rating scales. Procedures consisted of direct observation of parentchild interaction, but no significant differences were noted between the study group and control group when teachers rated students. However, the 1991 follow-up Strayhorn and Weidman study (as cited in McGoey et al., 2002) with the same subjects evidenced continued improvement in the children's behavior with significant improvements in classroom behavior as indicated by teacher ratings.

Pisterman et al. (1989) conducted a study of child compliance and parenting techniques with 46 families with preschoolers. The behavioral assessment consisted of 20 minutes of free play, a compliance task and parent-supervised activities. In the compliance activity the child was asked to copy a series of increasingly complicated designs while measuring the child's on task behavior. Then the parents were asked to supervise the child's completion of four ageappropriate puzzles. Compliance was relative to the total number of parent commands including frequency of child compliance, frequency of appropriate commands of parents, and parental consistency in reinforcing compliance. In summary the instrument measured ratings of compliance, parent-child interactions and parent management skills. Procedures consisted of a twelve-week group parent training intervention for 46 families with pre-schoolers with AD/HD. 
There were statistical gains on measures of compliance, parent-child interactions and parent management skills. Positive interaction made up more of the parental interaction than did directive behavior and this was maintained at follow-up. A three-month follow up showed maintenance of those gains. The study supports the hypothesis that improvement in child compliance occurs when parents improve behavior management skills. A major down fall of the study was that the research did not assess setting generalization from clinic to home (Pisterman et al., 1989).

Allen, Henke, Harris, Barer and Reynolds (1967) refer to a third type of intervention, behavioral management, which consists of using rewards for appropriate behavior; giving effective directions and requests; and teaching self-control with consistent methods of discipline. The participant was a four and a half year old child. The effects of the contingency of positive verbal comments on a four and half year old child with an attention span problem were evaluated. The teacher provided the child with praise after one minute of attending behavior and ignored all other behaviors. Attention increased as attending behavior brought a corresponding decrease in activity changes. The study supports the hypothesis that attending behavior can be taught or can be shaped by a teacher and maintained by social reinforcement. According to the study the number of activity changes decreased to half. Eventually the student was able to sustain 15-20 minutes pursuing a single activity. One problem with the student was that the social reinforcement procedures were not generalized to the family setting. Also, no other disruptive behaviors were targeted for intervention. The study was very limited as it was in the child's natural setting. 
The study by Drash et al., 1976, evaluated participants that were hyperactive and inattentive young children ages 2-4.8 years. Upon admission children were engaged in oppositional and maladaptive behaviors such as tantrums, defiance, short attention span, poor speech, and running away from home. Procedures of positive reinforcement, time-out and parent training were applied to the children after training. The parent's theoretical learning was measured and parents were observed to measure whether or not these principals were applied correctly. Parents were $77.5 \%$ compliant compared to $81.6 \%$ compliant behavior of therapists. The behavior management system yielded positive results of reduced disruptive, non-compliant behaviors of children toward mothers. In this study total disturbed behavior and distractibility fell from the $99^{\text {th }}$ percentile at the beginning of treatment to the $66^{\text {th }}$ percentile when the program was complete. The study supported the hypothesis that hyperactivity is primarily noncompliance with external demands. When the compliance behavior was modified so was the hyperactivity. The mean score was now at the $52^{\text {nd }}$ percentile, which is the same median score for all children. McGoey et al. does suggest that the study's reliability is questionable as it was reported descriptively.

Another study by McCain and Kelly in 1993 (as cited by McGoey et al., 2002) suggested the following. A five year old with $\mathrm{AD} / \mathrm{HD}$ and with disruptive behavior participated in the study. The child had a school to home note procedure indicating goals for each school activity. Incidents of on task behavior and disruptive behavior were monitored. On-task-behavior increased from $57 \%$ to $85 \%$. Disruptive behavior dropped from $29 \%$ of the time to $7 \%$ of the time. The activity rate change dropped from an average of eight to two. 
Additionally, the authors (McGoey et al., 2002; McGoey \& DuPaul, 2000) noted the following study. Participants were preschool children. Instruments included a positive rewards chart with identified positive classroom behaviors. Teachers rewarded behaviors by awarding buttons on a chart for positive behaviors and removed buttons with inappropriate behavior. Rewards were given based on the number of buttons at the end of the day. In this study there were acceptable measures for teachers and detailed methodology. There were decreases in disruptive behaviors with both interventions.

Many of the studies that McGoey et al. (2002) cite have limited samples, and occurred in laboratory settings instead of the school setting. This jeopardizes the generalized reliability of results. Many studies have not been replicated so research, though promising, shows inconsistency and inconclusive results.

Only Henry’s study of 1987 (as cited in McGoey et al., 2002) includes multiple intervention components of medication, symbolic modeling and parent training to address the compliant behavior of children with AD/HD. The Henry study of 1987 showed that a combination of medications, symbolic modeling and parent training was more effective than medication and symbolic modeling or medication alone in improving compliance. Though this is a single case study it shows promise.

Next I will review studies relative to ages 7-10. In these literature reviews there is not a discussion of functional impairments. The literature review only discusses the efficacy of treatment interventions. I suspect that functional impairments are not reintroduced, as the diagnostic criteria require that symptoms that indicate $\mathrm{AD} / \mathrm{HD}$ must be evident prior to the age of seven. The author, Jason Edwards, (2002) reviews the MTA Cooperative Group 1999-A study. 
This is the largest and best-controlled study in child mental health and referred to often. Over a fourteen-month period of time, studies were done on the effectiveness of medication, behavior treatment, combined treatment, and community care, where there was medication used in $67 \%$ of the children.

Participants in the study were children aged 7 to 10 . The instrument consisted of 19 measures of six dependent variables including $\mathrm{AD} / \mathrm{HD}$ symptoms, aggression, oppositional defiant disorder, internalizing symptoms, social skills, parent child relations and academic achievement. Procedures consisted of the following: The medication group received medication three times a day of Ritalin or dextroamphetamine for 14 months. The behavioral group consisted of parent training, school based interventions and a summer treatment program. Teachers completed behavior report cards and sent them home to parents who provided a homebased reward system. The next group was a combination of medication and behavioral group. The final group received community care as usual.

Results of the study found that all four groups improved over 14 months but that the combination medication and behavioral treatment program and medication were statistically superior to the community care groups. The combination of medication and behavior treatment was superior to behavior treatment on many measures. Medication was not statistically superior to the behavior treatments. The combination group that received both medication and behavior treatment scored statistically higher to the community care group's treatment. Combinations of behavior treatments and medication treatments were superior to behavior treatment alone. Medication treatment was not statistically superior to behavior treatment. The combination group treatment was superior to medication alone on 19 measures. The combination medication 
and behavior treatment group had less doses of medication on average than the medication treatment group. The combined behavior and medication treatment group had statistically higher percentages than all others groups including the medication treatment group.

In a study of $\mathrm{AD} / \mathrm{HD}$ elementary children who were given the Dunn and Dunn LearningStyle Inventory (Brand, Dunn, \& Greb, 2002) clues were provided about effectiveness or ineffectiveness of teaching strategies in the classroom. The authors note that Dunn and Dunn promote the use of learning style strengths rather than classifying individuals as having $\mathrm{AD} / \mathrm{HD}$. The learning style inventory was given to elementary school students in grades three through six. In the study by Brand et al. (2002) three learning style elements were significant. Large numbers of the $\mathrm{AD} / \mathrm{HD}$ children required low rather than bright light when doing academic tasks, and most lack persistence and were not able to function well in the morning. These children were more motivated with parental encouragement than the other children. None of the elements (the need for mobility or need for kinesthetic learning) normally associated with children with AD/HD were significantly different than those of average children. Pre-high school students preferred tactile and kinesthetic learning through patterns and routines and were teacher and parent motivated.

To summarize the data for preschoolers when it comes to academic services or community agency services Howell and Ratey (1995) and Henry (as cited in McGoey et al., 2002) indicated that the stimulant medication Ritalin abated behavioral problems in preschoolers. In the McGooey et al., 2002 literature review, Stage and Quiroz (1997), Pisterman et al. (1989), Drash et al. (1976), Bryant and colleagues, Henry, and Strayhorn and Weidman (as cited in McGoey et al., 2002) all recommended parent training and involvement. Additionally in the 
McGoey et al. (2002) literature review, McGoey and DePaul (2000), Drash et al. (1976), Allen et al. (1967), Binder and colleagues, Kyle and colleagues and Landau and McAninch (as cited in McGoey et al., 2002) indicated that successful behavioral intervention includes rewarding appropriate behavior, teaching self-control, giving effective directions or requests, and utilizing consistent discipline. In summary the most effective treatment for preschoolers with AD/HD appears to be a combination of interventions that include stimulant medications along with behavior management in the home and school.

For elementary school age children the MTA study by Edwards (2002) analyzes the most effective types of intervention including medication alone, behavioral treatment alone, a combination of medication and behavioral treatment or community care. A combination of medication and behavioral treatments were superior to other treatment requiring less medication than medication alone treatment. Brand et al. (2002) indicates that instead of focusing on symptoms of $\mathrm{AD} / \mathrm{HD}$ we should be focused on learning styles and the teaching environment to assist elementary children in learning. It does appear that prior to high school children learn better with tactile and kinesthetic learning that focuses on patterns and routines. Older elementary school children also do better with parent involvement, do better with a low light setting and function better later in the day. Since these children were already medically treated for $\mathrm{AD} / \mathrm{HD}$ classroom modifications and changes in teaching styles appear to be of additional assistance to medication alone.

In summary, the literature review for preschoolers and elementary school children suggests that behavior management at school and home along with stimulant medication is the most effective services for addressing issues of children with AD/HD. Very little is said about 
academic interventions other than taking into account the learning style of individuals with $\mathrm{AD} / \mathrm{HD}$. There were some recommendations for accommodations in the environment including strong parental support and the use of low lighting and noting that individuals with $\mathrm{AD} / \mathrm{HD}$ function better in the afternoon. I have discovered in practice that individuals with AD/HD tend to have difficulty getting up in the morning and tend to be late for functions that are scheduled early in the day.

\section{AD/HD Adolescent Literature Reviews}

\section{Functional Impairments}

Reeve and Schlander (2001) assessed frontal lobe functioning in adolescents with $\mathrm{AD} / \mathrm{HD}$ when they were given the Wisconsin Card Sorting Test and the Stroop Color and Word Test. The control measure was the Purdue Pegboard, which does not assess frontal lobe functioning. The adolescents with AD/HD performed significantly worse on color score, interference score and color/word score. There were problems with perseverance, perseverance errors as time went by and the numbers of categories completed.

Barkley's study of interventions to deal with AD/HD adolescents with high conflict with parents suggests that parents of adolescents continue to deal with $\mathrm{AD} / \mathrm{HD}$ issues of inattention, poor impulse control and over activity. His study included adolescents with co-morbid diagnoses of oppositional defiant disorder (Barkley, Edwards, Laneri, Fletcher \& Metevia, 2001).

Milberger (1998) hypothesized that those teens with AD/HD are at risk for substance abuse disorders. Those with accompanying co-morbid conduct disorders are at greater risk according to Sharon Milberger of Brown University. Participants consisted of the following: Milberger (1998) did a comparison of teen siblings with and without AD/HD. There were 
probands of 140 teens with $\mathrm{AD} / \mathrm{HD}$ and 120 teens without $\mathrm{AD} / \mathrm{HD}$ (control group). The instruments and procedures consisted of one and four year follow-ups, which were done with the diagnostic assessment Kiddie-SADS-E. High-risk siblings had higher rates of AD/HD than those that were not high risk. Siblings with AD/HD had higher rates of substance abuse than siblings without AD/HD. Siblings with AD/HD had earlier onsets of substance abuse than those without AD/HD.

In summary the literature review suggest that adolescents have issues with perseverance and perseverance errors as time goes by. Adolescents also have high conflict with authority figures as in parents resulting from issues such as inattention, poor impulse control and over activity. Finally studies that included co-morbidity suggest that it is often the case that you are dealing with more than one diagnosis when adolescents have been diagnosed with AD/HD. Adolescent Community Agency Treatment and Academic Services

Barkley et al. (2001) has done a study on the efficacy of problem-solving communication training (PSCT) vs. behavior management training (BMT) alone. They then combined the two (BMT/PSCT) to study their effectiveness in dealing with parent adolescent conflict in teenagers with AD/HD and Oppositional Defiant Disorder (ODD) (Barkley et al., 2001).

Participants were parents and teenagers. The instrument developed seven criteria as follows: Parent or teacher complaints of inattention, poor impulse control and over activity. Teenage participants had to have 12 of 18 symptoms listed in the DSM-IV-TR. They also had to have a score of 65 or higher on the inattention scale and aggression scale of the Child Behavior Check List and have at least four symptoms of ODD listed in the DSM-IV-TR. Procedures consisted of 18 treatment sessions held twice a week. Mid treatment evaluation occurred after 
the $9^{\text {th }}$ session and a post treatment evaluation occurred after the $18^{\text {th }}$ session. A two-month follow-up occurred after treatment. Effectiveness was determined with a Conflict Behavior Questionnaire with 20 true/false items to assess communication style and level of conflict in parent-adolescent interaction in the previous two weeks. An Issue checklist covered 44 topics on which parents and teens might disagree. The Parent-Teen Conflict Tactics Scale assessed verbal and physical forms of conflict. Parent, teacher and teen ratings were determined with a fourpoint symptoms scale for AD/HD-ODD in the DSM-IV-TR. A Conflict Rating System rated negative and positive communication. By the end of treatment $38 \%$ of individuals dropped out of the PSCT group while only 18\% had dropped out of the BMT/PSCT group. Both groups had significant improvement on measures completed by mother, father and teens. Direct observations substantiated this finding. Only $25 \%$ of individual participants or less showed reliable change, but as a family $34-70$ percent of families were normalized in the PSCT group and $42-80 \%$ were normalized in the combination group by the end of treatment (Barkley et al., 2001).

In the study of individuals in grades 5-12 (Brand et al., 2002) a learning style inventory was given. Eight differences were evident. One-third to one-fifth of individuals preferred learning in the afternoon in a structured environment with information presented in patterns and with the use of kinesthetic approaches. The need for tactile learning decreases with age. High school students expressed preferences for lower lighting, conformity and auditory learning.

The interventions that are suggested are as follows: Barkley et al. (2001) indicated that problem solving communication training and behavior management strategies both normalized parent child interactions, but were a little more effective in combination. Millberger suggests that there needs to be substance abuse intervention in these children prior to the age of 12 years. 
Brand et al., (2002) suggest modifications in teaching to individual's learning strengths and environmental changes to include preference to afternoon learning, structured environment, conformity, information presented in patterns, kinesthetic approach to learning decreasing as the student ages, auditory learning preferred as the student ages.

\section{Young Adults AD/HD Literature Reviews}

\section{Functional Impairments}

Barkley has another study (Barkley, Fischer, Smallish, \& Fletcher, 2002) about the persistence of attention-deficit/hyperactivity disorder into young adulthood He reviews the only four follow-up studies that have retained $50 \%$ or more of an original sample of children into adulthood: The 1993 Montreal study by Weiss and Hechtman and their colleagues (as cited by Barkley et al, 2002), the 1998 New York City study by Mannuzza, Klein, Bessler, Malloy, and LaPadula (as cited in Barkley et al., 2002), the 2001 Swedish study by Rasmussen and Gillberg (as cited in Barkley et al., 2002) and the present Barkley study from Milwaukee. All of the participants are samples of individuals who where diagnosed as AD/HD in childhood and followed into adulthood. Related to the discussion of participants and procedures Barkley does not discuss particular procedures and instruments for the Montreal Study due to the nonexistence of the DSM at the time of The Montreal Study. The criteria for participants were children who received a clinical diagnosis of hyperactive child syndrome based on high levels of restlessness and poor concentration that had existed over an extended period of time that caused difficulties at school and home. The Montreal study (as cited in Barkley et al., 2002) found that two-thirds of their original sample claimed to be troubled as adults by one or more disabling core 
symptoms: restlessness, impulsivity or inattention and one-third had at least moderate to severe levels of hyperactive, impulsive and inattentive symptoms (Barkley et al., 2002).

The Sweden study (as cited in Barkley et al., 2002) reported similar marked symptoms of $\mathrm{AD} / \mathrm{HD}$ in $49 \%$ of probands compared to $9 \%$ of controls. The original study used the diagnosis of minimal brain dysfunction from the original DSM in a subset of children whose teachers rated them with $\mathrm{AD} / \mathrm{HD}$ symptoms.

The New York City study (as cited in Barkley et al., 2002) followed two sets of children into adulthood. Of the first sample 31\% met the DSM-II criteria for AD/HD at the ages of $16-23$ or a mean age of 18.5 years. In the second sample $43 \%$ met the criteria for $\mathrm{AD} / \mathrm{HD}$. Eight years later, at mean age of 26 those who met the criteria for $\mathrm{AD} / \mathrm{HD}$ fell to $8 \%$ and $4 \%$ respectively. Barkley attributes the significant drop to two possible problems. First, those with co-morbid diagnosis of conduct disorder were eliminated making the severity of AD/HD less. Secondly, both Montreal and New York study switched from other to self-reporting at age 26. It should be noted that individuals with $\mathrm{AD} / \mathrm{HD}$ do not perceive their problems in the same manner as significant others. In general they see their behaviors and symptoms as less debilitating. Barkley notes also that the DSM-III lacks reliability with its absence of age-related thresholds for diagnostic symptoms lists related to developmental stages. It may be that children have not outgrown the symptoms, but only the criteria of the DSM-III (Barkley et. al., 2002).

In the Milwaukee study, Barkley, Fischer, Edelbrock, \& Smallish, 1990 (as cited in Barkley, 2001) used a group of 158 individuals diagnosed as hyperactive in childhood with a matched community control group of 81 individuals. They were originally assessed in 1979-80 at ages 4-12, again in 1987-1988 at ages 12-20, and finally in 1992-1996 at ages 19-25. The 
participation rate at the last study was $93 \%$ for the hyperactive group and $90 \%$ for the control group. A structured interview was created using the DSM-II-R symptoms list and participants rated the frequency of symptoms on a five point Likert scale. Fifteen other AD/HD related items were created to deal with time management, punctuality, organization, working independently, excessive socializing, forgetfulness and so on. Rating instruments also included Conner's Parent Rating Scale, a ten-item hyperactivity index. A home situation questionnaire with a Likert scale rated children's behavior problems in 16 different home and public situations. The WerryWeiss-Peters Activity Rating Scale was revised for use with parents to evaluate hyperactive behavior at home. High school transcripts recorded grade point averages and class rankings. Employers received a twenty-nine-item survey for behavior and job performance of the participant, criminal records were obtained, and the Young Adult Self-Report for the Child Behavior Checklist was modified for use by 18-30 year olds. There is a separate section for information about friends, educational performance, job performance and relationships with immediate family and partners.

Conclusions of parental reports indicated that $71 \%$ of participants had $\mathrm{AD} / \mathrm{HD}$ at mid adolescent but five years later the figure plummeted to 5\%for hyperactive groups if the reporting source was the young adult. The parent rate report was $46 \%$. If the DSM-IV-R was used the rate rose to $58 \%$. Using developmentally referenced criteria puts the rate even higher. Barkley questioned the accuracy of self-reporting based on the inconsistencies in participant and parent reporting in young adults (Barkley et al., 2002).

The authors of the 1985 study by Eysenck and Eysenck (as cited by Nigg et al., 2002) attempted to find links between personality traits and clinical symptoms in adults Those 
personality traits and clinical symptoms included extraversion or sociability; activity and assertiveness; conscientiousness or maintaining task focus and concentration in facilitating task and goal directed behavior; agreeableness or altruism, trust, compliance and concern for others versus antagonism and bullying, aggression and hostility; neuroticism which reflects negative emotionality with vulnerability to stress (there is a higher risk for mood disorders, depression and anxiety in those with AD/HD); and openness to new experiences. Participants included the following: Samples came from 535 students at Michigan State University, There were 142 parents with a mean age of 39.2, half of which had children with AD/HD. There were 293 students from the University of Denver and 290 parents with a mean age of 40.2, which came from Denver. There were 278 parents that came from San Francisco and 88 individual students with a mean age of 21.6 years, which came from the campus office offering disabilities services.

The instrument utilized in this study was The NEO Five Factor Inventory, which was used for self and spouse report in all samples except the Bay Area used the Big Five inventory for spouses. $\mathrm{AD} / \mathrm{HD}$ symptoms were determined through the DSM-IV-TR, the Wender-Utah Rating Scale and Achenback's Young Adult Self-report Scale. In procedures the authors assess Five Big Dimensions of personality in adults who met the criteria for AD/HD. Overall AD/HD symptoms were consistently related to the Big Five Dimensions of low Conscientiousness, low Agreeableness and high Neuroticism. The Wender-Utah scale and self-reports suggested that $\mathrm{AD} / \mathrm{HD}$ is related negatively to Extraversion and positively to Openness.

In another personality study (May \& Bos, 2000), one hundred forty adults were referred for testing for attention deficit hyperactivity disorder. One hundred four who were given the diagnosis of $\mathrm{AD} / \mathrm{HD}$ were divided into four model groups: $\mathrm{AD} / \mathrm{HD}$ adults, $\mathrm{AD} / \mathrm{HD}$ co-morbid 
adults, AD/HD-ODD (Oppositional Defiant Disorder) adults and AD/HD-ODD-co-morbid disorder. Instruments utilized were MCMI-II to assess personality features. Clinical interviews were conducted with the adult participant and a significant other. The participants received a DSM-III-R checklist, Gordon Diagnostic System, Conners Continuous Performance and Millon Multiaxial Inventory. The procedures identified as the dependent measure a 175 item true-false self-report questionnaire utilized to make assessments and treatment decisions about persons with emotional and interpersonal difficulties. The AD/HD only group had a prominent elevation on the histrionic scale. These individuals seek stimulation, excitement and attention having initial involvement with others, but the involvement does not last due to eventual boredom. They are colorful and charming socialites at parties and social gatherings, but tend to be loud and exhibitionistic with demanding behavior. They have intense emotional moments in friendships but do not usually sustain friendships.

The AD/HD co-morbid individuals had elevations on the avoidant and dependent personality scales. They are detached and isolated from others and have few friends.

AD/HD-ODD individuals were elevated on the histrionic, narcissistic, aggressive-sadistic and negativistic personality scales $50 \%$ of the time. They have difficulty with anger control, difficulty in relationships, resent authority and sabotage directives. They view relationships in terms of power, and see relationships in terms of winners and losers.

AD/HD-ODD co-morbid individuals reject social norms, are angry without warm emotions, which is considered weak, and they avoid and blame others (May \& Bos, 2000). Another study of adults with $\mathrm{AD} / \mathrm{HD}$ suggests that there are problems with time perception and time reproduction (Barkley, Murphy, \& Bush, 2001). Individual adults who were 
diagnosed with $\mathrm{AD} / \mathrm{HD}$ were compared to a control group without $\mathrm{AD} / \mathrm{HD}$ and were given structured clinical interviews about adaptive functioning, driving, employment, social relationships and the presence of other psychiatric disorders.

Subjects received neuropsychological tests and tests of motor vehicle driving ability. An examiner with a stopwatch asked participants to verbally estimate times determined by an electronic stopwatch and to reproduce six different time durations with verbal instructions to the examiner. The $\mathrm{AD} / \mathrm{HD}$ group significantly overestimated the sample durations relative to the control group and produced significantly shorter time reproductions than the control group. This suggests a deficit in sense of time primarily in time reproduction, but not time estimation. The original concept of testing for time reproduction and time estimation was developed by Zakey, 1990 (as cited in Barkley, Murphey, \& Bush, 2001).

Barkley et al. (2002) examines the Montreal, Sweden, New York and Milwaukee studies. In those studies each confirms continuation of symptoms of restlessness, impulsivity, inattention and hyperactivity in 39 to 78 percent of young adult cases. Variance may be attributed to changes in DSM criteria over the years or an absence of conduct disorders or co-morbidity, which reduced the rate in the New York Study. The other studies did not eliminate co-morbidity.

Nigg et al. (2002) did a study of the following personality traits, which typically appear to be associated with AD/HD. Those personality traits and clinical symptoms included extraversion or sociability; activity and assertiveness; conscientiousness or maintaining task focus and concentration in facilitating task and goal directed behavior; agreeableness or altruism, trust, compliance and concern for others versus antagonism and bullying, aggression and hostility; neuroticism which reflects negative emotionality with vulnerability to stress (there is a 
higher risk for mood disorders, depression and anxiety in those with $\mathrm{AD} / \mathrm{HD}$ ); and openness to new experiences. $\mathrm{AD} / \mathrm{HD}$ is associated with low conscientiousness, low agreeableness, and high neuroticism. The Wender-Utah scale used by Nigg et al. (2002) in his study of self-reports suggests that $\mathrm{AD} / \mathrm{HD}$ is negatively related to extraversion and positively to openness. This suggests typical personalities that would create inattention that results in carelessness in work habits, and personal relationship problems often associated with $\mathrm{AD} / \mathrm{HD}$. Behavior problems such as antagonism, bullying, aggression and hostility to others would also be reflected in these personality traits suggesting non-compliance delinquent type activities. Non-compliant behavior was indicated early on as a trait of $\mathrm{AD} / \mathrm{HD}$ for preschoolers. These may be reflected in comorbidity of conduct disorders, oppositional defiant disorders and substance disorders often associated in conjunction with AD/HD. Neuroticism can also be associated with co-morbidity of mood disorders and impact the ability of students to deal with stressful situations.

May and Bos (2000) examined the incidence of co-morbidity in individuals with AD/HD. They came up with four categories AD/HD only, AD/HD co-morbid, AD/HD and ODD (Oppositional Defiant Disorder) and AD/HD, Co-morbid, and ODD. The AD/HD group participants are characterized by having histrionic features, as in the need for stimulation, excitement and attention. Friendships are often replaced with the onset of boredom. These individuals are often loud and demanding. The AD/HD and co-morbid group is characterized as dependent, detached and isolated. The AD/HD ODD group is characterized as histrionic, narcissistic, gets angry, resents authority and sees relationships as power struggles. The AD/HD, ODD, Co-morbid group has a history of rejecting societal norms. They are aggressively angry and resentful with others, and have difficulty expressing empathy, as this is a sign of weakness. 
Finally, they are rejecting of relationships. All of these categories suggest extreme difficulties in interpersonal functioning suggesting the need for community mental health treatment services.

Thus far I can conclude through current research that restlessness, impulsivity, inattention and hyperactivity continue into adulthood. I can also make assumptions based on the literature that co-morbidity accompanies many cases of $\mathrm{AD} / \mathrm{HD}$ creating a host of interpersonal problems well into adulthood. Barkley's previous research (as cited in Barkley et al., 2001) suggests impairments in executive functions of planning, forethought, goal-directed behavior, flexibility, problem-solving, verbal working memory and self-directed speech, in addition to problems with time perception and reproduction in adults with AD/HD (Barkley et al., 2001). Imagine the impact of the inability of college students to have a working memory, plan, set goals, problemsolve and manage time to complete college work especially graduate work. These functional impairments in adults with $\mathrm{AD} / \mathrm{HD}$ suggest the continued need for or modification of academic strategies and professional resources such as community treatment services of medication or therapy.

\section{Adult Community Agency Services and Academic Services}

Wasserstein (2001) reiterates the issues of co-morbidity, independent adaptive functioning related to relationships and executive functioning problems. She suggests that in younger children and adolescents society or parents and teachers provide external controls of regulation that are not provided for adults. She recommends services of drug and psychosocial intervention. In terms of academic strategies she recommends external supports of day planners, computers and coaching, and cognitive remediation. Work strategies include the ability to plan and execute internal structure, which is difficult to do with adults who have difficulty with 
tardiness, completion of tasks and deadlines. The academic and work world must comply with the American Disabilities Act, section 504 to provide services to accommodate these individual in an academic and work setting.

\section{Qualitative Research and Grounded Theory}

Qualitative research is flexible, a rough sketch, in which the relationship and setting develop and change while quantitative research views change as undesirable. Research is exploratory in the beginning, becoming more structured as information evolves. Questions become more refined as a series of studies evolve (Devers \& Frankel, July 2000). Qualitative research is rich in description of people, places, and conversations and is not easily handled by statistical procedures. Techniques utilized are observation and in depth, open-ended interviewing, which is at most a loosely structured interview guide. Information is collected in the field where behaviors naturally occur rather than in a controlled environment.

Five features of qualitative research, which takes a narrative form, are indicated as follows: 1) It is naturalistic or in the actual settings and is concerned with context. 2) Qualitative research has descriptive data in the form of pictures or words rather than numbers. 3) It is concerned with process, rather than outcomes and products. 4) It is inductive rather than deductive. In other words, one does not set out to support or refute a hypothesis, but instead abstractions, built as particulars, are grouped together. 5) Meaning is of the utmost importance. In other words, qualitative research is concerned with how people make sense of their lives (Bogdan \& Bicklen, 1998, p. 6).

The open-ended or unstructured interview is an in-depth interviewing exploration of details for a topic. The respondent is not bound with alternatives of the interviewer or 
constraints on the length of the interviewee's response. Purposes are the exploration of undefined, new domains and the break down of domains into factors and sub-factors. They build a relationship with the interviewee, discover new data, and expand current data (Schensel, Schensel, \& LeComple, 1999).

The authors Strauss and Corbin (1998) indicate the following components to grounded theory: 1) Obtaining data through interviews and observation including the examination of documents, records and films. 2) The use of procedures to interpret and organize data. 3) Conceptualizing and reducing data. 4) Elaborating categories in terms of properties and dimensions and 5) Relating through a series of reducing, elaborating and relating or coding. Other procedures include non-statistical sampling, writing memos and diagramming and written verbal reports (Strauss \& Corbin, 1998, p.11-12).

As one moves towards coding procedures one must keep in mind the purposes of coding as follows: To build theory, not test theory; to use coding as an analytic tool for handling data; to consider alternative meaning of the phenomena; to be both systematic and creative; and to identify, develop and relate concepts that are building blocks of theory (Strauss \& Corbin, 1998, p. 13-14).

There are three areas of focus in coding procedures. Microanalysis occurs at the beginning of study for initial categories to suggest relationships among the categories through a combination of open and axial coding. Secondly, initial categories are generated with properties and dimensions and finally, relationships are discovered among the concepts (Strauss \& Corbin, 1998, pp.57-64). 


\section{CHAPTER THREE}

Introduction

The major purposes of this qualitative study are 1) to determine functional impairments that confront college age students with $\mathrm{AD} / \mathrm{HD}$ and 2) to determine what changes, modifications or continued academic strategies or treatment services are needed for college age students with $\mathrm{AD} / \mathrm{HD}$ as perceived by students, significant others, observation memos, student writing samples and college transcripts.

The following research questions were used to meet the major purposes:

1. What functional impairments suggest that a college age student may have $\mathrm{AD} / \mathrm{HD} ?$

2. How do these functional impairments affect (a) The academic function of AD/HD students in a college setting, (b) relationships with authority figures, professors, peers, and family members?

3. What is the impact of $\mathrm{AD} / \mathrm{HD}$ as the college student/young adult enters the workforce?

4. What resources, including teaching methods and other professional resources may need to be continued, be modified or be changed due to functional impairments of college age students with $\mathrm{AD} / \mathrm{HD}$ ?

5. What information from individuals with $\mathrm{AD} / \mathrm{HD}$ could be incorporated into an academic setting to ensure long-term success of students with $\mathrm{AD} / \mathrm{HD}$ ? 


\section{Participants}

The sampling included 10 interviewees who were recruited from student services of an Appalachia school of higher education or physician's offices, psychologist's or psychiatrist's private practices. There were five males and five female interviewees. Eight interviewees were undergraduate students and two interviewees were graduate students. The age range was 18 years to 25 years (see Table 1 page 53, Participant Characteristics). Students with AD/HD have a diagnosis based on the current criteria from the DSM- IV-TR. The diagnosis is confirmed by either student services or a provider of community treatment services. Students provided a college transcript to reflect academic functioning. Other criterion included attendance at a university within the past year. It is important to include students if possible who may have dropped out of an academic setting or may be at risk for dropping out of an academic setting in an attempt to determine whether or not their $\mathrm{AD} / \mathrm{HD}$ affected their decision to withdraw from their academic setting. Students also have worked or currently will be working at least a parttime job with a minimum of 15 hours of work each week. For the purpose of this research participants included only traditional students, ages18-25 years old.

A significant other who has known the individual at least a year and spends at least ten hours a week with the student participated in a similar interview answering semi-structured interview questions. These interviews also were tape-recorded and subjects were given a psuedo name to protect their confidentiality. The significant other examples included roommates, friends, a family member such as a spouse, parent or sibling, an employer, supervisor, or coworker who spends significant time with the student (see Table 1 page 53, Participant Characteristics). 
I have included students with co-morbidity in this study as the literature, in particularly the DSM-IV-TR, suggests that $\mathrm{AD} / \mathrm{HD}$ is often accompanied with other diagnoses, including learning disabilities, mental health issues such as anxiety and depression, oppositional defiant disorder and conduct disorders. Many of these students were receiving multiple services from student support services particularly for learning disabilities.

\section{Procedures}

Transferability of the study can occur if the following steps are replicated.

1. The West Virginia University Internal Review Board granted permission for this qualitative research project (see Appendix A).

2. Contact was made with the Director of Support Services at a local Appalachian University to invite students with a confirmed diagnosis of $\mathrm{AD} / \mathrm{HD}$ to participate in qualitative research.

3. Students were given information about the study with a cover letter, which explained the reasons for the study and reviewed the issue of confidentiality. In the cover letter the students were asked to invite a significant other to participate in the study. The criteria of the significant other were defined in the cover letter (see Appendix B).

4. The Director of Support Services assisted with scheduling interviews, which were given in a private confidential setting, a conference room in the office of Student Support Services.

5. Permission to interview the student was obtained in the audiotaped session. 
6. First the student was interviewed with the semi-structured interview (see student interview questions page 46). The interview was audiotaped and lasted 45 minutes to an hour. No videotaping was done in order to protect client confidentiality.

7. At the end of the interview students were asked to respond in writing to two written interview questions for a writing sample. Most of them typed them on the computer. One of the interviewees hand wrote his response. This activity was approximately 15-30 minutes (see student written interview questions page 50). (See writing samples Appendix D).

8. The significant other reviewed the cover letter and gave verbal permission for the interview on the audiotape. They also participated in a semi-structured interview (see questions on page 49) that lasted approximately 30-45 minutes. The interview was audiotaped. The significant others interviewed at their convenience. They scheduled their time through the Director of Support Services.

9. The interviews were transcribed by the research assistant, which was approved through WVU IRB process (see IRB document in Appendix A). Verbal consents were noted in the transcription.

10. All interviewees and significant other transcriptions had name and identification information changes to protect their identity. Tapes were destroyed once the tapes were transcribed. 
11. Some clues about themes were developed from the observation memos. The QSR N6 Nud*ist program did a word search of words or descriptions and their derivatives to see if the information supported and confirmed those general themes or categories in the transcriptions of the interviewee and the significant other. Writing samples were hand searched for the same word descriptions and behaviors.

12. Academic transcripts were requested and personal data was removed. Transcript documents were analyzed for numbers of Ds and Fs and GPAs.

13. The coded data was then given a general category for the theme of functional impairments. In addition the interviews were hand searched for behavioral examples of those functional impairments.

14. Those functional impairments were also assessed in the same manner for relationships and the work setting.

15. The number of references to the coded data words were counted and placed in chart format for each interviewee (see Table 3 Functional Impairments, page 74).

16. Information was totaled for each individual's functional impairments for general impairments, relationship impairments, academic impairments and work impairments and then totaled again for all the interviewees.

17. Finally, there was a count of individuals who had functional impairments in each general category. 
18. Based on the interviewee questions and significant other questions related to services the history of services was reviewed for each interviewee and divided into two categories of academic services and community agency services. Then the requested services were also divided similarly. This information was put into recommendations for academic services and community agency services.

\section{Interviews}

The following questions were administered to college age individuals who have been diagnosed with $\mathrm{AD} / \mathrm{HD}$ to determine 1) what functional impairments confront the college age students with $\mathrm{AD} / \mathrm{HD}$ and 2) what changes, modifications or continued academic strategies or treatment services are needed for college age student with AD/HD? (See Table 2, Sources of Information, page 54).

\section{Student Interview Questions}

Questions 1 and 2a address question one of major purposes: What functional impairments suggest that college age student may have $\mathrm{AD} / \mathrm{HD}$ and establishes a baseline of symptoms, which meets the criteria of DSM-IV-TR that AD/HD symptoms must occur prior to the age of 7 years old.

1. When and how did you become aware that you had AD/HD?

2. Throughout your years in school, how did $\mathrm{AD} / \mathrm{HD}$ affect you?

a) What do you remember about elementary school?

What kind of grades did you get?

What did you like to do and why? 
What was difficult for you in school?

What were you good at in elementary school?

Question $2 \mathrm{~b}$ answers question one, what functional impairments suggest that high school students may have $\mathrm{AD} / \mathrm{HD}$ by continuing to substantiate DSM-IV-TR symptoms.

b) What do you remember about your high school years?

What kind of grades did you get?

What did you like to do and why?

What was difficult for you in school?

What were you good at in high school?

Question 2c answers major purposes question number 2a, how do these functional impairments affect the academic functioning of college age students in a college setting?

c) College?

How is your G.P.A.?

What do you like to do and why?

What has been difficult for you in college?

What do you feel you are good at in college?

Questions 3a-d answer major purposes question one, what functional impairments suggest that a college age student may have $\mathrm{AD} / \mathrm{HD}$. The questions regarding elementary and high school years document the history of AD/HD according to the DSMIV-TR, and establishes that the diagnosis was established present prior to the age of seven years.

3. How were your relationships with others affected?

a) When you were in grade school what kind of reaction did you have from friends? 
Teachers? Principal?

b) When you were in grade school how did you get along with your mom and dad? How about your brothers and sisters? What about other family members that you hung out with?

c) When you were in high school what kind of reactions did you get from friends? Teachers? Principal?

d) When you were in high school how did you get along with your mom and dad? How about your brothers and sisters? What about other family members that you hung out with?

Questions 3e-f answer question 2b of major purposes questions, how do these functional impairments affect relationships with authority figures, professors, peers, and family members?

e) During your college years what kind of reaction did your friends have towards you? Professors?

f) How do you get along with family? Spouse or partner?

Question 4- 4a answers major purposes question what is the impact of $\mathrm{AD} / \mathrm{HD}$ as the college student enters the work force?

4. What if any difficulties have you had with work? Any accomplishments and successes?

a) How do you get along with coworkers? Your boss?

Questions 5-6 answer major purposes question 4, what resources including teaching methods and other professional resources may need to be continued, be modified or be changed due to functional impairments of college age students with AD/HD? 
5. What professional services have you had for your AD/HD? What was helpful or not helpful?

6. What types of services or teaching interventions have been helpful to you?
a) At college?
b) At Home?

Question 7 answers major purposes question 5, what information from individuals with $\mathrm{AD} / \mathrm{HD}$ could be incorporated into an academic setting to ensure long-term success of students with $\mathrm{AD} / \mathrm{HD}$ ?

7. What would you like college professors and/or employers to know about your $\mathrm{AD} / \mathrm{HD}$ condition?

\section{Significant others semi-structured interviews}

The following semi-structured interview questions were asked to significant others1) to determine functional impairments that confront the college age students with AD/HD and 2) to determine what changes modifications or continued academic strategies or treatment services are needed for college age students with $\mathrm{AD} / \mathrm{HD}$.

1. What is your relationship with the student?

Question two answers major questions and purposes 2a, how do these functional impairments affect the academic function of $\mathrm{AD} / \mathrm{HD}$ students in a college setting? It also answers major purposes question 3, what is the impact of $\mathrm{AD} / \mathrm{HD}$ as the college student/young adult enters the workforce.

2. What difficulties does this student experience at college, work or home? 
Question 3 answers major question and purposes $2 \mathrm{~b}$, how do these functional impairments affect relationships with authority figures, professors, peers and family members?

3. How does this student get along with others at college, home or work?

Question 4 answers major question and purposes 4, what resources including teaching methods and other professional resources may need to be continued, be modified, or be changed due to functional impairments of college age students with $\mathrm{AD} / \mathrm{HD}$.

4. What types of services do you feel this student needs from the college or community?

\section{Written student interview questions}

Each student was asked to provide a written response to the following two questions. The first question provided clues for major purposes question 1, 2a-b and 3, what functional impairments suggest that a college age student may have $\mathrm{AD} / \mathrm{HD}$; how do these functional impairments affect the academic function of $\mathrm{AD} / \mathrm{HD}$ students in a college setting and how do these functional impairments affect relationships with authority figures professors, peers and family members; and finally what is the impact of $\mathrm{AD} / \mathrm{HD}$ as the college student/young adult enters the workforce.

1) How do you feel that $\mathrm{AD} / \mathrm{HD}$ has impacted your life?

Written question 2 answered questions 4-5, what resources including teaching methods and other professional resources many need to be continued, be modified or be changed due to functional impairments of college age students with $\mathrm{AD} / \mathrm{HD}$ and what information from individuals with $\mathrm{AD} / \mathrm{HD}$ could be incorporated into an academic setting to ensure long-term success of students with $\mathrm{AD} / \mathrm{HD}$. 
2) What teaching strategies or professional services would you like professors or treatment providers to continue or change?

\section{Methods}

When researchers choose a study they must make the study a reasonable size and complexity so that it can be completed within reasonable time frames with adequate resources. One must think small relative to a qualitative research model (Bogdan \& Bicklen, 1998). Related to sampling issues it is not realistic or possible to study every member of a population due to resources, time and personnel limits. Related to variations in groups I will be utilizing reputable case selections by community experts in an academic setting. Comparable cases with specific characteristics of interest will be utilized as they have multiple similar structures, patterns and themes to see if they are stable across multiple settings and people (Schensel, Schensel, \& LeComple, 1999). This research will serve as a model of grounded theory work as theoretical saturation will not be reached due to the time constraints and the limited number of cases reviewed. This case study will only represent a small sample of the population at large.

There is a need to be cautious about samples. The definition of the population must be precise and one must be knowledgeable of the population's characteristics. Inclusion and exclusion criteria such as traits, behaviors or other qualifying features must be considered. One can control sampling biases by careful definitions of target groups, collecting data from more than one location, eliminating categorical prejudices, looking for hidden segments of the population and making sure you are accessible (Schensel et al., 1999).

According to Devers and Frankel (2000), complex comparative studies should not include more than twelve to fifteen cases. Sample criterion for college age students for this 
study includes the following: Ten college age individuals with attention-deficit/hyperactivity disorder $(\mathrm{AD} / \mathrm{HD})$ participated in unstructured interviews to determine what functional impairments confront college age students with AD/HD. A significant other was interviewed with each student. Please note that the interviewing of significant others associated with the individual with $\mathrm{AD} / \mathrm{HD}$ provided a total of 20 interviews.

\section{Data Analysis}

Data was compiled into categories and subcategories through coding data to determine phenomena to develop theory by themes, thinking, behaviors, affect, relationships, effective and ineffective strategies, ability to function, changes in symptoms as age progresses, and changes in ability to cope with this disability as age progresses. Some of these codes were originally broadly developed for a pilot study of a graduate student who dropped out of the doctoral program. Categories of functional impairments were adjusted as information progressed.

The sources of data that were used for this qualitative research included student semistructured interviews, significant other semi-structured interviews, student writing samples, observation memos, and documents such as mid-term reports and transcripts. Information is from the student's perspective or the significant other's perspective.

Grounded theory was selected for qualitative research due to the need to establish existing theory or develop new theory. There was no evidence of qualitative research for any individuals other than a couple of pre-school cases studies. In addition there were limited studies of adults with AD/HD and very limited studies geared to college age students with AD/HD. 
Table 1

\section{Participants}

\begin{tabular}{|c|c|c|c|c|c|c|}
\hline Student & Significant Other & Age & Ethnicity & Class & Major & G.P. A. \\
\hline Alfred & $\begin{array}{l}\text { Alexandria- } \\
\text { Girlfriend/Partner }\end{array}$ & 23 & Caucasian & $\begin{array}{l}\text { Graduate } \\
\text { Student }\end{array}$ & $\begin{array}{l}\text { MS, Exercise } \\
\text { Science }\end{array}$ & $\begin{array}{l}3.15 \\
4.00 \\
\end{array}$ \\
\hline Bella & $\begin{array}{l}\text { Brittany - } \\
\text { Aunt/Student Support } \\
\text { Employee }\end{array}$ & 19 & Caucasian & $\begin{array}{l}\text { First-time } \\
\text { Freshman }\end{array}$ & $\begin{array}{c}\text { BS, } \\
\text { Biochemistry }\end{array}$ & $\begin{array}{l}\text { Midterm } \\
\text { Report } \\
\text { 2 D's } \\
\end{array}$ \\
\hline Clarice & Christy - Tutor & 19 & Caucasian & $\begin{array}{l}\text { First-time } \\
\text { Freshman }\end{array}$ & $\begin{array}{c}\text { BA, } \\
\text { Psychology }\end{array}$ & $\begin{array}{l}\text { Midterm } \\
\text { Report } \\
\text { 2 D's }\end{array}$ \\
\hline Dianna & $\begin{array}{l}\text { Denise }- \text { Co- } \\
\text { worker/Friend }\end{array}$ & 25 & Caucasian & $\begin{array}{c}\text { Graduate } \\
\text { Student }\end{array}$ & $\begin{array}{l}\text { MS, Exercise } \\
\text { Science }\end{array}$ & $\begin{array}{l}2.70 \\
3.28\end{array}$ \\
\hline Ellen & Emma - Friend & 19 & Caucasian & $\begin{array}{l}\text { First-time } \\
\text { Freshman }\end{array}$ & Unknown & $\begin{array}{c}\text { No } \\
\text { Midterm } \\
\text { Report }\end{array}$ \\
\hline Frank & $\begin{array}{l}\text { Frances - Mother/ } \\
\text { Tutor at Student } \\
\text { Support Services }\end{array}$ & 23 & Caucasian & $\begin{array}{l}\text { Second } \\
\text { Year }\end{array}$ & $\begin{array}{c}\text { AAS, } \\
\text { Hospitality } \\
\text { Management }\end{array}$ & 2.92 \\
\hline Georgia & $\begin{array}{l}\text { Grace - Director of } \\
\text { Student Services }\end{array}$ & 21 & $\begin{array}{l}\text { African } \\
\text { American }\end{array}$ & $\begin{array}{l}\text { Second } \\
\text { Year }\end{array}$ & $\begin{array}{c}\text { AAS, } \\
\text { Hospitality } \\
\text { Management }\end{array}$ & 2.22 \\
\hline Hal & $\begin{array}{l}\text { Harold - } \\
\text { Brother/Roommate }\end{array}$ & 19 & Caucasian & Sophomore & $\begin{array}{l}\text { BS, Biological } \\
\text { Science }\end{array}$ & 3.82 \\
\hline Isaac & $\begin{array}{l}\text { Israel - Friend/Former } \\
\text { Roommate }\end{array}$ & 22 & Caucasian & Senior & $\begin{array}{c}\text { BBA, } \\
\text { Marketing }\end{array}$ & 3.15 \\
\hline Jack & Jim - Tutor & 20 & Caucasian & Junior & $\begin{array}{c}\text { BS, } \\
\text { Biomedical } \\
\text { Science }\end{array}$ & 3.67 \\
\hline
\end{tabular}


Table 2

\section{Information Sources Used to Answer Major Purposes and Research Questions}

\begin{tabular}{|c|c|c|c|c|c|}
\hline & $\begin{array}{c}\text { Student } \\
\text { Interview }\end{array}$ & $\begin{array}{c}\mathrm{SO} \\
\text { Interview } \\
\end{array}$ & $\begin{array}{c}\text { Writing } \\
\text { Sample } \\
\text { Questions }\end{array}$ & $\begin{array}{c}\text { Observation } \\
\text { Memos }\end{array}$ & $\begin{array}{c}\text { College } \\
\text { Transcripts }\end{array}$ \\
\hline $\begin{array}{l}\text { What functional impairments suggest that a } \\
\text { college age student may have } \mathrm{AD} / \mathrm{HD} \text { ? }\end{array}$ & $1,2 \mathrm{a}, 2 \mathrm{~b}$ & 2 & 1 & Yes & \\
\hline $\begin{array}{l}\text { How do these functional impairments affect } \\
\text { a) the academic function of } \mathrm{AD} / \mathrm{HD} \\
\text { students in a college setting, b) } \\
\text { relationships with authority figures, } \\
\text { professors, peers, and family members? }\end{array}$ & $\begin{array}{l}2 \mathrm{c}, 3 \mathrm{a}, 3 \mathrm{~b} \\
3 \mathrm{c}, 3 \mathrm{~d}, 3 \mathrm{e} \\
3 \mathrm{f}\end{array}$ & 2,3 & 1 & & Yes \\
\hline $\begin{array}{l}\text { What is the impact of } \mathrm{AD} / \mathrm{HD} \text { as the } \\
\text { college student/young adult enters the } \\
\text { workforce? }\end{array}$ & $4 a$ & 2 & 1 & & \\
\hline $\begin{array}{l}\text { What resources, including teaching } \\
\text { methods and other professional resources } \\
\text { may need to be continued, be modified, or } \\
\text { be changed due to functional impairments } \\
\text { of college age students with AD/HD? }\end{array}$ & 5,6 & 4 & 2 & & \\
\hline $\begin{array}{l}\text { What information from individuals with } \\
\mathrm{AD} / \mathrm{HD} \text { could be incorporated into an } \\
\text { academic setting to ensure long-term } \\
\text { success of students with AD/HD? }\end{array}$ & 7 & & 2 & & Yes \\
\hline
\end{tabular}




\section{CHAPTER FOUR}

Analysis

As setting or context codes developed general information on the setting, topic or student was sorted and defined. In this process I examined perspectives held by the subjects and their shared norms and rules. As suggested by Bogdan and Bicklen process codes developed to deal with time periods such as stages, steps to careers and sequences of events (Bogdan \& Bicklen, 1998, p. 169-175). In my case it is important to see how the symptoms of AD/HD have changed or evolved to create different issues or whether the issues and problems remain the same as students age and mature. Activity codes were developed which clarified occurring kinds of behavior in individuals with AD/HD. Event codes or infrequent or limited units of data were developed that relate to specific activities occurring in the setting or lives of individuals interviewed. The researcher developed strategy codes that related to tactics and methods or techniques that individuals use to accomplish things. The researcher developed relationship and social structure codes. Methods codes were developed concerning how to conduct the research. For example observation notes were developed by kind instead of chronological order. As the researcher developed a preliminary list of coding categories a coding system evolved with limited codes of 30-50 categories. Ultimately major codes developed to include a general wide range of activities, attitudes and behaviors (Bogdan \& Bicklen, 1998, p. 175-188).

When developing themes of functional impairments, I concur that some of these behaviors might also be exhibited in the general population. When considering themes that developed into general functional impairments, relationship impairments and work impairments, I considered the examples in the context of whether or not the literature review considered these 
behaviors as indicators of impairments, or were at least similar to those indicated in the literature review. I also considered whether or not there was a history of similar impairments. The general context of the conversation surrounding the example was considered and finally the information from the significant other interview was considered. The question was then asked, "Does this behavior impact the interviewee's ability to function at school, work or home or their relationships in those settings?"

There are many elliptical marks in the quotes. Some parts of the response have been deleted because students with AD/HD often change subjects, add irrelevant information, and contradict themselves before making their final comment. Taking the extraneous verbal comments out does not give the reader the total picture of how difficult it is to follow the conversation with students with AD/HD. However it does make the examples easier to follow for the purpose of the analysis.

\section{Functional Impairments}

If you refer to Table 3, page 74, Table 3 counts types of functional impairments for each interviewee and the significant other. Table 3 also answers major purpose question one and research question one. Ten college university students ages 18-25 were interviewed along with ten significant others with a semi-structured interview. At the conclusion of the interviews general themes that evolved from the observation memos in terms of functional impairments included behavioral impairments in concentration, organizational issues, time related issues, and hyperactive responses. Co-morbidity occurred in many instances along with the AD/HD and is also indicated as a functional impairment. Coded data words or short phrases of descriptions of behavioral issues developed into the general themes listed above. Forms or derivatives of those 
coded base words were searched in the QSR N6 NUD*IST software for qualitative research. For example under impairments in concentration the word forgetfulness is the main word but derivatives of that word such as forget, forgot, forgotten and forgetting were part of the search. Memory was a base word under impairments in concentration, but the search also included derivatives of that word such as memorization and memorize. The search word was then utilized to find the number of examples of behavioral issues under the themes of the functional impairments. I also included in my search by hand clear behavioral examples of those coded words. Those total numbers included examples from the semi-structured interviews of both the interviewee and the significant other as well as observed behaviors from the observation memos and the content information indicated by the interviewee from the writing samples. I also split the analysis of the writing sample to include the content under functional impairment, but also to include an analysis of the writing skills under the section, Academic Functional Impairments.

Data that was coded and that led to a general theme of impairments in concentration and included six behaviors that were referenced in the search: Those key behaviors included attention, distraction, focus, forgetfulness, memory and lack of interest or boredom. Data that was coded that led to a general theme of organizational impairments included losing items, misplacing items, scheduling/time management, routine, structure, and study skills/habits. Data that was coded for time related issues included extra time, more time and extensions. 
Search words that were coded for data for the general theme hyperactive issues included descriptions of behaviors such as excessive movement/restless energy, skipped subject or words, and rapid thoughts/conversation. Finally, examples of impulsive behaviors such as reacts and not thinking things through were coded under the functional impairment of hyperactive issues.

Co-morbidity includes other diagnoses such as Mental Health or Learning Disabilities. Co-morbidity is included because there is a high correlation of incidence with AD/HD.

\section{Interviewee Alfred and Significant Other Alexandria}

For the first student Alfred, it appears that functional impairments continued into his college years. During the interview Alfred indicated impairments in concentration with the coded word attention, which he referenced one time. Focus was mentioned two times, memory one time and lack of interest or boredom one time. For example under focus he referred to a conversation with a friend who questioned him about taking tests in a separate, controlled environment. He said, "I have ADD. I cannot focus for an exam here with all of you yahoos sitting around, shuffling your papers, blowing your nose, and crinkling your water bottles. I can't deal with that. I need peace and quiet to think." For memory he said, "Organic was tough... there was a lot of memorization stuff." For lack of interest he said, "There are few things that I can actually read and be interested in. You know if it's something outside of a career course it's going to be hard for me to read the material unless it's something that I'm pretty much interested in and want to know more about it." 
Under themes of organization, Alexandria, his significant other, reported a structure issue. She said, "He's very OCD where everything has to be perfect. Something's a little bit off and he goes crazy."

Under time related issues, Alfred mentions one instance and Alexandria reports one instance of time related issues as in needs extra time to complete tasks. The interviewee has to stop frequently and takes many breaks therefore requiring more time to complete the task. For example Alexandria, his significant other reports, "By either putting in more time and effort or say he has problems concentrating, he does go do one thing and then comes back to it and then goes back to it again."

The interviewee or the significant other did not indicate hyperactive responses during the interview. However, in the observation memo Alfred was observed to have motor movements of talking with his hands and jumping in subject matter. He appeared to squirm in his seat.

For co-morbidity Alexandria indicated that Alfred has co-morbidity with dyslexia, a reading disability.

In summary Alfred reported continued functional impairments during his college years with impairments in concentration with difficulty with attention, focus, memory and boredom. One organizational issue was noted with the need for structure. Both Alfred and Alexandra indicated that he needed extra time to complete tasks. Alfred exhibited hyperactive responses as evidenced in the observation memos with restless movements and skipped subjects without the normal transitions in conversation as well as rapid conversation. Alfred has, according to Alexandria, co-morbidity with dyslexia, a reading disability (see Table 3 Functional Impairments, page 74). 
Interviewee Bella and Significant Other Brittany

For Bella examples of impairments in concentration included one example of distraction and one for forgetfulness. Her significant other, her aunt, reported two instances of forgetfulness. For example Bella said, “Currently I'm on a lap top list. So we have a computer lab we have to work in...but I get so distracted by the people that sit in there. It's just really, really difficult to get my papers done and do quizzes on line or any thing in there." For the memory impairment she says, "It makes me seem irresponsible when it's actually just a lack of ability to remember." Her significant other indicated, "She does forget things because of her $\mathrm{AD} / \mathrm{HD}$, but she does her best... to do her best."

For the functional impairment in organization Bella indicated problems with scheduling five times and study/skills habits one time. Her significant other, Brittany, reports losing or misplacing items twice and scheduling three times. She mentioned study skills one time.

For example Bella cited from her writing sample a scheduling issue, "I also have to write down appointments, important dates, to do lists, ect. in at least three different places if I even hope to remember them." Bella explains, "I have to go to extremes in my studying habits to drill information into my head." Brittany, her significant other, indicated as an example, "...this is the first place where she has had to study. She has a tutor that she meets with once a week who is working with her on time management and study skills."

Bella related two incidences of a need for extra time to complete tasks. Her significant other did not indicate this as an issue. An example of the need for extra time was referred to as “... What I've really had problems with is the testing. Normally it's a fifty-minute class ... but trying to squish a test in ... in fifty minutes is really stressful, and I'm exhausted...." 
Under hyper responses Bella was observed to have movement and restless energy and rapid paced conversation in the interview. She kept moving her hands and fidgeting.

There were no instances of co-morbidity indicated by either Bella or Brittany In summary both Bella, the interviewee and Brittany, the significant other indicated impairments in concentration with references to problems with distraction, memory and forgetfulness. For impairments in organization there were many examples of scheduling/time management problems and study/skills and habits. Her significant other also mentioned lose/misplace items. The interviewee indicated she needed extra time to complete a task. The observation memo indicated that she had excessive movement. There was no indication by either party that there was co-morbidity (see Table 3 Functional Impairments, page 74). Interviewee Clarice and Significant Other Christy

In functional impairments for concentration with Clarice, Table 3 Functional Impairments, page 74 indicated one example of lack of interest or boredom for example she mentions that, "When I'm bored sometimes I'll get out a sheet of paper and start drawing something or sketch something." Christy, her significant other tutor, cites not only lack of interest or boredom, but also distraction as an issue. For example, Christy describes Clarice as being “distractible, but if she follows a structure she's usually pretty good about that."

For impairments in organization Clarice cites only one issue with routines, but Christy indicates five references to problems with scheduling and time management. For example Christy states, "Clarice has a lot of time management issues which has to be addressed, of course for her in order to be successful at college. So we do things like-she keeps an agenda. We work on daily calendars ... cause the ADD affects her more in time management than it does anything 
else." She also referenced study skills/habits twice. In reference to study skills and habits Christy said, "She is also in the remedial program ... which works on time management, study skills, deficit areas according to their learning disability..."

Neither Clarice, the interviewee, or the significant other mention hyperactive responses as an issue. In addition, neither Clarice nor Christy indicated co-morbidity.

In summary both Clarice, the interviewee, and Christy, the significant other, indicated impairments in concentration with problems with distraction and boredom. For organizational issues Clarice indicated problems with routines. Christy cited multiple times that there were issues with scheduling and study habits/skills. Neither the interviewee nor significant other mentioned the need for extra time to take tests. Neither Clarice nor Christy indicated comorbidity (see Table 3 Functional Impairments, page 74).

Interviewee Dianna and Significant Other Denise

Under impairments in concentration Dianna indicated no impairments. However, her coworker and friend significant other cited examples of distraction four times. For example Denise indicated, “... but she can get off on tangents and she'll become distracted very easily from things that wouldn't normally distract the typical student."

Though Dianna mentioned impairments in organization, Denise did not indicate functional impairments. Dianna indicated one example each of issues with scheduling and structure. Related to scheduling Dianna, the interviewee said, “...I kind of picked out the subject of organization because being organized with my time I was able to know ok from 11-12 I came to tutoring for this subject and so they help me stay organized in that class." Following the interviewer quote of "So a lack of structure?" She said, "Yeah, because I was always used to 
having someone there to support me. Then not having anybody." She was referring to a loss of family support, which she had in high school to keep her organized.

Dianna did not mention time related issues but Denise, her significant other, cited 'needs extra time to complete task' a total of three times. She said, "Once she knows the material she can reproduce it just as fast as anyone else without a disorder, but it's just that initial learning and being tested on it you know for the time."

Dianna cited one example of hyperactive response. She indicated, "I'm just off the wall and everywhere like talking about two different things and doing one thing and having a conversation and then skipping to another part of the conversation and just everywhere. Not so good." Denise, the significant other, indicated two incidences of skipping subjects or words. She said, "We'll be walking down the street and talking about something like maybe a class, a paper or a test and something will happen and she'll go 'oh' ... and you are like where did that come from?" ... "She'll be like well I just saw that car drive down the street or a bird flew by or something else will just randomly pop into her mind and she'll want to talk about it."

Dianna, the interviewee, indicates a reading learning disability, dyslexia, under comorbidity. Her significant other did not indicate impairment in this area.

In summary, both the interviewee and significant other indicated issues of impairments in concentration with problems with distraction. Relative to organizational issues Dianna, the interviewee, noted issues with scheduling and structure. Though the interviewee did not mention the need for extra time her significant other Denise did mention that Dianna needs extra time to complete tasks. Both the interviewee and significant other indicated issues with hyperactive 
responses as in skipping sentences or words. Dianna, the interviewee indicated that she has comorbidity with the reading disability, dyslexia (see Table 3 Functional Impairments, page 74). Interviewee Ellen and Significant Other Emma

Ellen indicated one functional impairment for concentration, distraction. She had no impairments in organizational issues. She did, however, indicate impairment in time related issues as in "needs extra time." Ellen noted, "I take all testing here in the student support center because it's quiet and plus I get extra time..." Her significant other, Emma, did not reference any issues for impairments in concentration, organization or time related issues.

The primary issues in functional impairments indicated by the interviewee, Ellen and her significant other, Emma, her friend, were in the areas of hyperactive responses. Ellen indicated one example of rapid conversation and one example of skipping words or sentences. For example in the observation memo Ellen was observed to make no sense i.e. skipped around in subject or missed words. For example I asked, "What does your RA advisor do for you?" She said, "the RA s for the kids; for the freshman like [indiscernible] my classes are really good. I have friends in them...." She jumped from RA to classes to friends with no transitions. Emma, the significant other, cited one example of skipping words or sentences. She said, "She doesn't make sense in conversations because she skips words and leaves out information. We were walking along and all of a sudden out of the blue she said, 'I rescued a dog. Threw it in the car.' They [other students] said she's weird, we don't understand her."

For co-morbidity she indicated when asked about learning disabilities, "I know I have another thing but I forget what it is." 
In summary, Ellen, the interviewee mentioned one impairment in concentration with the issue distraction. Ellen mentioned no issues with organizational impairments. She did mention that she needed extra time to perform tasks. For hyperactive responses there was evidence of rapid conversation and skipped words or sentences indicated by both the interviewee and significant other. Ellen indicated that there is co-morbidity with a learning disability (see Table 3 Functional Impairments, page 74).

Interviewee Frank and Significant other Frances

For impairments in concentration, Frank, the interviewee indicated two instances with distraction and two incidences with focus. He said, "I often have to go to secluded places such as a library to do homework where I cannot be distracted at all." He also said, "Simple things such as seeing an old friend can easily distract me from ten minutes of work because I want to talk to them." He also cited an example of focus issues, "Uh I guess a problem I have is staying focused. I work at the mall now, so if I see someone I know I got to... I talk to them, but I also know when to quit talking to them and get back to work." His significant other, his mother Frances, noted two memory issues in the area of math. For example she said, "He loses his place or he can't remember what the steps of the processes are." He also said, "So like if he is doing two or three digit division umm he'll get lost in the steps. He may know what the steps are, but if he's doing two or three digits he may remember it for the first digit, but then he gets to the second and third and the processes get messed up."

In terms of organization issues Frank the interviewee noted one issue of time management. He said, "Probably I'd say knowing...just staying on top of things... knowing when I have to study...just time management. Time management has been probably the most 
difficult thing umm to use your time wisely." His mother notes one issue of scheduling and one issue of structure. Related to scheduling Frances, the significant other, mother said, "I think he was probably eighteen when he got his second job and I said, 'You know, you're an adult now and you need to be treated like an adult. And I'm not going to take responsibility for making sure you get to work when you're supposed to be there." In terms of structure issues she said, "Umm like at home he is a neat freak, and you would think that someone who is disorganized as much as he is when it comes to school work would be disorganized in their family life as well as their home life...His room is absolutely spotless-everything has a place. Umm the closet is neat as a pin." This appears to be a compensation for his feelings of disorganization and a useful tool to help students with $\mathrm{AD} / \mathrm{HD}$.

In terms of time related impairments Frank reports one instance. He said, "It can take someone such as my self an hour to learn something that another student can learn in ten minutes...I just take longer to understand things."

His mother indicated an issue with impulsive responses, as in she said, "But after he broke it off with her for probably a month or two he realized that he had made a really big mistake."

In terms of co-morbidity both Frank and Frances, his significant other mother indicated a mental health issue with anxiety. Frank, the interviewee, said, "It was kind of sometimes a shocked reaction when I told them that I had anxiety." Frances, the significant other mother said, "Umm he is extremely AD/HD and also has generalized anxiety disorder...."

In summary, Frank, the interviewee, and his mother, Frances the interviewee, indicated impairments in concentration. Frank and his mother indicated problems with distraction, focus 
and memory. In terms of organizational issues there were issues with time management i. e. getting to work on time and structure. He noted that it takes extra time for him to complete tasks. The significant other indicated issues with impulsivity, a hyperactive response. Both Frank, the interviewee and his mother, the significant other indicated co-morbidity in the area of the mental health diagnosis, generalized anxiety disorder (see Table 3 Functional Impairments, page 74).

Interviewee Georgia and Significant Other Grace

For functional impairments in concentration Georgia indicated two examples of distraction. She said "Umm they put me in a curtain so I won't get distracted." The observation memo notes that she is distractible and has trouble organizing her thoughts. Georgia has difficulty speaking and looks away as though she is trying to organize every response to the semi-structured interview questions. Grace, her significant other who is the Director of Support Services and provides support to the interviewee, indicated two problems with focus. For example, she said, "Physical exercise...even if it's a walk. I think that would help her focus a little better." She also said, "Right, uh probably her biggest problem is sitting down to focus to follow through on the studying."

Georgia listed no impairments for organizational issues. However her significant other, Grace, indicates one issue with scheduling. She said, "Well for one thing she works with a learning specialist. One of the primary jobs of a learning specialist is to help her get organized. They organize time management skills. She meets with her every week, goes over what she has due for the next couple of weeks, umm asks how she's doing in each class, what are your grades on tests, assignments.” Additionally, Grace, the significant other mentioned issues three times 
with structure. For example she said, "Overall, I think she needs the structure we provide. If she didn't have that structure with the tutoring she would have a really very difficult time in her classes."

In terms of time related issues Georgia mentioned one instance of needing extra time to complete tasks. Georgia states, "Learning takes me a long time to do because I'm slow." Neither the interviewee nor the significant other mentions hyperactive responses.

Georgia the interviewee and Grace the significant other did not indicate either a learning disorder or mental heath issue.

In summary under impairments in concentration Georgia, the interviewee and Grace, the significant other, noted issues with distraction and focus. Though Georgia did not mention organizational issues as impairment Grace the significant other indicated an organizational issue with scheduling/time management and structure issues. Georgia does mention the need for extra time to complete tasks. Neither of them mentioned hyperactive responses. Georgia the interviewee and Grace the significant other did not indicate either a learning disorder or mental heath issue (see Table 3 Functional Impairments, page 74).

Interviewee Hal and Significant Other Harold

For functional impairments in concentration Hal mentioned distraction two times. For example he said, "I remember many times when I find myself wasting time just sitting there thinking about nothing or what is happening outside, anything but what I am suppose to be thinking." When the interviewee said, "Um you can have your tests read to you here." The interviewer asked, "Is that helpful to you?" and he responded with, "Umm for me not so much because I get distracted by the person during the test..." Hal mentioned one instance of memory 
issues and indicated a focus issue. He said, "Well I mean I had problems remembering to do it." He was referring to his dog-sitting job. He also said, "It has made memorizing and learning new material hard because of the time commitment and other things going on in the room." There was one mention of forgetfulness by Hal.

Under organizational issues both Hal and Harold mention scheduling/time management as areas of difficulty a total of four times. "I know she...the tutor helps us schedule homework...or what homework I should get done or else I get overwhelmed by it." He also said, “... I know that before we go to do our homework we're with a tutor to see how much homework we should get done. How much time like usually...like two... at least two hours for each homework, and then it kind of helps us spread it out." Harold mentioned routine one time as in "routines are a big thing because..." Harold quickly jumped subjects when he trailed off. I should have redirected him for clarification. He further noted in three instances the need for Hal to have structure. He said, "Like I kind of help structure what he does at school.... I kind of help structure how he does things a little bit and it's kind of frustrating because I try to take care of myself."

Under the theme time related issues Hal noted the need for extra time to complete tasks five times. Harold mentioned this two times in reference to Hal. For example, he said, "It's hard when you're trying to get stuff done 'cause I don't know I mean it's hard. You can find yourself trying to read like a sentence for an hour I mean...." For co-morbidity Harold mentions that Hal has a reading disability, minor dyslexia.

In summary Hal, the interviewee mentions distraction, focus, forgetfulness and memory as issues for impairments in concentration. Hal, the interviewee, and his brother, the significant 
other, indicated issues with organization in the areas routine or time management and scheduling. The significant other also mentions the need for structure for Hal. Both Hal and Harold the significant other mentioned the need for extra time to complete tasks under time related issues. According to the significant other, Harold, his brother has a reading disability, minor dyslexia (see Table 3 Functional Impairments, page 74).

Interviewee Isaac and Significant Other Israel

Isaac indicated no impairments in concentration but his significant other indicated one issue of focus and one issue of lack of interest/boredom. Israel mentioned, "I guess the reason that he felt comfortable listening to ...I guess they help him focus more on his work because he was listening to something he felt comfortable with [in reference to use of head phones while studying]." He also stated, "I think when he's interested in something that he can process more stuff in his head and remember more than anything and be able to talk about it and communicate it without having to really study anything, 'cause that's just something he automatically knows in the process."

For organizational issues Isaac refers to two issues with study habits and skills. He said in reference to the tutors, "Like they sit down and go through the book with me, highlight the important parts, show me what I need to do, and show me how to understand it and show me the better study habits, and how it is to study and that's helpful."

Related to time related issues which were inferred in his writing sample Isaac states, "The way it has impacted my life by the way that I have to work harder for everything than most do." In terms of hyperactive responses both the interviewee and significant other reported issues. Isaac has two instances of rapid conversation/thoughts. The observation memo states 
Isaac makes good eye contact, but talks a little fast and is short and to the point. His significant other Israel mentioned three times excessive motor movement and five instances of rapid paced conversation. Israel said, “A lot of people didn’t understand Isaac as much as I understand Isaac by me being his roommate. Israel stated that Isaac said, "'Like I got to get moving for the radio show.' He was really hyper on the radio show." Israel indicates two examples of impulsivity. He said, "Yeah, he kind of just reacts." In his response to Isaac about his car breaking down, Israel said, "No we're not going to call 911. I don't want to talk to no police officer about this. He says we'll have to wait for the police officer to come, and he'll just make me do something I already know I have to do." There were no learning disabilities or mental health issues reported by either Isaac or Israel.

In summary, though Isaac mentioned no impairments in concentration, Israel, his significant other mentioned issues with focus and lack of interest having an impact on Isaac's ability to perform tasks. Isaac also mentioned the importance and need for study habits and skills under organizational issues. It was inferred that by working harder on tasks he would need more time than others to complete tasks. In terms of hyperactive responses Isaac was observed to have rapid conversation and Israel, his significant other, reflected on his excessive motor movement and rapid paced conversation. He described impulsive behavior. There were no learning disabilities or mental health issues reported by either Isaac or Israel (see Table 3 Functional Impairments, page 74).

Interviewee Jack and Significant Other Jim

For impairments in concentration Jack, the interviewee, noted one time an issue with attention, three times an issue with distraction, three times an issue with focus and three times 
lack of interest or boredom. He noted for attention, "With learning disabilities I feel it has impacted my life in the since that it makes it difficult for me to pay attention with all the noise and various distractions that are going on around me." This is a direct quote from the writing sample, which indicated a spelling error and the wrong use of the word sense. He also said, "The various difficulties that they don't understand is how you may not appear and always act hyper but inside you [sic] head it feels as if your mind is racing or like a ping pong ball is just bouncing all over very fast; in addition to that they don't understand just how easy it is to become distracted and how hard it is to focus with various things going on." He noted for boredom, "I guess the reading of the book umm kind of trips me up. Where I read really, really slow and I don't... and then I can hear different things and then I have different things where I kind of be more interested in doing."

In terms of organizational issues he noted one time a scheduling issue and two times study habits issues. In terms of organizational issues Jim, his significant other tutor, states in reference to study skills, "For certain classes they should have better access to notes. Like the professors should post them on line where everyone can get to them. That would help out in certain classes and just tutoring services with clarification of things."

Jack did not mention any need for extra time to perform tasks. His significant other states, "Primarily he runs into problems occasionally with his notes that the teacher's going too fast and he can't get everything written down that he needs to fully describe something. During our tutoring session we usually flesh those out so he has a better understanding."

In terms of hyperactive responses there were three incidences of excessive motor movement. Jack mentions one time of skipped subjects or words. There is one for rapid 
thoughts/conversation. He states, "I fidget a lot." He also states, "The various difficulties that they don't understand is how you may not appear and always act hyper but inside you [sic] head it feels as if your mind is racing or like a ping pong ball is just bouncing all over very fast...." In reference to the you which should be your, this is a direct quote. Regarding missing words, he stated in the writing sample, "For example when people text me or I text them just the way we both may word things and miss words, because I am always leaving words out where I will say in my head and believe I wrote it when in actuality I never typed it. So, it is at times hard to always get our messages across."

In summary, impairments in concentration were noted in the areas of attention, distraction, focus and interest by the interviewee, Jack. The significant other Jim noted organizational issues in issues with study habits and scheduling. Though Jack, the interviewee did not mention the need for extra time to perform tasks his significant other did indicate that the professors go much to fast to get things written down. Hyperactive responses identified by Jack, excessive motor movement and missing words or sentences. For co-morbidity Jack has two learning disabilities, reading, English language disability (see Table 3 Functional Impairments, page 74).

A summary of the number and types discussions of issues that indicated functional impairments by the interviewees and significant others is noted in Table 3, page 74 . 
Table 3

Functional Impairments in College

Reported by Interviewee and Significant Other

\begin{tabular}{|c|c|c|c|c|c|c|c|c|c|c|c|c|c|c|c|c|c|c|c|c|c|c|c|c|c|c|c|c|c|c|c|}
\hline & & 龸 & 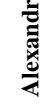 & & 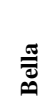 & 窟 & & $\frac{\mathscr{U}}{\mathbb{U}}$ & $\frac{B}{d=0}$ & & 苞 & פั̆ & & 흠 & 薝 & & 崖 & 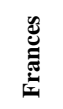 & & 葋 & 苞 & & 茎 & 픙 & & 芯 & 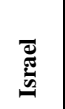 & & 总 & 寻 & 哭 \\
\hline \multicolumn{32}{|l|}{ Concentration } \\
\hline Attention & $\mathrm{H}$ & 1 & & & & & & & & $\mathrm{H}$ & & & & & & $\mathrm{H}$ & & & & & & & & & & & & $\mathrm{H}$ & 1 & & 2 \\
\hline Distraction & & & $\mathrm{H}$ & & 1 & & & & 1 & & & 4 & & 1 & & & 2 & & & 2 & & & 2 & & & & $\mathrm{H}$ & & 3 & & 16 \\
\hline Focus & $\mathrm{H}$ & 2 & & & & & & & & & & & & & $\mathrm{H}$ & & 2 & & & & 2 & $\mathrm{H}$ & 1 & & $\mathrm{H}$ & & 1 & $\mathrm{H}$ & 3 & & 11 \\
\hline Forgetfulness & & & & & 1 & 2 & & & & $\mathrm{H}$ & & & & & & & & & & & & $\mathrm{H}$ & 1 & & $\mathrm{H}$ & & & & & & 4 \\
\hline Memory & $\mathrm{H}$ & 1 & 1 & $\mathrm{H}$ & & $\mathrm{H}$ & & & 1 & & & & & & & & & 2 & & & $\mathrm{H}$ & & 1 & & & & & & & & 6 \\
\hline Lack of Interest & $\mathrm{H}$ & 1 & & $\mathrm{H}$ & & $\mathrm{H}$ & & 1 & 1 & $\mathrm{H}$ & & & & & $\mathrm{H}$ & & & $\mathrm{H}$ & & & & & & & & & 1 & $\mathrm{H}$ & 3 & & 7 \\
\hline \multicolumn{32}{|l|}{ Organizational } \\
\hline Misplace Items & & & & $\mathrm{H}$ & & 2 & & & & & & & & & & $\mathrm{H}$ & & & $\mathrm{H}$ & & & $\mathrm{H}$ & & & & & & & & & 2 \\
\hline $\begin{array}{l}\text { Scheduling/Time } \\
\text { Management }\end{array}$ & & & & $\mathrm{H}$ & 5 & 3 & & & 5 & & 1 & & $\mathrm{H}$ & & & $\mathrm{H}$ & 1 & 1 & & & 1 & & 1 & 3 & & & & & 1 & & 22 \\
\hline Routine & & & & & & & & 1 & & & & & & & & & & & & & & & & 1 & & & & & & & 2 \\
\hline Structure & & & 1 & & & & $\mathrm{H}$ & & 1 & & 1 & & & & & & & 1 & & & 3 & & & 3 & & & & & & 2 & 12 \\
\hline Study Skills & & & & & 1 & 1 & & & 2 & & & & & & & & & & & & & & & & & 2 & & & 2 & & 8 \\
\hline \multicolumn{32}{|l|}{ Time Related } \\
\hline Needs more time & & 1 & 1 & & 2 & & & & & & & 3 & & 1 & & & 1 & & & 1 & & & 5 & 2 & & 1 & & & & 1 & 19 \\
\hline \multicolumn{32}{|l|}{ Hyperactive } \\
\hline $\begin{array}{l}\text { Excessive Move/ } \\
\text { Restless Energy }\end{array}$ & $\mathrm{H}$ & 1 & 1 & & 1 & & & & & & & & & & & & & & & & & & & & & & 3 & $\mathrm{H}$ & 3 & & 9 \\
\hline $\begin{array}{l}\text { Rapid Thoughts/ } \\
\text { Conversation }\end{array}$ & & & & & & & & & & & & 1 & & 1 & & & & & & & & & & & & 2 & 5 & & 1 & & 10 \\
\hline $\begin{array}{l}\text { Skipped words or } \\
\text { Subjects }\end{array}$ & & 1 & 1 & & 1 & & & & & & 1 & 2 & & 1 & 1 & & & & & & & & & & & & & & 1 & & 9 \\
\hline Impulsivity & & & & & & & & & & & & & & & & & & 1 & & & & & & & & & 2 & & & & 3 \\
\hline Co-morbidity & & & $\mathrm{Y}$ & & & & & & $\mathrm{Y}$ & & $\mathrm{Y}$ & & & $\mathrm{Y}$ & & & $\mathrm{Y}$ & $\mathrm{Y}$ & & & & & $\mathrm{Y}$ & $\mathrm{Y}$ & & & & & $\mathrm{Y}$ & & \\
\hline $\begin{array}{l}\text { Type (Mental Health/ } \\
\text { Learning } \\
\text { Disability }\end{array}$ & & & $\mathrm{L}$ & & & & & & $\begin{array}{l}\mathrm{M} \\
\mathrm{H} \\
\end{array}$ & & $\mathrm{L}$ & & & $\mathrm{L}$ & & & \begin{tabular}{|l}
$\mathrm{M}$ \\
$\mathrm{H}$ \\
\end{tabular} & $\begin{array}{l}\mathrm{M} \\
\mathrm{H} \\
\end{array}$ & & & & & $\mathrm{L}$ & $\mathrm{L}$ & & & & & $\begin{array}{l}\mathrm{L} \\
\mathrm{L} \\
\mathrm{L}\end{array}$ & & 11 \\
\hline
\end{tabular}

Note. H represents history reported by student or significant other. 


\section{Relationship Functional Impairments}

Functional impairments in relationships were coded by behaviors to develop themes of impairments in communication with coded behavior issues in listening, misunderstanding, and self-advocacy. By self-advocacy I mean the ability to relate to others in a confident manner to express one's views and needs and to form social networks with authority figures, peers, and significant others. I also recoded all of the behaviors that were listed under functional impairments and applied them to relationships. This process provided the answer to research question two $b$ for each student. If you recall under the theme impairments in concentration I included attention, distraction, focus, forgetfulness, and memory, lack of interest and boredom. Under organizational issues I included lose/misplace items, scheduling/time management, routine, structure, and study skills/habits. I also developed the theme of time related issues as in needs extra time to complete tasks. Finally, I developed the theme of hyperactive responses with behavioral issues of excessive movement/restless energy, rapid thoughts/conversation, skipped words/subjects, reacts, not thinking things through. I did not include co-morbidity because there was no clear reference to co-morbidity and its impact on relationships. You will find a summary of relationship impairments in Table 4 A-F Relationship Impairments, pages 94-99.

\section{Interviewee Alfred and Significant Other Alexandria}

In regards to authority figures for college i.e. professors, teachers, and coaches for the theme impairments in communication in university setting Alfred listed one example of not understanding by others for authority figures, teachers, professors and coaches. He said, "You know ...you know I think if you could explain to them what it was and put them in a situation where they would have momentary ADD I think then they would truly understand what it was 
like." For the theme impairments in concentration related to professors. Alfred lists one impairment in attention (related to his professors), "I think they need to realize that it's ... you know ... it doesn't make you any less of a student just because you have a little harder time paying attention."

In relationship to peer (friends) he listed the theme of impairment in communication one example of not understanding by others. He said, "And half the time they'd be jealous. They'd be like, 'Damn it why can't I get that? What do I have to do to get diagnosed?' You know they'd be asking me questions. They'd be wanting that kind of services that I was getting."

For authority figures in the family (parents/adult relatives), Alfred listed for the theme, impairments in communication, the issue of not understanding by others when he stated, "My grandfather doesn't really understand why I'm in college, so you know, but they were never really involved with the school aspect or the disability aspect. They were never ... it was something they didn't understand, and they were supportive in a sense that well, you know, they would look at our mother and, go well, you're the educator do whatever you think is best."

For peers in the family (siblings and cousins) he listed under the theme impairments in communication not understanding by others. He said, "I have the two sisters and we've always got along very well. Umm the only thing is they might crack a joke and be like you know we're the one who doesn't have this issue, but we still have to come and ask you for help on these classes." The sisters were making fun of him and indicating that in spite of his disorder they had to ask for his help.

Alexandria under significant other partner mentions a hyperactive response wherein Alfred skips subjects or words. She said, "When he writes or talks sometimes he mixes up the 
words and I have to sit there and figure out which one he really means." There is one example of rapid thoughts/conversation. "Its probably thinking too fast and using the wrong word when he... using the wrong word in the wrong situation when it's really a different word."

In summary Alfred mentioned issues with a lack of understanding in the theme of communication impairments issues within the university setting with the authority figures of professors and peers. He also mentioned difficulty with paying attention as an issue with professors under impairments in concentration. In terms of family relationships he noted that his siblings make an issue of his AD/HD when they ask for help. Finally his significant other notes the hyperactive response of skipping or using the wrong words in conversation and rapid thoughts/conversation. There were no functional impairments mentioned by either Alfred or Alexandra with authority figures (bosses) or peers (co-workers) in the area of work (see Table 4 A-F Relationship Impairments, pages 94-99).

\section{Interviewee Bella and Significant Other Brittany}

In relationship to college relationships with authority figures (professors) with the behavior, self-advocacy, Brittany noted concerning Bella, the interviewee, "She's intimidated by her professors from what I have seen. It's hard to... she didn't go ... she was supposed to go talk to the science professor after the first test, and she was afraid that she didn't do well and so she kept putting off until after the second test. Umm I think she's really intimidated by them. She doesn't seem to be ... I'm pushing her to you know ... to go talk to them ... they are your advocates, but she's still a little bit intimidated."

Bella noted as an issue the communication impairment of self-advocacy with college peers. She said, “... If I have a problem ... uh the first couple of weeks I had roommate 
problems, and you know just having someone there-an adult figure that can give advice because they do work at the university helped a lot."

Under family related authority figures (parents) themes for impairments in communication for the issue, misunderstanding, there were three examples cited by Bella and Brittany her significant other, aunt. Bella states, "So this ... it's just started because when I first wanted to get medicated you know dad wasn't supportive, so by the time you know ..." She also said, "Mom is still in her selfish phase [indiscernible]. She has a new boyfriend and he is supporting her, and she is happy at the moment." Brittany, her significant other, said, "Her mother right now is not able to function as a mother ... She knows she can't rely on her, so she doesn't, but she's friendly enough with her, and you know she's not angry. She's just ... you know this is where she is right now, and she says, usually it's the parents saying this, but she says, 'Mom is just going through a phase."”

Under impairments in communication with the issue, misunderstanding by others, Bella listed two examples of two significant other issues, "He [her boyfriend] hated my friends, umm yep, he would ... he did joke about a lot of things, but I mentioned that it would annoy me or upset me and he continued, so basically I just like couldn't take it anymore.” “ It ended kind of really abruptly, but I ended it. I wanted to end it. I had been thinking about it for a couple of days, but uh basically he was just really manipulative, I guess and unsupportive."

Under hyperactive responses impairments for the issue reacts without thinking/impulsivity there was one issue with her significant other. Bella stated, "Umm breakups are really easy, I guess. We never fight about anything. I'm more of a lover not a fighter 
unless it's really something intense. Actually this past relationship was the only thing I really ever fought about anything, and ...."

In summary there were issues under communication impairments as in misunderstanding with authority figures, college professors as well as college peers. Under authority figures in the family Bella indicated under communication impairments misunderstanding she has relationship issues with both parents. She did not indicate any issues with peer siblings. She had issues with her significant other hyperactive responses of impulsivity or reacts without thinking, as she noted that she has issues with break-ups. In her interview she discussed multiple breakups and shortlived relationships. There were no issues related to work authority figures (bosses) or peers (coworkers) (see Table 4 A-F Relationship Impairments, pages 94-99).

\section{Interviewee Clarice and Significant Other Christy}

In relationship to college authority figures (Teachers/Professors/Coaches) Christy, the significant other, tutor, noted impairments in communication with one issue of listening related to the interviewee, Clarice. She said, "The auditory processing doesn't really affect her much at home. It affects her big time in college because I know that professors have given her test dates, assignment dates, instructions for assignment and things where she doesn't get it because it's not written down." She also noted a functional impairment in communication with the issue of Clarice not advocating for herself with peers. She said, "Her parents and I forced her to stay in the dorms so that she could establish relationships in summer school before the fall term started." In context Christy, the tutor, notes that Clarice has difficulty making friends.

In family relationships with authority figures (parents/adult relatives) she indicated a functional impairment in communication with an issue of listening. She indicated, "Clarice gets 
along well with her parents, although there are times when her parents get very frustrated with her because umm she doesn't take some of the advice that's given her that she probably ought to take."

There were two issues related to functional impairments in communication with misunderstanding. Clarice indicated an issue with her family adult relative as follows, "There is with one, and today and still to this day it's my aunt. She ... I have a cousin who also has $\mathrm{AD} / \mathrm{HD}$, but she doesn't really know, and we think she has something else, but we don't know." She also said, "...That I wish she would accept the fact there is something else wrong with her, my cousin, and deal with the problem instead of ignoring it. It's not going to get any better. That kind of makes me angry at her."

In summary Clarice has impairment in communication with the issue of not listening with authority figures (professors) in her college setting as well as not advocating for herself in friendships with peers creating an additional communication impairment according to Christy. She also has a communication impairment of an issue of listening that affects her relationship with family authority (parents). There were no issues with family peers (siblings, cousins). When asked if the interviewee had any issues with family authority figures Clarice expressed anger toward her aunt who has a child with what Clarice feels is AD/HD. She does not feel her aunt is willing to do any thing about it. Therefore, she feels not understood by others resulting in another impairment in communication with authority (adult relatives). There was no indication of impairments with work authority or peer co-workers (see Table 4 A-F Relationship Impairments, pages 94-99). Interviewee Dianna and Significant Other Denise 
In relationship to college authority figures (teachers/professors/coaches) the interviewee, Dianna indicated functional impairments in communication with the issue of misunderstanding five times. She said, “Umm like I was saying to be able to understand that I can't help it. It's not something that I choose to do. I mean it's something that's a matter with me like I can't help it. I mean I didn't choose to be AD/HD." She also said, "I sure most of us don't want to be AD/HD. It's just how we are. So I mean if the employers, professors, and teachers could be able to understand more that it's a disability basically. I mean we do our best to control it, but it's something that you can't always help." Denise, her significant other, noted, [referring to professors] "A lot of them kind of don't understand it, and kind of give her a hard time about it..." Denise also said, "He doesn't seem to understand her needs as far as from a learning standpoint. Once she knows the material she can reproduce it just as fast as anyone else without a disorder, but it's just that initial learning and being tested on it you know for the time, but I don't think he quite understands." Denise, the co-worker, friend and tutor, further said, "So when I do see her experience issues with professors that kind of take the 'well, this is not how it's going to be in real life' attitude, umm I take issue with that as a friend, and as a co-worker, and as someone who works with people that have different types of learning disorders and you know AD/HD." Under impairments in communication Denise, the significant other, also noted an issue of not advocating for self to others. She said, "At school when she's in classes, right, she does have issues sometimes conveying what her disorder is to some of the professors."

In relationship to authority figures, professors, Dianna indicated impairment in concentration with the issues of distraction. She noted, "Yeah and then sometimes when I like to think about things when I'm doing my test I don't just stare down. I kind of like stare at things. 
I stare at the wall. I stare up at the ceiling. Some professors think that my eyes are wondering at that time and looking for other answers on tests next to me where I'm not cheating I'm just...."

Relative to family relationship, authority figures (parents/adult relatives), Dianna indicated as communication impairment the issue of misunderstanding one time. She said, "Yeah, I mean I didn’t get medicated until I came to college here obviously. I really had to beg my mom to let me just because I don't think she's for that... medication, but she's like, 'oh try that, it's like a diet for your blood type.' I say mom, 'I'm in college I can't eat just what I want to eat unless you're going to pay for it' ... I mean so I was finally able to get my mom to let me take the medication."

In summary there were functional impairments in communication for Dianna with authority (college professors) in the area of misunderstanding, as well as the family authority figure, her mother. There was an issue with an impairment in concentration with distraction relative to the professor thinking she was cheating because she was not looking down. There was no mention of functional impairments in relationships with peers at college or with peers in the family (siblings or cousins). Finally, there was no mention of functional impairments in relationships with authority figures or peer co-workers at work (see Table 4 A-F Relationship Impairments, pages 94-99).

Interviewee Ellen and Significant Other Emma

In relationship to functional impairments in the area of communication with college Authority Figures (teachers/professors/coaches) there were no reports by the interviewee, Ellen or the significant other, Emma. However with college peers the significant other indicated as a communication functional impairment for Ellen the issue misunderstanding one time. Emma 
said, "Sometimes I don't understand her and I say uh huh 'cause I didn't understand, so she repeats herself." She also indicated as a communication functional impairment that there is an issue of self-advocacy for self to others, as in being able to make friends, by stating, "I'm about her only friend at college... She needs groups like Campus Crusade to help her make friends.”

In terms of functional impairment of organization Emma the significant other indicated an issue of scheduling/time management with peers. She noted, "Ellen wants to go out all the time, and I'm studying all the time. The inference here was that individuals in college normally have to spend a lot of time studying. Yet Emma is saying that the priority for Ellen is recreational. Although Ellen as a freshmen did not get any Ds or Fs for midterm, her writing sample had 11 total errors. This is an indication of rushing through tasks indicating a time management issue/priority. Emma went on to say, "When we are working on class projects Ellen already has her project done a week ahead of time." Emma noted skipped word/subjects one time under hyperactive issues with college peers, "She doesn't make sense in conversations because she skips words and leaves out information."

For family authority functional impairments of hyperactive responses Emma noted impulsivity in Ellen as in reacts without thinking by stating, "Her dad gave her a credit card and she said, 'I spent too much money.",

In summary there appears to be no functional impairments in the area of communication with college authority figures (professors). However with college peers there are communication impairments, which directly affect her ability to make friends. In terms of functional impairments in organization there is an issue of scheduling/time management to balance her time between schoolwork and socialization with college peers. There are also hyperactive responses 
with peers in skipped words or subjects. Finally hyperactive impulsivity in this case may directly affect her relationship with her family authority figure (father). There were no indications of difficulties with family peers (cousins or siblings). Finally, there were no issues with authority figures (bosses) or peer co-workers in the work setting (see Table 4 A-F Relationship Impairments, pages 94-99).

Interviewee Frank and Significant Other Frances

In relationships with college authority figures (teachers/professors/coaches) relative to impairments in communication with the issue misunderstanding Frank said, "The professors have been good. Some have been just jerks that I just act good, so I want to get out of class ... just get it done with.” Frank did not report issues with peer college students.

With family authority figures (parents/adult relatives) Frances, who was Frank’s mother, indicated functional impairments in communication as in misunderstanding. She said, "His dad doesn't probably have the same understanding that I have, but it's simply that his dad hasn't worked in this field as long as I have, so he's really dealt with it from a parent's perspective on the outside that knew nothing about it."

Relative to significant other functional impairments under the theme hyperactive responses, Frances indicated impulsivity or reacting without thinking when she said, “And eventually when he came to college she was still a sophomore in high school umm and he broke it off with her. But after he broke it off with her, for probably a month or two, he realized that he had made a really big mistake. And he was really very anxious over the fact that he made a mistake like that and realized that was an impulsive decision." 
In regards to work authority figures (bosses/supervisors) there was an indication of functional impairments in organization, with scheduling/time management. Frances noted, “... I think he was probably eighteen when he got his second job and I said, you know, you're an adult now and you need to be treated like an adult. And I'm not going to take responsibility for making sure you get to work when you're supposed to be there.” Frank indicated two issues with peer (co-workers) when he noted as reacts without thinking, "I don't have very good patience with some of my co-workers. One of them actually reminds me of when I was in middle school. [Indiscernible] says whatever is on her mind [implying saying whatever is on your mind without thinking]. I know from past experience that that doesn't go well, so she knows how to make me mad."

In summary Frank has some impairment in communication with the college professors (authority) and family authority as in misunderstanding. Neither the interviewee nor significant other indicated that Frank had issues with college peers or family peers (siblings or cousins). Relative to his significant other (girlfriend) his mother indicated a hyperactive response of impulsivity noting that her son regrets his decision. He has not had a significant other since. There had been an issue with work-related issues as in organizational impairments as in getting to work on time, a scheduling/time management issue. Finally, there are some issues with impulsivity with anger toward a co-worker who bugs him (see Table 4 A-F Relationship Impairments, pages 94-99).

Interviewee Georgia and Significant Other Grace

Georgia indicated an issue of misunderstanding for functional impairments with communication with authority figures (teachers/professors/coaches). In her writing sample 
Georgia states as her example, "I wish that the professors should change their subjects so the students can understand it more and continue with the lectures." Her significant other, Grace, Director of Student Support Services, noted college peer functional impairments in communication with the issue of listening. She noted, "I was just talking to her about a situation that it was the way she saw it and the way I saw it, but she has a hard time listening to what someone else is saying. She tends to misread body language inferences." She further noted as a hyperactive functional impairment an issue in impulsivity as in ends friendships frequently. Grace said, "As far as college goes I think that she has trouble making friends and with some of the relationships she had with friends that she has made. They don't always last."

In terms of family authority relationships (parent, grandmother) Georgia stated in relationship to an issue, misunderstanding, "Just don't call me that because that's not right. She just... and I keep telling her, I keep telling her that's ... that's how I act. Just say that's how I act now but never call me stupid, dumb, crazy or anything else like that." Grace stated in terms of significant other relationships (boyfriends), “... she shared experiences about boyfriends and it seems that they never last very long either." There were no issues with work authority figures, or co-workers.

In summary, Georgia has communication impairments with college authority figures (professors) with the issue of misunderstanding as in feeling that the professor doesn't understand her. Additionally she has college peer relationship issues due to communication impairment as in not listening and hyperactive responses of impulsivity noting that relationships don't seem to last long. She has had impairments in communication with her family authority as in misunderstanding with her grandmother who raised her. In terms of significant others 
(boyfriends) she shows impulsivity by having very short term relationships. There were no issues with work authority figures, or co-workers (see Table 4 Relationship Impairments A-F, pages 94-99).

\section{Interviewee Hal and Significant Other Harold}

In relationship impairments with authority figures (teachers/professors/coaches) Hal indicated twice impairments in communication with misunderstanding as an issue. He indicated, "Umm well it depends on the professor I mean some professors are very understanding and they help you a lot, and then some seem kind of annoyed, but I mean that they ... you know 'cause for people with $\mathrm{AD} / \mathrm{HD}$ at the Student Support Center they have to ... you know ... it's a lot more work because they have to send tests over here uh I don't know, I mean..." He also continued with the following, "Some professors seem annoyed. Some professors that are ... like there are good ones and there are bad ones, and the Student Support Program here ... they try to tell you which ones work best with the program, I don't know ... uh like for a little more understanding. Umm I don’t know. I mean they seem okay." In context in relationship to a time related issue, the student seemed frustrated that professors were annoyed with having to provide the opportunity for students to take more time to complete tasks through student support services. He did not report any college peer relationship impairments.

Hal, the interviewee indicated organization issues as a functional impairment with authority figures (parents/adult relatives) in the area of scheduling/time management with one example. He said, "Yeah, well I think my grandmother's ADD too 'cause she does many different projects at once and never seems to finish them. I mean 'cause she gets on one project 
and then she kind goes onto the next and forgets about the one there, so I mean ... And we all seem to ... we have to have a list or we don't get anything done."

Harold, Hal's significant other who is his peer in the family (brother) noted organizational issues as a functional impairment, which creates two issues with him in the area of structure. He said, “And it's also because I try to give him a plan to try to help structure his time. He looks at me and he says, "What are we going to do now?" He states, "I know I kind of help structure how he does things a little bit, and its kind of frustrating because I try to take care of myself." He also indicates the issue of scheduling/time management as one issue. He said, "Like I know this morning he's like, 'what are we going to have for breakfast this morning'? I said, 'I don't know'. He said, 'Can you make it for me,' and I said, 'No it's in the fridge.' It seems like I have to take extra steps to try and take care of him." He further indicated an issue of structure as an issue with organizational impairments.

In summary, Hal indicates impairments in relationships in the area of communications as in misunderstanding with authority figures (professors) at the college. He also notes that the need to take extra time to complete tasks creates a relationship issue with authority figures with professors. In terms of peers at the college he does not address any functional impairments in his relationships. However, there are functional impairments in the relationship with his brother, who is also his roommate, and who notes issues of structure and time management/scheduling under organizational impairments. In terms of his authority figure (parents/adult relatives) he indicates that his grandmother's organizational impairments in scheduling/time management as she takes on multiple projects often not completing them and that there must be a list for everyone, including himself, for many of his family members to get things done. This is clearly 
an example of organizational issues for family members that can create conflict. Hal or Harold, his significant other (brother), does not mention any impairment with work either with authority figures (bosses) or peers (co-workers) (see Table 4 Relationship Impairments A-F, pages 94-99). Interviewee Isaac and Significant Other Israel

In terms of relationship functional impairments in college with authority figures (teachers/professors/coaches) Isaac indicates impairment in communication as in misunderstanding. He states in his writing sample, "I would like professors to understand just because you have a problem doesn't mean we are dumb or not smart. We just learn in different ways and that to cut us some slack because we just learn different and we can do it. It may take longer but we will get through it." He also noted that his functional impairment in concentration as in the issue of attention had created impairment in the relationship with his professor. $\mathrm{He}$ stated, "I put my head down the other day and he's like, 'If you have a problem with my class you can leave.' I didn't even do anything. Uh he just says like the Student Support Program and other programs on campus are really stupid and mean nothing to the school."

In terms of college peer (friends) Isaac's significant other Israel, his roommate cites an organizational functional impairment with the issue structure that causes impairments in peer relationships. This was disruptive to the normal structure of their day-to-day living and was in the context of the conversation an impulsive decision. He said he wanted to move to another place. "At the same time I was thinking do I really want to move too? I don't want another roommate cause I'm already used to one. So I decided to move too, so we both ended up moving all of our stuff. It was a hassle moving everything from there to all the way over to Wonderland.” 
Israel the significant other roommate noted functional impairments with hyperactive responses that contribute to relationship impairments as in the issue of rapid conversation, racing thoughts. He states, "But like some of my friends would be like man Isaac he's just real hyped I don't want to stay a while everything just so got to be so loud and the way he talks." Other examples were cited by Israel that reflects hyperactive responses such as reacts without thinking or impulsivity, which contribute to impairments in peer relationships. He indicated five examples. Two of the examples follow: He said, "And he was just saying, 'Oh the reason why I wasn't your roommate ... the reason I left being your roommate is because Melissa told me that, who is Rebecca's girlfriend, said I shouldn't be friends with you and I shouldn't be your roommate no more." “And there's been times when we was living in Candy Land I think, in another dorm and his girlfriend lived in Wonderland, so he asked can we move from Candy Land to Wonderland just because she was in Wonderland." He noted an example of his response to him being broke down on the highway as follows. "Like if you need help with anything he'll be there for you. I called him and he said 'I'll be right there to help you out' and he was very caring. Like I know when he came he was like 'Oh my God we got to do something. We got to call 911. We got to call 411.' I was like Isaac, 'We're not going to call 911. We're not going to call 411 either. We're just going to call the tow truck company." "Yeah, he kind of just reacts. 'No we're not going to call 911. I don't want to talk to no police officer right now about this. We'll have to wait for the police office to come, and he'll just make me do something I already know I have to do."”

Israel noted relationship impairment with the family authority figures (parents/adult relatives) as in impairments in communication with listening. He said, "Even his mother said, 'I 
don't think you all are going to get married' and that kind of hurt him a lot. I was just trying to explain, well Isaac you just got to look at what she's looking at from her point of view of how she thinks as looking from the outside in."

Israel noted impairments in communication as in misunderstanding with his significant other (girlfriend). Israel said, "Like I'll never forget when his girlfriend broke his heart and you know said a lot of mean things to him and stuff." In terms of his significant other girlfriend he noted self-advocacy twice with respect to family relationship impairment. He said, [Referring to Isaac's relationship with his girlfriend] "When you look at the relationship on the outside I'm not the only person that could see this. Many people saw this. She wanted ... she made him work out." Israel further stated, "She wanted him to be this body builder type of person, and I could tell that Isaac ... He really didn't really want that for himself. But his girlfriend really put him down in a lot of ways and really lowered his self-esteem, and made him feel like he was the worst person they ever dated. And that really hurt him really badly."

There were no impairments in work relationships with authority figures (bosses/supervisors). However there were impairments indicated with peer co-workers with impairments in concentration with the issue of forgetfulness. Isaac, the interviewee said, "I got along with most of them. Some would gripe at me for forgetting to put like a lobster fork on it, but I was like we're busy I don't have time for it. You know I'm sorry if I forgot...”

In summary, Isaac and Israel noted issues of relationship impairment in the college with authority (professors) as in misunderstanding with his professor and with impairment in concentration (attention issue) in that the professor took his behavior as disinterest and he asked the student to leave. There was negative impact with Israel as a college peer in which 
organizational impairment, structure, caused disruption with an impulsive move based on the needs of his girlfriend. He also reflected that Isaac would not listen to the family authority figure (mother) about her insight into his relationship with his girlfriend. This created impairments in communication. Within his significant other relationship with his girlfriend Israel felt that Isaac, the interviewee had impairment in hyperactive responses making impulsive decisions that were not well thought out. He noted that he had poor communication with her especially when it came to misunderstanding. Though Isaac or Israel did not indicate problems with authority at work, peer co-workers did rib him about forgetting the lobster fork on the plate (see Table 4 A-F Relationship Impairments, pages 94-99).

\section{Interviewee Jack and Significant Other Jim}

With authority figures (teachers/professors/coaches) there were relationship issues in communication as in misunderstanding. Jack the interviewee, stated, "Some of them will assist you after class-give you and ask you different things to make sure you're getting it. And some of them will be a complete jerk and just look at and say tough luck." There were no reports of impairments with peers at the college level.

There was one issue of impairments in the relationships with family authority figures (parents/adult relatives) as in the issue of misunderstanding in which Jack noted, "I have no use for him." He was referring to his father. There was only history of impairments with peer siblings/cousins. In terms of his significant other relationship with his girlfriend he states a communication issue of misunderstanding, "I always have to keep repeating myself, and I guess the way in which I word things and the way she words things and ... I guess neither would understand what the other is saying with the intent behind the message, so..." Jim, his 
significant other stated in reference to Jack's relationships, “ He gets along with people a lot better than I do. He is much more sociable. And everybody likes him and he does a very good job." He was not familiar with his family situation.

There were no work relationship impairments with authority figures (bosses) or peers (co-workers).

In summary Jack feels misunderstood by professors with communication issues resulting in functional impairments for relationships. There are no indicated issues with peers at college. There was one issue with family authority figures in misunderstanding with his father. There is nothing current for peer siblings/cousins. There is also a communication issue with his significant other girlfriend in which he feels misunderstood. There are no indicated impairments with work authority figures or peer co-workers reported by either Jack or his significant other (see Table 4 Relationship Impairments A-F, pages 94-99).

A summary of the number and types discussions of issues that indicated impairments to relationships by the interviewees and significant others is noted in Tables 4 Relationship Impairments A-F, pages 94-99. 
Table 4 A

Impairments in Current Relationships

\begin{tabular}{|c|c|c|c|c|c|c|c|c|c|c|c|c|c|c|c|c|c|c|c|c|c|}
\hline College & 总 & 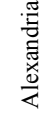 & $\stackrel{\Xi}{\bar{\Xi}}$ & 空 & $\frac{\mathscr{g}}{\tilde{E}}$ & 离 & 营 & 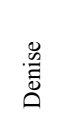 & $\frac{\bar{\Xi}}{\overline{\overline{\mid}}}$ & 节 & 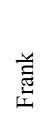 & 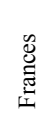 & 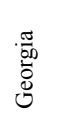 & $\underset{\mathscr{Z}}{\mathscr{E}}$ & 焉 & 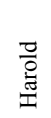 & 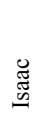 & \begin{tabular}{|l}
$\overline{\mathscr{E}}$ \\
馬
\end{tabular} & $\begin{array}{l}\stackrel{u}{\ddot{~}} \\
\end{array}$ & $\Xi$ & 告 \\
\hline $\begin{array}{l}\text { Authority } \\
\text { Figures (Teachers/ } \\
\text { Professors) }\end{array}$ & \multicolumn{2}{|c|}{$\mathrm{H}$} & \multicolumn{2}{|c|}{$\mathrm{H}$} & & & \multicolumn{2}{|c|}{$\mathrm{H}$} & \multirow{2}{*}{\multicolumn{2}{|c|}{$\mathrm{H}$}} & & & & & \multicolumn{2}{|c|}{$\mathrm{H}$} & \multicolumn{2}{|c|}{$\mathrm{H}$} & \multirow{2}{*}{\multicolumn{2}{|c|}{$\mathrm{H}$}} & \\
\hline Communication & & & & & & & & & & & & & & & & & & & & & \\
\hline Listening & & & & & & 1 & & & & & & & & & & & & & & & 1 \\
\hline Misunderstanding & 1 & & & & & & 2 & 3 & & & 1 & & 1 & & 2 & & 1 & & 1 & & 12 \\
\hline Self-Advocacy & & & & 1 & & & & 1 & & & & & & & & & & & & & 2 \\
\hline Concentration & & & & & & & & & & & & & & & & & & & & & \\
\hline Attention & 1 & & & & & & & & & & & & & & & & 1 & & & & 2 \\
\hline Distraction & & & & & & & 1 & & & & & & & & & & & & & & 1 \\
\hline Focus & & & & & & & & & & & & & & & & & & & & & \\
\hline Forgetfulness & & & & & & & & & & & & & & & & & & & & & \\
\hline Memory & & & & & & & & & & & & & & & & & & & & & \\
\hline Lack of Interest/Boredom & & & & & & & & & & & & & & & & & & & & & \\
\hline Organizational & & & & & & & & & & & & & & & & & & & & & \\
\hline Lose/Misplace Items & & & & & & & & & & & & & & & & & & & & & \\
\hline Scheduling/Time Managem & & & & & & & & & & & & & & & & & & & & & \\
\hline Routine & & & & & & & & & & & & & & & & & & & & & \\
\hline Structure & & & & & & & & & & & & & & & & & & & & & \\
\hline Study Skills/Habits & & & & & & & & & & & & & & & & & & & & & \\
\hline Time Related & & & & & & & & & & & & & & & & & & & & & \\
\hline Needs Extra Time & & & & & & & & & & & & & & & 1 & & & & & & 1 \\
\hline Hyperactive & & & & & & & & & & & & & & & & & & & & & \\
\hline $\begin{array}{l}\text { Excessive Movement/ } \\
\text { Restless Energy }\end{array}$ & & & & & & & & & & & & & & & & & & & & & \\
\hline $\begin{array}{l}\text { Rapid Thoughts/ } \\
\text { Conversation }\end{array}$ & & & & & & & & & & & & & & & & & & & & & \\
\hline Skipped Words or Subjects & & & & & & & & & & & & & & & & & & & & & \\
\hline $\begin{array}{l}\text { Reacts Without } \\
\text { Thinking/Impulsivity }\end{array}$ & & & & & & & & & & & & & & & & & & & & & \\
\hline
\end{tabular}

Note. $\mathrm{H}$ represents history reported by student or significant other. 
Table 4 B

Impairments in Current Relationships

\begin{tabular}{|c|c|c|c|c|c|c|c|c|c|c|c|c|c|c|c|c|c|c|c|c|c|}
\hline College & 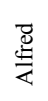 & 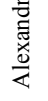 & $\stackrel{\frac{\pi}{\pi}}{\oplus}$ & 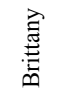 & 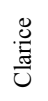 & 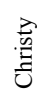 & 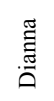 & 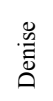 & 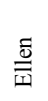 & 莺 & 营 & 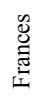 & 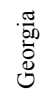 & 巡 & $\Xi$ & 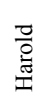 & 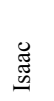 & $\begin{array}{l}\overline{\widetilde{\varpi}} \\
\underline{\mathscr{n}}\end{array}$ & 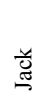 & $\Xi$ & 勿 \\
\hline $\begin{array}{l}\text { Peers } \\
\text { (Friends) }\end{array}$ & & & \multicolumn{2}{|c|}{$\mathrm{H}$} & \multicolumn{2}{|c|}{$\mathrm{H}$} & \multicolumn{2}{|c|}{$\mathrm{H}$} & & & \multicolumn{2}{|c|}{$\mathrm{H}$} & \multicolumn{2}{|c|}{$\mathrm{H}$} & & & \multicolumn{2}{|c|}{$\mathrm{H}$} & \multicolumn{2}{|c|}{$\mathrm{H}$} & \\
\hline \multicolumn{22}{|l|}{ Communication } \\
\hline Listening & & & & & & & & & & & & & & 1 & & & & & & & 1 \\
\hline Misunderstanding & 1 & & & & & & & & & 1 & & & & & & & & & & & 2 \\
\hline Self-Advocacy & & & 1 & & & 1 & & & & 1 & & & & & & & & & & & 3 \\
\hline \multicolumn{22}{|l|}{ Concentration } \\
\hline \multicolumn{22}{|l|}{ Attention } \\
\hline \multicolumn{22}{|l|}{ Distraction } \\
\hline \multicolumn{22}{|l|}{ Focus } \\
\hline \multicolumn{22}{|l|}{ Forgetfulness } \\
\hline \multicolumn{22}{|l|}{ Memory } \\
\hline \multicolumn{22}{|l|}{ Lack of Interest/Boredom } \\
\hline \multicolumn{22}{|l|}{ Organizational } \\
\hline \multicolumn{22}{|l|}{ Lose/Misplace Items } \\
\hline Scheduling/Time Management & & & & & & & & & & 1 & & & & & & & & & & & 1 \\
\hline \multicolumn{22}{|l|}{ Routine } \\
\hline Structure & & & & & & & & & & & & & & & & & & 1 & & & 1 \\
\hline \multicolumn{22}{|l|}{ Study Skills/Habits } \\
\hline \multicolumn{22}{|l|}{ Time Related } \\
\hline \multicolumn{22}{|l|}{ Needs Extra Time } \\
\hline \multicolumn{22}{|l|}{ Hyperactive } \\
\hline \multicolumn{22}{|l|}{$\begin{array}{l}\text { Excessive Movement/ } \\
\text { Restless Energy }\end{array}$} \\
\hline $\begin{array}{l}\text { Rapid Thoughts/ } \\
\text { Conversation }\end{array}$ & & & & & & & & & & & & & & & & & & 1 & & & 1 \\
\hline Skipped Words or Subjects & & 1 & & & & & & & & 1 & & & & & & & & & & & 2 \\
\hline $\begin{array}{l}\text { Reacts Without } \\
\text { Thinking/Impulsivity }\end{array}$ & & & & & & & & & & & & & & 1 & & & & 5 & & & 6 \\
\hline
\end{tabular}

Note. $\mathrm{H}$ represents history reported by student or significant other 
Table 4 C

Impairments in Current Relationships

\begin{tabular}{|c|c|c|c|c|c|c|c|c|c|c|c|c|c|c|c|c|c|c|c|c|c|}
\hline Family & 苞 & 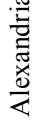 & $\stackrel{\frac{\pi}{\bar{D}}}{\bar{D}}$ & 蔦 & 节 & 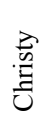 & 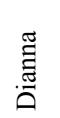 & 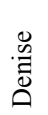 & $\stackrel{\text { ㄹ }}{\overline{\overline{\mid}}}$ & 营 & 荡 & 过 & 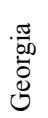 & 迎 & 画 & 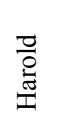 & $\underset{\mathscr{J}}{\mathscr{\mathscr { W }}}$ & $\underset{\mathbb{\pi}}{\tilde{\Phi}}$ & $\underset{\tilde{J}}{\stackrel{u}{\sigma}}$ & $\Xi$ & 量 \\
\hline $\begin{array}{l}\text { Authority } \\
\text { Figures } \\
\text { (Parents/Adult Relatives) }\end{array}$ & & & \multicolumn{2}{|c|}{$\mathrm{H}$} & & & & & & & \multicolumn{2}{|c|}{$\mathrm{H}$} & \multicolumn{2}{|c|}{$\mathrm{H}$} & & & & & \multicolumn{2}{|c|}{$\mathrm{H}$} & \\
\hline \multicolumn{22}{|l|}{ Communication } \\
\hline Listening & & & & & & 1 & & & & & & & & & & & & 1 & & & 2 \\
\hline Misunderstanding & 1 & & 2 & 1 & 2 & & 1 & & & & & 1 & 1 & & & & & & 1 & & 10 \\
\hline Self-Advocacy & & & & & & & & & & & & & & & & & & & & & \\
\hline \multicolumn{22}{|l|}{ Concentration } \\
\hline \multicolumn{22}{|l|}{ Attention } \\
\hline \multirow{2}{*}{\multicolumn{22}{|c|}{$\begin{array}{l}\text { Distraction } \\
\text { Focus }\end{array}$}} \\
\hline & & & & & & & & & & & & & & & & & & & & & \\
\hline \multicolumn{22}{|l|}{ Forgetfulness } \\
\hline \multicolumn{22}{|l|}{ Memory } \\
\hline \multirow{2}{*}{\multicolumn{22}{|c|}{$\begin{array}{l}\text { Lack of Interest/Boredom } \\
\text { Organizational }\end{array}$}} \\
\hline \multicolumn{8}{|l|}{ Organizational } & & & & & & & & & & & & & & \\
\hline \multicolumn{22}{|l|}{ Lose/Misplace Items } \\
\hline Scheduling/Time Management & & & & & & & & & & & & & & & 1 & & & & & & 1 \\
\hline \multicolumn{22}{|l|}{ Routine } \\
\hline \multirow{2}{*}{\multicolumn{22}{|c|}{$\begin{array}{l}\text { Structure } \\
\text { Study Skills/Habits }\end{array}$}} \\
\hline \multirow{2}{*}{\multicolumn{22}{|c|}{$\begin{array}{l}\text { Study Skills/Habits } \\
\text { Time Related }\end{array}$}} \\
\hline & & & & & & & & & & & & & & & & & & & & & \\
\hline \multicolumn{22}{|l|}{ Needs Extra Time } \\
\hline \multicolumn{22}{|l|}{ Hyperactive } \\
\hline \multicolumn{22}{|l|}{$\begin{array}{l}\text { Excessive Movement/ } \\
\text { Restless Energy }\end{array}$} \\
\hline \multicolumn{22}{|l|}{$\begin{array}{l}\text { Rapid Thoughts/ } \\
\text { Conversation }\end{array}$} \\
\hline \multicolumn{22}{|l|}{ Skipped Words or Subjects } \\
\hline $\begin{array}{l}\text { Reacts Without } \\
\text { Thinking/Impulsivity }\end{array}$ & & & & & & & & & & 1 & & & & & & & & & & & 1 \\
\hline
\end{tabular}

Note. $\mathrm{H}$ represents history reported by student or significant other. 
Table 4 E

Impairments in Current Relationships

\begin{tabular}{|c|c|c|c|c|c|c|c|c|c|c|c|c|c|c|c|c|c|c|c|c|c|}
\hline Family & 总 & 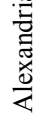 & $\frac{\tilde{7}}{\overline{0}}$ & 胥 & 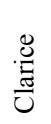 & 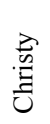 & 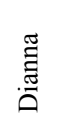 & 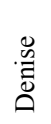 & 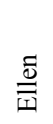 & 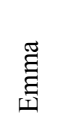 & 皆 & 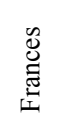 & $\begin{array}{l}\frac{\pi}{50} \\
\bar{\Xi} \\
0 \\
0\end{array}$ & 巡 & 馬 & 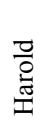 & 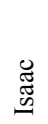 & $\underset{\mathbb{E}}{\vec{\Phi}}$ & 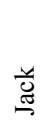 & $\Xi$ & 哭 \\
\hline $\begin{array}{l}\text { Significant Others } \\
\text { (Partners/ } \\
\text { Girlfriends/ } \\
\text { Boyfriends) } \\
\end{array}$ & & & \multicolumn{2}{|c|}{$\mathrm{H}$} & & & \multicolumn{2}{|c|}{$\mathrm{H}$} & & & \multicolumn{2}{|c|}{$\mathrm{H}$} & \multicolumn{2}{|c|}{$\mathrm{H}$} & & & & & \multicolumn{2}{|c|}{$\mathrm{H}$} & \\
\hline \multicolumn{22}{|l|}{ Communication } \\
\hline Listening & & & & & & & & & & & & & & & & & & & & & \\
\hline Misunderstanding & & & 2 & & & & & & & & & & & & & & & 1 & 1 & & 4 \\
\hline Self-Advocacy & & & & & & & & & & & & & & & & & & 2 & & & 2 \\
\hline \multicolumn{22}{|l|}{ Concentration } \\
\hline \multicolumn{22}{|l|}{$\begin{array}{l}\text { Attention } \\
\text { Distraction }\end{array}$} \\
\hline Distraction & & & & & & & & & & & & & & & & & & & & & \\
\hline \multicolumn{22}{|l|}{ Focus } \\
\hline \multicolumn{22}{|l|}{ Forgetfulness } \\
\hline \multirow{2}{*}{\multicolumn{22}{|c|}{$\begin{array}{l}\text { Memory } \\
\text { Lack of Interest/Boredom }\end{array}$}} \\
\hline & & & & & & & & & & & & & & & & & & & & & \\
\hline \multicolumn{22}{|l|}{ Organizational } \\
\hline \multicolumn{22}{|l|}{ Lose/Misplace Items } \\
\hline \multirow{2}{*}{\multicolumn{22}{|c|}{$\begin{array}{l}\text { Scheduling/Time Management } \\
\text { Routine }\end{array}$}} \\
\hline & & & & & & & & & & & & & & & & & & & & & \\
\hline \multicolumn{22}{|l|}{ Structure } \\
\hline \multirow{2}{*}{\multicolumn{22}{|c|}{$\begin{array}{l}\text { Study Skills/Habits } \\
\text { Time Related }\end{array}$}} \\
\hline & & & & & & & & & & & & & & & & & & & & & \\
\hline \multicolumn{22}{|l|}{ Needs Extra Time } \\
\hline \multicolumn{22}{|l|}{ Hyperactive } \\
\hline \multicolumn{22}{|l|}{$\begin{array}{l}\text { Excessive Movement/ } \\
\text { Restless Energy }\end{array}$} \\
\hline $\begin{array}{l}\text { Rapid Thoughts/ } \\
\text { Conversation }\end{array}$ & 1 & & & & & & & & & & & & & & & & & & & & 1 \\
\hline Skipped Words or Subjects & 1 & & & & & & & & & & & & & & & & & & & & 1 \\
\hline $\begin{array}{l}\text { Reacts Without } \\
\text { Thinking/Impulsivity }\end{array}$ & & & 1 & & & & & & & & & 1 & & 1 & & & & & & & 3 \\
\hline
\end{tabular}

Thinking/Impulsivity 
Table 4 F

\begin{tabular}{|c|c|c|c|c|c|c|c|c|c|c|c|c|c|c|c|c|c|c|c|c|c|}
\hline \multicolumn{22}{|c|}{ Impairments in Current Relationships } \\
\hline Work & 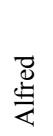 & 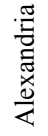 & $\frac{\mathscr{0}}{\overline{0}}$ & 宓 & 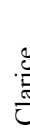 & 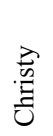 & 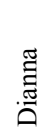 & 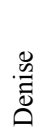 & $\frac{\bar{\Xi}}{\overline{\bar{I}}}$ & 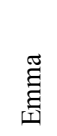 & 慈 & 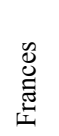 & 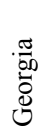 & $\stackrel{\mathscr{\pi}}{\tilde{B}}$ & 五 & 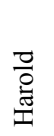 & $\underset{\mathscr{E}}{\mathscr{G}}$ & 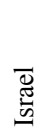 & 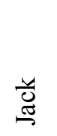 & $\Xi$ & 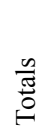 \\
\hline $\begin{array}{l}\text { Authority Figures B } \\
\text { (Bosses/Supervisors) } \\
\text { Peers C } \\
\text { (Co-workers) }\end{array}$ & & & & & & & & & \multicolumn{4}{|c|}{$\mathrm{H}$} & & & & & & & & & \\
\hline Communication & & & & & & & & & & & & & & & & & & & & & \\
\hline Listening & & & & & & & & & & & & & & & & & & & & & \\
\hline Misunderstanding & & & & & & & & & & & & & & & & & & & & & \\
\hline Self-Advocacy & & & & & & & & & & & & & & & & & & & & & \\
\hline Concentration & & & & & & & & & & & & & & & & & & & & & \\
\hline Attention & & & & & & & & & & & & & & & & & & & & & \\
\hline Distraction & & & & & & & & & & & & & & & & & & & & & \\
\hline Focus & & & & & & & & & & & & & & & & & & & & & \\
\hline Forgetfulness & & & & & & & & & & & & & & & & & $\begin{array}{l}1 \\
\mathrm{C}\end{array}$ & & & & 1 \\
\hline Memory & & & & & & & & & & & & & & & & & & & & & \\
\hline Lack of Interest/Boredom & & & & & & & & & & & & & & & & & & & & & \\
\hline Organizational & & & & & & & & & & & & & & & & & & & & & \\
\hline Lose/Misplace Items & & & & & & & & & & & & & & & & & & & & & \\
\hline Scheduling/Time Management & & & & & & & & & & & & $\begin{array}{l}1 \\
\mathrm{~B}\end{array}$ & & & & & & & & & 1 \\
\hline Routine & & & & & & & & & & & & & & & & & & & & & \\
\hline Structure & & & & & & & & & & & & & & & & & & & & & \\
\hline Study Skills/Habits & & & & & & & & & & & & & & & & & & & & & \\
\hline Time Related & & & & & & & & & & & & & & & & & & & & & \\
\hline $\begin{array}{l}\text { Needs Extra Time to Complete } \\
\text { Task }\end{array}$ & & & & & & & & & & & & & & & & & & & & & \\
\hline Hyperactive & & & & & & & & & & & & & & & & & & & & & \\
\hline $\begin{array}{l}\text { Excessive Movement/ } \\
\text { Restless Energy }\end{array}$ & & & & & & & & & & & & & & & & & & & & & \\
\hline $\begin{array}{l}\text { Rapid Thoughts/ } \\
\text { Conversation }\end{array}$ & & & & & & & & & & & & & & & & & & & & & \\
\hline Skipped Words or Subjects & & & & & & & & & & & & & & & & & & & & & \\
\hline $\begin{array}{l}\text { Reacts Without } \\
\text { Thinking/Impulsivity }\end{array}$ & & & & & & & & & & & $\begin{array}{l}2 \\
\mathrm{C}\end{array}$ & & & & & & & & & & 2 \\
\hline
\end{tabular}


Academic Functional Impairments and Writing Sample Issues

Analyzing and coding the students' college transcripts/midterm reports and writing samples answered research question 2a by determining how functional impairments affect students in a college setting. A discussion of each student's academic functional impairment follows.

Interviewee Alfred

Alfred is a 23 year-old white male graduate student. He currently has a 4.0 average in graduate school and had a 3.15 average in undergraduate school. He is a graduate student in the exercise science program. For issues related to academics he has no Ds or Fs in graduate or undergraduate school. His significant other Alexandra says, "By this point there aren't many difficulties because he has found ways to overcompensate that make up for where his disability applies..." When asked how he does that she said, "By either putting in more time or say he has problems concentrating he does go do one thing then comes back to it then goes back to it again." Alfred notes that he needs extra time for reading and writing (see Table 5 Academic Functional Impairments, page 107).

Alfred's writing sample showed problems with content, topic development and lacking details. There were three grammatical errors in word usage and mechanical errors of two misspelled words (see Table 6 Writing Sample Analysis, page 108).

\section{Interviewee Bella}

Bella is an 18 year-old white female undergraduate student majoring in Biochemistry. She has only received a midterm report indicating that she has a D in Principles of Chemistry, and a D in Applied Calculus. "It's just a lot more difficult for me to make things up than it is to 
borrow other people's ideas." She said, "For reading the words are already there. Sometimes I have to go back and reread a paragraph or a page or two because I've noticed my mind goes wandering, but the words are already there on the paper."

For calculus she says, “...My calculus professor I really don’t understand. He has [indiscernible]. So I'm kind of teaching myself, but I got a 95 on the test. It is math so I'm pretty good at it. I'm alright." She got a D in Calculus for midterm. Brittany, her significant other, aunt said, "I ' $\mathrm{m}$ thinking about getting her another tutor for her science because she has a D in that class." There is a discrepancy in self-report versus how well she actually did on her mid-term report. Relative to writing she says, "I 'm just, you know making it up in my head whereas with a paper you have to put the information down" (see Table 5 Academic Functional Impairments, page 107).

Bella had good organization in her writing sample with appropriate content, topic development and clear details. She had no grammatical errors or punctuation and spelling errors (see Table 6 Writing Sample Analysis, page 108).

Interviewee Clarice

Clarice is a 19 year-old white female majoring in General Psychology. She has only received a mid term report indicating subjects with a $\mathrm{D}$ or $\mathrm{F}$. She has a $\mathrm{D}$ in her psychology class and a D in her math class. Christy, her significant other tutor said, "She's fantastic in math but can not...I don't know if it's really a disability for her in written expression except she kind of has an OCD mentality about the written expression. She feels like she can't do it and has to be coerced lots of times to frequently write things." "She still is requiring assistance in math at the college level because it's again the processing issue that's associated with the ADD that 's 
causing her difficulty with her math classes in college" (see Table 5 Academic Functional Impairments, page 107).

In Clarice's writing sample she had poor organization and lacking content with a lack of topic development and supporting details. She wrote only two sentences with one sentence for each question. In those she had one grammatical error and two mechanical errors of punctuation (see Table 6 Writing Sample Analysis, page 108).

\section{Interviewee Dianna}

Dianne is a 25 year-old white female majoring in physical education. She had an undergraduate GPA of 2.7. She had Ds in the following classes: Principles of Biology, General Chemistry Two, Environmental Chemistry, Politics, Scientific Foundation of Phys. Ed., Principle of Chemistry Lab II. She also had an F in History-World since 1850. Her current graduate GPA is 3.28. She is majoring in Exercise Science. She has no Ds or Fs in graduate school. Her friend, Denise commented, "But when she's in the process of learning and anyone can tell you reading a book is not exactly the most entertaining thing. Studying is not the most entertaining except for someone with her disorder you can see how it's easily... Even more how easy it is for her to become distracted and it takes her longer." Denise noted that Dianna needed extra time to get the reading done (see Table 5 Academic Functional Impairments, page 107).

Dianna's writing sample was lacking content with limited topic development and comprehension. She also lacked details. She had three grammatical errors and no punctuation or spelling errors (see Table 6 Writing Sample Analysis, page 108). 
Interviewee Ellen

Ellen is a white 19 year-old freshman female student. She received no midterm report as her grades are $\mathrm{C}$ or above per the Director of Support Services. Her major is unknown. In her writing sample content she said, "I have problem with my writing skills and some of my reading because I can not correct my writing skills by myself because I think it is correct so I use a program to read my writing to me." "For writing I have a program that read [sic] the paper I wrote to help me fix it." "For some of the books I read for school I get on audio tape and read the book while listen to it” (see Table 5 Academic Functional Impairments, page 107).

In terms of Ellen's writing sample she had limited comprehension, but she did develop her topic. She did have supporting details. However she had eight grammatical errors even though she had spell check on the computer. She also had two spelling errors (see Table 6 Writing Sample Analysis, page 108).

\section{Interviewee Frank}

Frank is a 23 year-old white male undergraduate student obtaining an Associate's degree in Hospitality Management. He has a GPA of 2.92. He had an F in Business Mathematics, which he took over to obtain a D. He had a D in Managing Catering Operations. His significant other mother said, "Because of his processing issues he has difficulty with all math processing. So anything after long division ...I mean he can memorize multiplication facts but to do like a long division...extremely difficult." She says, "He loses his place or he can't remember what the steps of the processes are... So like if he is doing two or three digit division he'll get lost in the steps. He may know what the steps are, but if he's doing two or three digits he may remember it for the first digit but then he gets to the second and third and the processes get 
messed up." Frank noted that he needs extra time for math (see Table 5 Academic Functional Impairments, page 107).

Franks writing sample had good organization in his content with supporting details. He had five grammatical errors and would occasionally leave out words. He had one punctuation error. There were no spelling errors (see Table 6 Writing Sample Analysis, page 108).

\section{Interviewee Georgia}

Georgia is a 21 year-old African American female obtaining an Associate degree in Hospitality Management. She has a 2.22 GPA. She has had 3 Fs in College Study Skills, Fundamentals of Computers, and Written Communication. She has had Ds in 3 classes: Fundamentals of Computers, Travel Tour and Hospitality, and Managing Catering Operations. Grace, Director of Support Services, said, "She really struggles with math and that's caused her great pain. She's taken a developmental course three times in math and hasn't passed it ... At one point I wasn't sure if she would be capable of graduating, but I do think she will if she can get through the math" (see Table 5 Academic Functional Impairments, page 107).

For Georgia's writing sample Georgia had poor content and comprehension. She answered both questions with only two sentences. Her topic development was lacking in details. There were four grammatical errors and no punctuation or spelling errors (see Table 6 Writing Sample Analysis, page 108).

\section{Interviewee Hal}

Hal is a 19 year-old white male undergraduate student majoring in Biological Science. He has a 3.82 GPA. He has no Ds or Fs. He notes as issues in academic functioning, "Keeping up with the reading." He noted, "You scan the text book in there and it reads to you. I've got it on 
my laptop. Yeah, and you press the read button and it has different voices...then you press the read button and it reads to you." He was referring to the Kurzweil Reading Program. Hal indicated that he needed extra time in reading (see Table 5 Academic Functional Impairments, page 107).

Hal's writing sample had good comprehension, but poor topic development and lacking supporting details. He had two grammatical errors. He had no punctuation or spelling errors (see Table 6 Writing Sample Analysis, page 108).

Interviewee Isaac

Isaac is a 22 year-old white male undergraduate student majoring in marketing. He has a 3.15 GPA. He has had no Ds or Fs. He states, "Like I understand the material...just like when I was reading and stuff I wouldn't comprehend it and it was very aggravating and my writing skills weren't very good. Also because of I just couldn't comprehend so it was really hard for me. It took me a long time to finally get going but once I did I strived, thrived, or ..." (see Table 5 Academic Functional Impairments, page 107).

Isaac's writing sample had issues with content. He had issues with topic development and lacking details. There were comprehension issues with understanding who he was referring to. There were eight grammatical errors and no punctuation or spelling errors (see Table 6 Writing Sample Analysis, page 108).

Interviewee Jack

Jack is a 20 year-old white male undergraduate student majoring in biomedical science. He has a 3.67 GPA. He has no Ds or Fs. He stated, "And I guess the reading of the book kind of trips me up some where I read really, really slow and I don't.... and then I can hear different 
things then and I have different things where I'd kind of be more interested in doing." "...I have the dyslexia and then I have a reading disorder and a written language disorder...I knew I learned differently but I couldn't figure out why. And then they told me I just had an English disorder is the way they told me... and they just meant this is why you have trouble like writing papers and have a lot of trouble with like your grammar and sentence structure and being able to word things." Jack noted that he needs extra time in reading (see Table 5 Academic Functional Impairments, page 107).

Jack's writing sample was good in content with good topic development and supporting details. He had some issues in comprehension with wordiness that made it difficult to follow. There were 17 grammatical errors and 5 punctuation errors. There were no spelling issues. His content was specific to the questions I asked in the writing sample and his was the most extensive (see Table 6 Writing Sample Analysis, page 108).

Please refer to Tables 5 Academic Functional Impairments, page 107 and Table 6 Writing Sample Analysis, page 108 to view the break down of information for each interviewee. 
Table 5

Academic Functional Impairments Reported by Interviewee and Significant Other

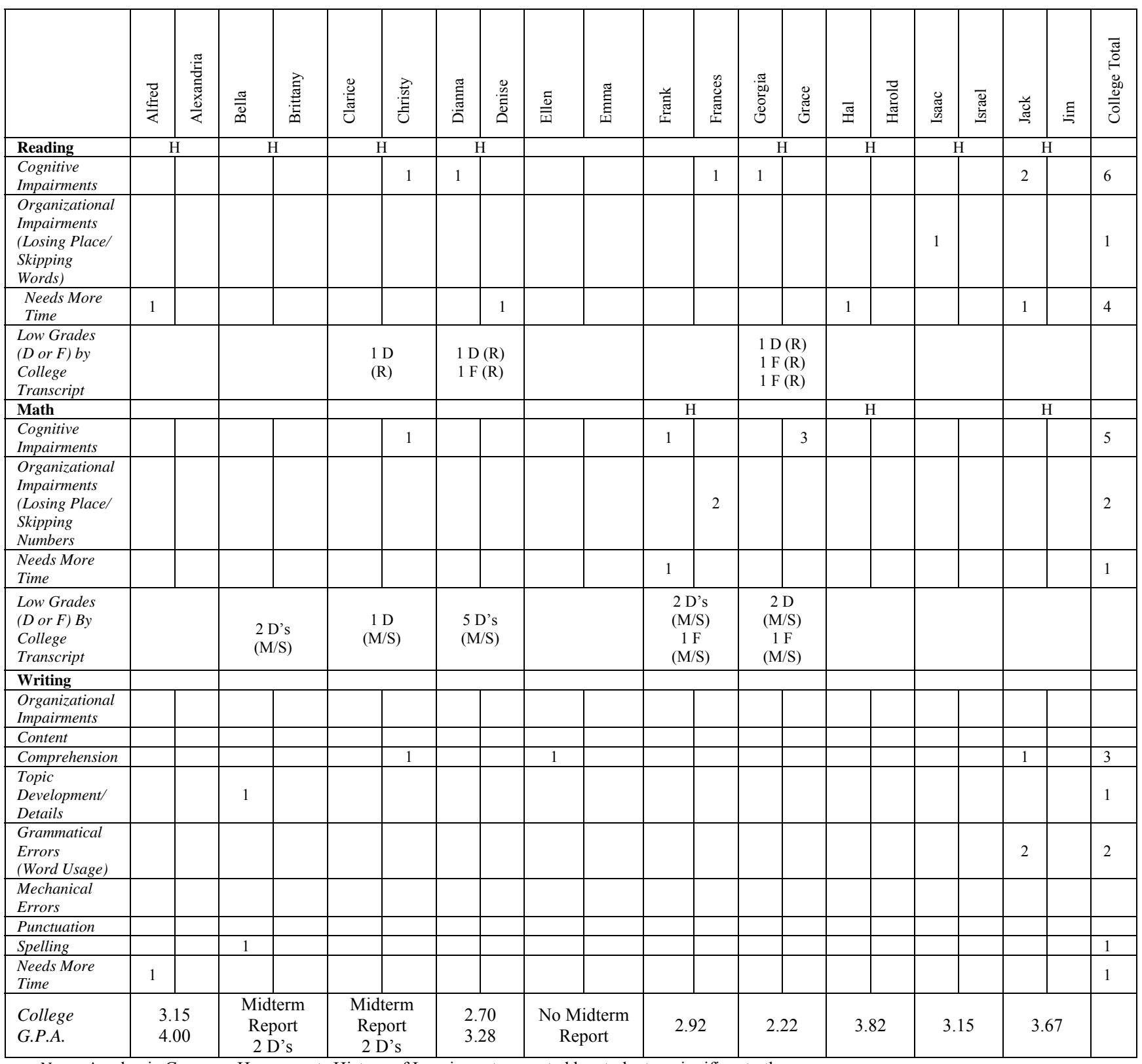

Note. Academic Courses. $\mathrm{H}$ represents History of Impairments reported by student or significant other.

$\mathrm{R}$ indicates Reading-Based $\mathrm{M} / \mathrm{S}$ indicates Math or Science-Based 
Table 6

Writing Sample Analysis

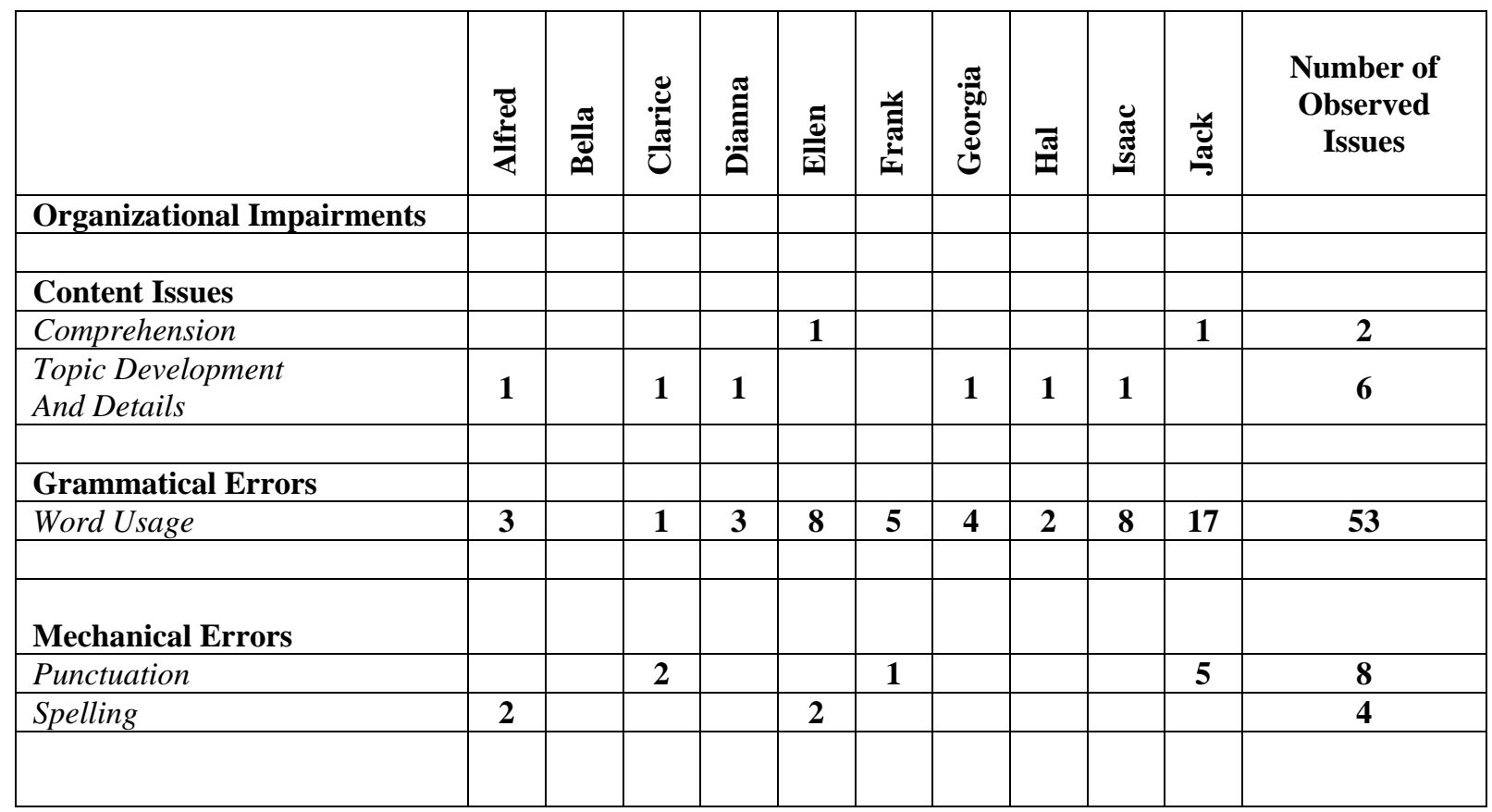




\section{Work Functional Impairments}

A discussion of work functional impairments answers research question three, what is the impact of $\mathrm{AD} / \mathrm{HD}$ as the college student/young adult enters the workforce. The following section indicates work functional impairments reported by each student and their significant other (see Table 7 Work Functional Impairments, page 116).

Interviewee Alfred and Significant Other Alexandria

Alfred has a history of working in a hardware store and currently works as a tutor in the support services center. Alfred identified under concentration impairments the issue of lack of interest/boredom, which affects work. He noted, "I mean I hated stocking shelves. I hated doing that $\ldots$ that was just mind numbing $\ldots$ just item on a hook $\ldots$ item on a hook $\ldots$ item on a hook ... Oh there was a lot of boredom at the hardware store." Alexandria, his significant other, did not report any functional impairment within work.

In summary Alfred indicated concentration impairments with a lack of interest as an issue for work performance (see Table 7 Work Functional Impairments, page 116).

\section{Interviewee Bella and Significant Other Brittany}

Bella works at a work-study position in the science center. Bella identified two reports of lack of interest/boredom under concentration impairments that affect work to include the following. She said, “It's so easy to say I can't come in today, you know I'm sick or I can't come in today, so it's kind of I have to motivate myself to actually get up and go... I'll have uh tons of homework and I'll have had classes for three or four hours of the day ... I'm exhausted ... didn't get much sleep the night before ...” She cites, “... I'm about to almost double my hours every week over in the science department. I'm working for work-study and I think it's 
going to help me realize, you know I don't have a lot of time to waste. Hopefully the doubling of hours will increase my productivity... at the moment because I do have a lot of free time to just goof off. It kind of makes me feel like I'm not getting as much done, as I should be. It kind of makes me feel like I'm skipping work, so it's kind of a motivational issue." Brittany, her significant other, mentions no impairment in work function.

In summary Bella indicates motivational issues or lack of interest and boredom as affecting her work performance (see Table 7 Work Functional Impairments, page 116). Interviewee Clarice and Significant Other Christy

Clarice worked in her father's company in a secretarial position. Clarice does not mention any impairment in work function. "I did the mail. I think I shredded. Uh sometimes I would copy things.” Her significant other, Christy notes, “... Only job she had was with her dad's company ... so you know they're probably a lot more tolerant of her work related habits than another employer, and unfortunately she hasn't really worked for anybody outside of family. So that's hard to determine."

In summary there were no mentions of impairments in Clarice's work function (see Table 7 Work Functional Impairments, page 116). Interviewee Dianna and Significant Other Denise

Dianna has worked in retail sales in a bookstore and in body fragrance sales. Dianna noted time related issues as an impairment as in needs extra time to complete task in terms of her questions related to work. She said, "And then business world employees I mean just know that it might take me a little bit longer to do something but I'm doing it." 
In terms of impairments in concentration she noted an issue of lack of interest. She cited the example, "There were some times when I would have to be like the greeter. You're standing there...I mean, it wasn't fun because, 'Hi, welcome to Smells So Good. Would you like to buy anything? No.' Like it's just not productive, but when I was like behind the cash register or something I was always doing something. So I was like getting eight balls in my head then."

She noted in terms hyperactive responses that she's had a situation of reacts without thinking/impulsivity while working in a bookstore. She said, "In a book store you can't be loud, so it was hard to be quiet and actually be able to do my task that I had to do." Denise did not mention work impairments.

In summary Dianna mentioned the need for extra time to complete tasks as a time related issue when performing work tasks. She further noted impairment in concentration when she lost interest in her task. In the area of impulsivity she noted a situation of forgetting and talking loud without thinking as an issue in the bookstore job (see Table 7 Work Functional Impairments, page 116).

Interviewee Ellen and Significant Other Emma

In terms of organizational issues there were two issues of scheduling that affected her work. Ellen said, "I only worked once as a gate guard and I hated it so much ... The Company and the pool changed my schedule so much ...I didn't like the company at all after they started changing my schedule there.” Her significant other, Emma, made no mention of work impairments.

In summary in terms of organizational issues, Ellen mentioned that schedule changes affected her work in a negative way (see Table 7 Work Functional Impairments, page 116). 
Interviewee Frank and Significant Other Frances

Frank works in retail at the mall. He has a history of organizational impairment as in not getting to work due to not writing down his schedule and losing his job. Frank noted as an impact on work concentration impairment with the issue of distraction. He said, "Simple things such as seeing an old friend can easily distract me from ten minutes of work because I want to talk to them." For impairments in concentration that affect his work he mentioned issues with focus twice. In his writing sample he states, "At work it affects me in the aspect that I have to concentrate twice as hard to get my work done." In his interview he said, "Uh I guess a problem I have is staying focused. I work at the mall now, so if I see someone I know I got to ... I talk to them, but I also got to know when to quit talking to them and get back to work."

He noted his work was impacted with hyperactive responses as in the issue reacts without thinking/impulsivity. He said, “... I don’t have very good patience with one of my co-workers ... says whatever is on her mind. I know from past experience that that doesn't go well, so she knows how to make me mad." He further said, "I'm grateful I don't work with her very much ... she just knows things ... she does things to make me mad ... she knows how to cut to my anger cord ..."

The significant other, his mother, reports impairments that affect work with organizational issues such as scheduling twice in the interview. She said, “... If he would hear something about his schedule he wouldn't write it down, so therefore if there was a change in schedule ... he didn't get it ... he eventually lost his job due to not being able to keep his schedule straight and not showing up for work when they were expecting him." She also said, "I think he was probably 18 when he got his second job and I said, you know, you're an adult now 
and you need to be treated like an adult. And I'm not going to take responsibility for making sure you get to work when you're supposed to be there ..."

In summary Frank has issues with impairments in concentration with focus on the job. He also mentions being distracted from his job with friends who talk to him. His hyperactive responses affect his impulsivity with getting angry with co-workers. He has had a history of not being able to keep up with work schedules or getting up to get to work (see Table 7 Work Functional Impairments, page 116).

Interviewee Georgia and Significant Other Grace

Georgia has a history of working as a secretary. Georgia did not report any issues that affected her work function. Georgia noted, "I did secretary work. My ... I get mail, copy, umm put information in the computer, answer the phone ..." Grace, her significant other did not mention any work impairments in the interview. There was no mention of impairments in work function (see Table 7 Work Functional Impairments, page 116). Interviewee Hal and Significant Other Harold

Hal has a history of working as a pet sitter and mowing lawns. Hal mentioned concentration impairments that affected work with two examples of memory issues. He stated, "Well, I mean I had problems remembering to do it ..." He also said, "That's when my mom came in there I mean for when I had to take care of another dog. She would ask me did you go feed the ... dogs today." Harold did not mention any impairment with work.

In summary Hal noted concentration impairments with two examples of memory issues that affected his work performance (see Table 7 Work Functional Impairments, page 116). 
Interviewee Isaac and Significant Other Israel

Isaac has worked as a waiter in a seafood restaurant. He also works at the radio station as an intern. Isaac, the interviewee, mentioned concentration impairment as in forgetfulness that affected his work performance. He states in reference to co-workers "Some would gripe at me for forgetting to put like a lobster fork on it, but I was like we're busy I don't have time for it. You know I'm sorry if I forgot and that's the only thing I...." Israel, the significant other roommate noted a hyperactive response, as in reacts without thinking/impulsivity with work. "I actually had this happen to me on Friday when I was at the radio station I was interviewing someone and after the interview I stepped back to talk to the person because he wanted to talk to me some more and Isaac was yelling in the back, 'man this going on right here' ... I'm trying to be like, 'Isaac I can't have you yelling right now because I know you're trying to get my attention about something you want to ask me ... After I get to this person I'll get to you.' It didn't work out that way."

In summary Isaac was viewed to have concentration impairments as in forgetfulness and hyperactive responses that were impulsive that affected his work function (see Table 7 Work Functional Impairments, page 116).

Interviewee Jack and Significant Other Jim

When asked by the interviewer, "In your work life what, if any, difficulties did you have with work?” Jack stated, “...Here in the Student Support Program there's not too many ... like if someone calls in and they ask a question and I'm not sure exactly how to explain it. I explain it to the best of my abilities, but sometimes they will call and I don't know how to answer it. So I try to find someone that can answer and I'll just transfer to them or I'll go get them ..." 
Jim, his significant other stated, "He's does just fine. It's where you have to do a lot of different tasks like mail runs, answer the phone, talk with people as they come in. It's usually fairly good." The interviewer asked, "So he's able to perform those kinds of work tasks." The interviewee stated, "A lot better than I would ..." Jack was not viewed to have a work functional impairment (see Table 7 Work Functional Impairments, page 116). 
Table 7

Work Functional Impairments

Reported by Interviewee and Significant Other

\begin{tabular}{|c|c|c|c|c|c|c|c|c|c|c|c|c|c|c|c|c|c|c|c|c|c|}
\hline $\begin{array}{c}\text { Work Functional Impairments } \\
\text { That Affect Job Motivation } \\
\text { And Performance }\end{array}$ & 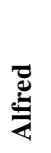 & 吾 & 气 & : & 冚 & 䞶 & 节 & $\stackrel{\mathscr{n}}{\Xi}$ & 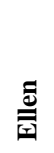 & 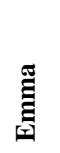 & 葭 & 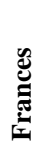 & 兘 & :ँّ & 茎 & 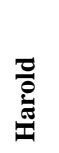 & 芯 & 离 & 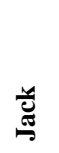 & 貝 & $\begin{array}{l}\text { College } \\
\text { Totals }\end{array}$ \\
\hline \multicolumn{22}{|l|}{ Concentration } \\
\hline \multicolumn{22}{|l|}{ Attention } \\
\hline Distraction & & & & & & & & & & & 1 & & & & & & & & & & 1 \\
\hline Focus & & & & & & & & & & & 2 & & & & & & & & & & 2 \\
\hline Forgetfulness & & & & & & & & & & & & & & & & & 1 & & & & 1 \\
\hline Memory & & & & & & & & & & & & & & & 2 & & & & & & 2 \\
\hline Lack of Interest & 1 & & 2 & & & & 1 & & & & & & & & & & & & & & 4 \\
\hline \multicolumn{22}{|l|}{ Organizational } \\
\hline \multicolumn{22}{|l|}{ Misplace Items } \\
\hline Scheduling/Time Management & & & & & & & & & 2 & & & 2 & & & & & & & & & 4 \\
\hline \multicolumn{22}{|l|}{ Routine } \\
\hline \multicolumn{22}{|l|}{ Structure } \\
\hline \multicolumn{22}{|l|}{ Study Skills } \\
\hline \multicolumn{22}{|l|}{ Time Related } \\
\hline Needs More Time & & & & & & & 1 & & & & & & & & & & & & & & 1 \\
\hline \multicolumn{22}{|l|}{ Hyperactive } \\
\hline \multicolumn{22}{|l|}{$\begin{array}{l}\text { Excessive Movement/ } \\
\text { Restless Energy }\end{array}$} \\
\hline \multicolumn{22}{|l|}{ Rapid Thoughts/Conversation } \\
\hline \multicolumn{22}{|l|}{ Skipped Words or Subjects } \\
\hline Impulsivity & & & & & & & 1 & & & & 2 & & & & & & & 1 & & & 4 \\
\hline
\end{tabular}


Academic and Community Agency Services

History, Current Services and Requested Services

Analyzing coded data for academic and community agency services determined what resources, teaching methods, and professional resources or services need to be continued, modified or changed due to functional impairments that college students have. This process answered major purpose question two and research questions four and five of the study. A discussion of each student's history of services received, current services, and requested services follows. The following information was condensed from the interviews of interviewees and their significant others. Information was also included from the writing sample questions.

Alfred. Alfred has received the following academic services: By history he received psycho-educational evaluation and school based remedial service, tutoring services, and writing software, and Kruzweil reading software. He noted that the reading and writing software were not helpful. In addition he had community agency assistance with diagnostic services and medication, Ritalin, from physicians.

Currently Alfred receives academic services of tutoring from the support services program with special accommodations for testing, time extensions and a distraction free environment. Alexandra, the significant other, notes that the student support services program provides structure and organization and a family support system, as well as social interaction. He receives no community agency services at this time.

He would like to have for future academic services specialized training for professors in understanding AD/HD. He doesn't request community agency services. 
Bella. Bella has received the following academic services: By history she received no academic services or community agency services because she was not diagnosed until she went to college. Although the interviewee had symptoms previous to college her family minimized the need for treatment. Her aunt, tutor, recognized the issues and had her tested. Currently she receives tutoring for time management services and study skills through the student support services program. Her aunt is an employee at student support services and is an advocate for her. Her biology professor puts notes on-line that she is able to access. Currently for community agency services she is in the process of obtaining medication for her $\mathrm{AD} / \mathrm{HD}$.

For academic services she would like to have extra tutoring for her science class. In addition she requested more scholarships for students with $\mathrm{AD} / \mathrm{HD}$.

Clarice. Clarice has received the following academic services: She has had tutoring services since the first grade. She went through the Wilson Reading System. She has had speech therapy.

From community agencies she had services from Hope Children's hospital where she received diagnostic services and psychological services to help her deal with AD/HD. For community agency services she was treated with an undetermined type of medication for her $\mathrm{AD} / \mathrm{HD}$. She received psychological treatment for anorexia.

She currently receives tutoring services from the support services program, which assists her with homework. She receives accommodations for her disability with extended time for taking tests. She is in a remedial program for time management and study skills. Also, she is in the social support program, a club, which provides activities for students with disabilities. Currently, she receives medical services from the community for medication for her $\mathrm{AD} / \mathrm{HD}$. 
She would like to have academic services with professors informing her of when tests will be, as well as extensions in time for projects and tests. Christy, her significant other, suggests support from the community, to be open to those with disabilities.

Dianna. Dianna received academic services in the past. Those included specialized tutoring services off site. She had special arrangements to take a class with a pass/fail grade so she could graduate. There were no past community agency services identified.

Currently she receives tutoring services from the support services program. Her accommodations are extended tests times and a distraction free environment when she takes tests. She receives community agency services from the medical profession and takes timereleased Adderall.

She would like professors to become more advanced with current technology and to be educated about $\mathrm{AD} / \mathrm{HD}$. Denise suggested more education with professors about $\mathrm{AD} / \mathrm{HD}$ as a processing disorder. She also suggested more of the hands on learning style as a teaching method.

Ellen. Ellen had a history of academic services with an extra teacher and a case manager in her classroom. For community agency services she received psychological testing. She also received medical services and was put on the $\mathrm{AD} / \mathrm{HD}$ medication, Concerta.

She currently receives academic services such as tutoring at student support services. She has three tutors for math, music and remediation. She gets extended test times. She utilizes audiotaped books and uses a writing program for fixing writing mistakes. For community agency services she receives medical services for the medication, Concerta, for her AD/HD. 
For future services her significant other recommended she participate in an extra curricular activity such as Campus Crusade to make friends.

Frank. In his history of academic services during his elementary school years Frank changed to a school that was more able to accommodate his $\mathrm{AD} / \mathrm{HD}$. He had a second teacher in his high school classes. For community agency services he received psychological testing and counseling services. He was diagnosed with generalized anxiety disorder and received stimulant medication for his $\mathrm{AD} / \mathrm{HD}$ until he was twelve years old. He was then placed on the medication, Strattera.

Currently he receives academic support with tutoring from the student support services program. The tutors break down information into smaller units. The tutors serve as an extended family to him. His mother also works in the student support center. For community agency services he receives medical services for the medication, Strattera. He also takes Trazodone for his anxiety.

For future academic services he requested that professors be more patient and kind. Georgia. For her history of academic services Georgia received math tutoring. For community agency services she received medical services and a physician diagnosed her with $\mathrm{AD} / \mathrm{HD}$. She also received counseling services.

Currently she receives academic services in the form of tutoring at student support services. She receives extended test times and a distraction free room to take tests. She works with a learning specialist for time management and study skills. Student Support Services provide Georgia with structure. They also serve as an advocate with her family and offer social support through the Student's Club. There are no community agency services at this time. 
Georgia requests for future academic services that professors need to understand that she can do the work. She is just slow. Her significant other, Grace, suggested that she should participate in an exercise program, which would help her focus. She also felt that medication would be helpful. She felt that counseling would be helpful to help her with relationship issues and self-awareness.

Hal. For the history of academic services Hal indicated that he received math tutoring with a tutor, who used flash cards and redirecting techniques to focus him. She rewarded him with candy for correct answers. In high school he was given extended test times. In the community agency history he had psychological testing and received medical services for the medication, Concerta.

Currently for academic services he receives tutoring from student support services. They assist by breaking learning into smaller units. Harold says that student support services has helped Hal by providing structure, extended test times, and distraction free rooms. In terms of community agency services he currently receives medical services with medication, Straterra, for his $\mathrm{AD} / \mathrm{HD}$. He belongs to a Christian organization where he receives socialization.

For academic services he requested that professors know that although it may take longer he will eventually get it. Also he would like professors to refocus him if they see him zoning out. In his writing sample he said that teachers should provide repetition and reminders for instructions, information, etc. He also needs reminders for appointments out of his daily schedule. He noted the need to continue to take tests in private rooms. Lastly he said that professors should give rewards for correct answers such as candy or something like that. He did not request any community agency services. 
Isaac. For his history of academic services Isaac received specialized services out of the classroom. In elementary school the teacher would read his test to him. He had speech services. There was a past history of community agency services of psychological testing, counseling services for fifteen years and medical services for the medication, Adderall for his AD/HD.

Currently he receives academic services through the student support services program where he receives tutoring. He uses the professors' on-line Power Point notes to assist him in the classroom. For community agency services he continues to receive medical services with medication, Adderall, for his AD/HD.

For future requests for academic services he, in a hostile tone, requested that professors understand that individuals learn in different ways and that they can do the work. It just takes longer. For community agency services his significant other Israel mentions that he feels that Isaac could benefit from counseling to clear up some issues.

Jack. For a history of academic services Jack was put in a classroom that was slower paced with less work-demand. For professional services he received medical services for the medication, Ritalin, when he was little. He noted that it did not help him.

Currently Jack receives academic services of one-on-one tutoring through the student support services program for all of his classes. He has received diagnostic testing where he was diagnosed with a reading and English/language disorder. The tutor assists him with writing his papers, studying for exams and helps him fill in the bubbles on the electronic scoring sheet. There are no current community agency services.

For future requests for academic services in the writing sample he noted that all colleges should have a student support services program similar to John Doe University (JDU). He would 
like professors to slow down and use other teaching styles that promote classroom interaction. He noted that professors should be educated about AD/HD. His significant other, Jim, feels that learning style tests should be given to students to determine their best style of learning for tutoring services. There were no requests for community agency services.

It should be noted that many of the students have strong educated family members and mentors with academic backgrounds, which more than likely contributes to the student's ability to enter college. 


\section{CHAPTER 5}

Summary of Results

Ten college university students ages 18-25 were interviewed along with ten significant others with a semi-structured interview. Open coding occurred at the conclusion of the interviews as general themes that evolved from the observation memos in terms of functional impairments included behavioral impairments in concentration, organizational issues, time related issues, and hyperactive responses. Co-morbidity occurred in many instances along with the $\mathrm{AD} / \mathrm{HD}$ and is also indicated as a functional impairment.

Axial coding of words or short phrases of descriptions of behavioral issues developed into the general themes listed above. Also any forms or derivatives of those coded base words were searched in the QSR N6 NUD*IST software for qualitative research. For example under impairments in concentration the word forgetfulness is the main word but derivatives of that word such as forget, forgot, forgotten and forgetting were part of the search. Memory was a base word under impairments in concentration, but the search also included derivatives of that word such as memorization and memorize. The search word was then utilized to find the number of examples of behavioral issues under the themes of the functional impairments. I also included in my search by hand clear behavioral examples of those coded words. Those total numbers included examples from the semi-structured interviews of both the interviewee and the significant other as well as observed behaviors from the observation memos, and the content information indicated by the interviewee from the writing samples. I also split the analysis of the writing sample to include the content under functional impairments, but also included an analysis of the writing skills under the section Academic Functional Impairments. 
Data that was coded and that led to a general theme of impairments in concentration included six behaviors that were referenced in the search: Those key behaviors included attention, distraction, focus, forgetfulness, memory and lack of interest or boredom.

Data that was coded that led to a general theme of organizational issues included losing items, misplacing items, scheduling/time management, routine, structure, and study skills/habits. Data that was coded for time related issues included extra time, more time and extensions. Search words that were coded for data for the general theme or category hyperactive issues included descriptions of behaviors or properties such as excessive movement/restless energy, skipped subject or words, and rapid thoughts/conversation. Finally, examples of impulsive behaviors such as reacts and not thinking things through were coded under the functional impairment of hyperactive responses. Co-morbidity includes other diagnoses such as Mental Health or Learning Disabilities.

\section{Summary of Overall Functional Impairments}

The following is a summary of information from Table 3 Functional Impairments page 74 that suggests functional impairments for college/university students with $\mathrm{AD} / \mathrm{HD}$ continue beyond elementary or the high school years. This summary also provides the answer to major purpose one and research question one of this study.

If you refer to the first theme or category, impairments in concentration in Table 3

Functional Impairments you will note six behavioral issues or properties of attention, distraction, focus, forgetfulness, memory, lack of interest/ boredom. If you combine the information from the interviewees, the significant other, the content information from the writing sample as well as observation memos you will find that 10 out of 10 interviewees had impairments in 
concentration. This suggests that AD/HD continues with adults ages 18-25. Of the description words that indicated impairments in concentration attention was referenced 2 times, distraction 16 times, focus 11 times, forgetfulness 4 times, memory 6 times, and lack of interest/ boredom 7 times. There were 46 references to impairments in concentration for 10 interviewees. There are specific examples of this in Chapter Four under each interviewee.

If you refer to the second theme, organizational impairments in Table 3 Functional Impairments, page 74 there are five behavioral issues listed: Lose/misplace items, scheduling/time management, routine, structure, study skills/habits. If you combine the information from the interviewees, the significant other, the content information from the writing sample as well as observation memos you will find that 9 out of 10 interviewees had organizational impairments. The coded description words, and behavioral examples of those descriptions indicated that the behavioral issue, lose/misplace items, was referenced two times. Scheduling or time management was referenced 22 times, routine 2 times, structure 12 times, and study skills/habits 8 times. There were 46 references to organizational impairments for 10 interviewees.

If you refer to the third theme, time related issues in Table 3 page 74 Functional Impairments the behavior needs extra time to complete tasks is listed as an issue. Nine out of 10 interviewees made reference to the need for extra time to complete tasks. There are a total of 19 references to this behavioral issue for 10 interviewees.

If you refer to the fourth theme, hyperactive responses in Table 3 Functional Impairments page 74 there are four behaviors: excessive movement/ restless energy, rapid thoughts/conversation, skipped words/subjects, and reacts without thinking/impulsivity. With 
the combined sources of information you will find 7 out of 10 interviewees had hyperactive responses. There were 9 references to excessive/movement restless energy, 10 references to rapid thoughts/conversation, 9 references to skipped words/subjects and 3 references to reacts without thinking/impulsivity. There were a total of 31 references to impairments of hyperactive responses.

If you refer to the fifth theme of co-morbidity in Table 3 Functional Impairments page 74, which included learning disabilities and mental health diagnoses in addition to $\mathrm{AD} / \mathrm{HD}, 7$ out of 10 have co-morbidity issues. There were eight learning disabilities reported and three mental health disabilities. A total of 11 references to co-morbidity were indicated for 10 interviewees. Some of the interviewees have more than one type of co-morbidity.

\section{Summary of Relationship Functional Impairments}

\section{College University Relationships}

If you refer to Table 4 A-F page 94-99 all of the overall categories of functional impairments are noted, but there is an additional theme of impairments for communication that I considered for their impact on relationships. Table 4 also provides the answer to research question $2 \mathrm{~b}$ concerning the affect of functional impairments on relationships. I did not include co-morbidity because it was not referenced in the interviews, writing samples or observation memos in terms of functional impairments in relationships. Behavioral issues included for communication impairments were issues with listening, misunderstanding, and self-advocacy.

Authority figures. I assessed impairments in relationships in the university setting and included for authority figures (professors) and for peers (friends). Table 4 A includes as authority figures a reference to professors, teachers, and coaches due to the establishment of 
history in elementary and high school years. The interviewees only referenced college professors in the college/university years (see Table 4 A College Authority Figures, page 94).

In reference to communication with professors, the behavioral issue of listening was referenced one time. Misunderstanding was referenced 12 times and self-advocacy was referenced 2 times. Nine out of 10 of the interviewees mentioned communication issues with college university authority figures (professors).

In reference to impairments in concentration that affected relationships with professors there were 3 out of 10 interviewees that reported problems in this area. For the behavioral issue attention there were two references. There was one reference to distraction, and there were no references to focus, forgetfulness, memory and interest/boredom.

Relative to impairments in organization with the behavioral issues of lose/misplace items, scheduling/time management, routine, structure, and study skills/habits there were no references to these issues affecting the relationship with professors.

Time related issues were identified as impacting the relationship with professors by one interviewee with only one reference. This may not be an issue for students as all of these students are currently getting extra time for tests and services at the student support services program.

In terms of hyperactive responses including excessive movement/restless energy, rapid thoughts or conversation, skipped words/subjects, and reacts without thinking/impulsivity, there were no references to those behaviors that may have affected relationships with professors. There were a total of 19 references for impairments in relationships with authority figures (professors) (see Table 4 A College Authority Figures page 94). 
Peers. I also assessed impairments in relationships in the university setting for peers (see Table 4 B College Peers, page 95). Six out of 10 interviewees had references to behavioral issues that impacted their relationships with peers. For impairments in communication there was one reference to listening, two for misunderstanding and three for self-advocacy or a total of six references. In regards to impairments in concentration with peer relationships at the university to include attention, distraction, focus, forgetfulness, memory, lack of interest/boredom there were no references.

In terms of organizational impairments that affected relationships 2 out of 10 expressed issues. For lose/misplace items there were no references, scheduling/time management was referenced one time. For routine and study skills/habits there were no references to impairments in the relationship due to those behavioral issues. There was one reference to structure that impacted peers. There were two total references in organizational impairments. There were no references to time related issues as in needs extra time to complete tasks.

In terms of hyperactive responses 4 interviewees out of 10 interviewees reported impacts on their peer relationships. For excessive movement/restless energy there were no responses. For rapid thoughts/conversation there was one report of impact on peer relationships. For skipped words/subject there were two reported incidences. For reacts without thinking/ impulsivity there were six responses. The combined total for hyperactive responses is nine (see Table 4 B College Peers, page 95).

\section{Family Relationships}

Authority Figures. We assessed relationship impairments with family members (see Table 4 C Family Authority Figures, page 96). Authority figures included parents and adult 
relatives. Peers were siblings or cousins. Significant other relationships included partners, boyfriends, and girlfriends. None of the students were married. Only one interviewee lived with a partner and that was Alfred.

In terms of family authority relationships (parents, adult relatives), 10 out of 10 interviewees reported impairments in relationships with family authority members. For the impairment of communication, there were 8 out of 10 interviewees that referenced behavioral issues. There were 2 responses for listening, 10 for misunderstanding, and none for selfadvocacy. In the area of impairments in concentration no interviewees reported problems. There were no references to attention, distraction, focus, forgetfulness, memory, and lack of interest/boredom.

In the area of organizational impairments, 1 of 10 interviewees referenced impairment. There was one under scheduling and time management. There were no references to lose/misplace items, routine, structure, or study skills/habits. In terms of time related issues there were no references to this impairment.

In terms of hyperactive responses, 1 of 10 interviewees reported the behaviors in reference to impairments in family authority relationships. There were no references to excessive movement/restless energy, rapid thoughts/conversation, skipped words or subjects and only one reference to reacts without thinking/impulsivity (see Table 4 C Family Authority Figures, page 96).

Peers. In terms of family peer relationships, including siblings and cousins, 2 out of 10 interviewees reported behaviors that impacted their relationships with peers (see Table $4 \mathrm{D}$ Family Peers, page 97). In communication impairments 1 out of 10 indicated issues. The issue 
of being misunderstood is referenced one time in impairments in their relationships with peers. There were no references to listening or self-advocacy. In impairments in concentration there were no issues of attention, distraction, focus, forgetfulness, memory or lack of interest/boredom. Under organizational impairments 1 out of 10 reported impairments in their relationship with peers. There was one reference for scheduling/time management and two for structure for a total of three references. There were no references to lose/misplace items, routine, study skills/habits. There were no reports for impact on peer relationships with time related issues. For hyperactive responses there were no reports of impact on peer relationships including the areas of excessive movement/restless energy, rapid thoughts/conversation, skipped words or subjects, or reacts without thinking/impulsivity (see Table 4 D Family Peers, page 97).

Significant Others. In terms of significant others (partners, boyfriends, girlfriends) 6 out of 10 interviewees had relationship impairments (see Table 4 E Significant Others, page 98). For communication 3 out of 10 expressed that they had impairments in communication. There were no references for listening, four references for misunderstanding, and two for self-advocacy. For impairments in concentration that impacted relationship there were none referenced including attention, distraction, focus, forgetfulness, memory, and lack of interest/boredom. For organizational issues no interviewees reported impairments that affected partner relationships. That included lose/misplace items, scheduling/time management, routine, structure, and study skills/habits. For time-related issues that impacted partner relationships, none were referenced. For hyperactive responses 4 out of 10 mention that behavioral issues had an impact on their partner relationships. In the area of excessive movement/restless energy there were no references. For rapid thoughts/conversation there was one reference. Under skipped 
words/subjects there was one reference. For reacts without thinking/impulsivity there were three references. There were a total of five references in hyperactive responses (see Table $4 \mathrm{E}$ Significant Others, page 98).

\section{Work relationships}

Authority Figures (bosses). Table $4 \mathrm{~F}$ Work Relationships, page 99 refers to impairments in relationships with authority figures (bosses) and peers (co-workers). Only 1 of 10 interviewees reported impairments in their relationship with bosses. There were no reports of communication impairments, concentration impairments, time related issues or hyperactive responses that impacted relationships with the boss and only one organizational issue impacted the authority (boss) relationships and that was in reference to scheduling/time management. There was one total reference to organizational issues.

Peer (co-workers). In relationship to peer (co-workers) 2 interviewees out of $10 \mathrm{had}$ issues with relationships at work (see Table $4 \mathrm{~F}$ Work Relationships, page 99). There were no reports of impairments listed under communication. Under impairments in concentration there was 1 interviewee of 10 that was affected in the area of forgetfulness. There were no impairments in relationships caused by organizational issues. There were no time related issues that impacted the relationship with peer co-workers. In terms of hyperactive responses 1 interviewee of 10 reported impact on peer co-worker relationships. There were two incidences referenced under reacts without thinking/impulsivity. There was nothing for excessive movement/restless energy, rapid thoughts/conversation or skipped words or subjects. There were four references totaled to suggest that peer relationships were impacted with functional impairments. 


\section{Summary of Academic Functional Impairments}

All 10 of the interviewees receive tutoring services from the student support services. All of the interviewees either had impairments in reading including English/Literature, History, Psychology or impairments in math and science classes or impairments in writing skills (see Table 5 Academic Functional Impairments, page 107). Five out of 10 students had received at least one D or F. Of the classes that require reading skills, interviewees received three Ds and three Fs. For classes that would require math/science related skills there were 12 Ds and 2 Fs. The overall GPA for undergraduate students was 3.09. However this does not include freshmen, which had only received a midterm report if they had a D or F. Of the three freshmen two out of three received two Ds each. One did not receive any Ds or Fs. The overall GPA for graduate students was 3.64 .

The following categories for themes for academic functional impairments were developed through the interviews with the interviewee and significant other. The development of these themes also provided the answer to research question $2 \mathrm{a}$, how do these functional impairments affect the academic function of $\mathrm{AD} / \mathrm{HD}$ students in the college setting. Reading and math were coded with cognitive impairments and organizational issues that reflected losing place and skipping numbers or words.

For reading 6 out of 10 interviewees were determined to have impairments in reading. For reading cognitive impairments there were six references. In addition there was one reference to organizational issues in reading as in losing place. Four out of 10 interviewees said that they needed extra time to read. 
For math 3 out of 10 interviewees were determined to have impairments in math. For math cognitive impairments there were five references. In reference to organizational issues in math as in losing place or skipping numbers or words there were two for losing place. One of 10 interviewees said that they needed extra time to complete math problems (see Table 5 Academic Functional Impairments, page 107).

In relationship to writing issues I gathered information from the interviews, which included the following impairments: Organizational impairments, which consist of comprehension and content issues of topic development and details. I also included under grammatical errors word usage. The last category consisted of mechanical errors of punctuation and spelling.

From the interviewees and significant other interviews 4 out of 10 reported issues currently with writing. For organizational issues there were four references of writing issues, two references to grammatical errors and one reference to mechanical error. There was one reference by one interviewee to the need for more time to write. There were seven total references to academic impairments with writing (see Table 5 Academic Functional Impairments, page 107).

In addition to the interviews the writing sample was also coded with the same impairment data coding as the interviews (see Table 6 Writing Sample Analysis, page 108). (For writing samples see Appendix D). In the writing samples 9 out of 10 interviewees had functional impairments in writing. In relationship to organizational impairments with issues of comprehension there were a total of two references. For content issues there were six references. For grammatical errors such as word usage there were 53 errors. For mechanical errors of 
punctuation there were eight errors and four spelling errors. As noted the interviewees writing issues were substantially under reported in comparison to the actual writing sample.

\section{Summary of Work Functional Impairments}

The analysis and coding of work functional impairments answered research question three in determining the impact of $\mathrm{AD} / \mathrm{HD}$ on the college student/young adult as they enter the workforce. One needs to take into account that students were not working in skilled labor positions for which they were being trained. Therefore, it is expected that the demands for unskilled labor would require less education and technical skills.

Of the ten interviewees, 7 out of 10 reported impairments in work function (see Table 7 Work Functional Impairments, page 116). Six out of 10 individuals reported impairments in concentration. There was a total reference to impairments in concentration of 10 incidences. There were none for attention, one for distraction, two for focus, one for forgetfulness, two for memory and four for lack of interest/boredom. There were 2 interviewees of 10 who had issues with organizational impairments. For organizational impairments there were a total of four impairments referenced: None for lose or misplace items, four for scheduling/time management, none for routine, none for structure, and none for study skills/habits. One interviewee out of 10 had a time related issue. For time related issues, as in needs extra time to complete task, there was one reference. There were 3 interviewees out of 10 that had hyperactive responses that affected work function. For hyperactive responses there were a total of four references: None for excessive movement/restless energy, none for rapid thoughts/conversation, none for skipping words or subjects and four for reacts without thinking/impulsivity (see Table 7 Work Functional Impairments, page 116). 


\section{Discussion: Agreement or Disagreement with the Literature Review}

\section{Overall Functional Impairments}

In the research to assess overall functional impairments in university students ages 18-25, 10 out of 10 of the interviewees had impairments in concentration, 9 out of 10 interviewees had organizational impairments, 9 out of 10 interviewees made reference to the need for extra time to complete tasks and 6 out of 10 interviewees had hyperactive responses. Finally, 7 out of 10 have co-morbidity issues along with $\mathrm{AD} / \mathrm{HD}$ with learning disabilities and/or mental health issues. The literature confirms that individuals with $\mathrm{AD} / \mathrm{HD}$ have these issues. (Refer to Table 3 Functional Impairments, page 74).

According to Hallowell and Ratey (1995) individuals with AD/HD continue to have functional impairments and maladaptive behavior into early adulthood. He said that the hyperactivity seems under control, but that in adults it may appear as cognitive restlessness. Cognitive restlessness can take the form of rapid thoughts/conversation and skipped words/subjects which interviewees frequently reported. Cognitive restlessness, along with distractibility, inattention, and impulsivity contributes to disorganized behavior resulting in an inability to complete tasks at school and work. These behaviors also have a negative impact on relationships with others (Hallowell and Ratey, 1995). Reeve and Schlandler (2001) gave the Stroop Color and Word Test that separated word and color naming stimuli to 20 adolescents. The results indicated that those with $\mathrm{AD} / \mathrm{HD}$ were more sensitive to task irrelevant information. The problems with perseverance and error rate increased as time passed. This is consistent with inattention. Those results pointed to frontal lobe problems, a genetic issue which implies a permanent condition. 
Barkley et al. (2002) also reported follow-up studies of children to adulthood in the Milwaukee study. He used 158 individuals who were diagnosed with hyperactivity in childhood. They were originally assessed for hyperactivity at ages 4-12 and then 12-20 and again at 19-25 years. He used the DSM-II-R plus 15 characteristics of AD/HD including time management, punctuality, organization, working independently, excessive socializing, forgetfulness and so on. Also included was Conner's Rating Scale. Employers were given a survey for behavior and job performance. The child behavior self report was modified for adults. Parents said that at mid adolescence $71 \%$ had $\mathrm{AD} / \mathrm{HD}$, but five years later the adolescent reports was only $5 \%$. Parent's report of hyperactivity was $46 \%$. If the DSM-IV-TR was used, then the rate rose to $58 \%$ (Barkley et al., 2002). Interestingly the combined report of the interviewees and significant others indicated that 6 of 10 or $60 \%$ of the 10 interviewees who are receiving academic support services still have AD/HD hyperactive symptoms. This supports my conclusion, that college age students with AD/HD still have functional impairments, and are in need of academic services and community agency services.

The category of time related issues as in needs extra time to complete tasks is substantiated by (Barkley, Murphy, \& Bush, 2001) where subjects were given nueropsychological tests and tests of motor vehicle driving ability. An examiner with a stopwatch asked participants to verbally estimate times determined by an electronic stopwatch and to reproduce six different time durations with verbal instructions to the examiner. The AD/HD group overestimated the sample durations relative to the control group and produced significantly shorter time reproductions. This suggest a deficit in sense of time in time reproduction, but not time estimation. It would seem that the distractibility caused by frontal 
lobe issues would cause impairments in the ability to complete tasks in the same time frame as individuals without $\mathrm{AD} / \mathrm{HD}$.

The diagnostic code manual (DSM-IV-TR, 2000), which mental health professionals utilize for assessing individuals notes that high co-morbidity of other diagnoses accompanies AD/HD. Wasserstein (2001) reiterates the issues of co-morbidity and independent adaptive functioning related to relationships and executive functioning problems.

In summary the literature review findings indicate functional impairments that are consistent with reports of impairments in the areas of organization, time related task issues, hyperactive responses and co-morbidity. This was the same in the qualitative research study.

\section{Relationship Functional Impairments}

\section{College University Relationships}

Authority Figures. In terms of impairments in relationships 9 out of 10 of the interviewees mentioned communication issues with college university authority figures (professors) (see Table 4 A College Authority Figures, page 94). In reference to impairments in concentration that affected relationships with professors there were 3 out of 10 interviewees who reported problems in this area. With impairments in organization with the behavioral issues of lose/misplace items, scheduling/time management, routine, structure, and study skills/habits there were no references to these issues affecting the relationship with professors. Time related issues were identified as impacting the relationship with professors by one interviewee with only one reference. In terms of hyperactive responses including excessive movement/restless energy, rapid thoughts or conversation, skipped words/subjects, and reacts without thinking/impulsivity,

there were no references to those behaviors that may have affected relationships with professors. 
There were a total of 19 references for impairments in relationships particularly in the area of communication with authority figures (professors) (see Table 4 A College Authority Figures, page 94).

Peers. Six out of 10 interviewees had references to behavioral issues that impacted their relationships with peers (see Table 4 B College Peers, page 95). Five of 10 students had impairments in communication. In regards to impairments in concentration with peer relationships at the university to include attention, distraction, focus, forgetfulness, memory, lack of interest/boredom there were no references. In terms of organizational impairments that affected relationships 2 out of 10 expressed issues. There were no references to time related issues. In regards to hyperactive responses a total of 4 interviewees out of 10 interviewees reported impacts on their peer relationships (see Table 4 B College Peers, page 95). Family Relationships

Authority Figures. In terms of family authority relationship (parents, adult relatives), 10 out of 10 interviewees reported impairments in relationships with family authority members (see Table 4 C Family Authority Figures, page 96). There were impairments in communication, with 8 out of 10 interviewees that referenced behavioral issues. For impairments in concentration no interviewees reported problems. For organizational impairments, 1 of 10 interviewees referenced an issue. In terms of time management there were no references to this impairment. In terms of hyperactive responses 1 of 10 interviewees reported the behaviors in reference to impairments in family authority relationships.

Peers. For family peer relationships 2 out of 10 interviewees reported behaviors that impacted their relationships with peers (see Table 4 D Family Peers, page 97). For 
communication impairments there was 1 out of 10 with an indication of misunderstanding. There were no impairments in concentration. In organizational impairments 1 out of 10 reported impairments in their relationship with peers. There were no reports for impact on peer relationships with time related issues. In hyperactive responses there were no reports of impact on peer relationships.

Significant Others. In terms of relationships with significant others 6 out of 10 interviewees had relationship impairments (see Table 4 E Family, Significant Other, page 98). In communication 3 out of 10 expressed that they had impairments. There were no impairments in concentration that impacted relationships. For organizational issues no interviewees reported impairments. There were no time-related issues that impacted partner relationships. There were hyperactive responses for 4 out of 10 interviewees.

Work relationship impairments

Authority Figures (Bosses). Only 1 of 10 interviewees reported impairments in work relationships with bosses (see Table 4 F Work Relationship Impairments, page 99). There were no reports of communication impairments, concentration impairments, time related issues or hyperactive responses that impacted relationships with the boss. Only one organizational issue impacted the authority (boss) relationship and that was in reference to scheduling/time management.

Peer (Co-workers). Two interviewees out of 10 had issues with relationships at work (see Table 4 F Work Relationship Impairments, page 99). There were no reports of impairments listed under communication. Under impairments in concentration there was 1 interviewee of 10 that was affected in the area of forgetfulness. There were no reported impairments in 
relationships caused by organizational issues. There were no time-related issues with peer coworkers. For hyperactive responses 1 interviewee of 10 reported an impact on peer co-workers.

In this study all of the students expressed conflict with professors along the lines of communication. Half of the students expressed some form of conflicts with peers and all of the interviewees expressed conflict with family authority figures. There was much less conflict expressed concerning peer co-workers and authority (bosses) with work (see Table 4 A-F Relationships, pages 94-99). This may be because the positions are largely unskilled labor that does not require high levels of technical skills, which would likely not produce as high of an error rate. In addition, the levels of responsibility would be less. Barkley did a study on the efficacy of problem-solving communication training vs. behavior management and a combination of the two for 18 weeks of treatment with adolescents, who had conflict relationships with parents. These adolescents also had Oppositional Defiant Disorder. After eighteen weeks $42-80 \%$ of those families were normalized (Barkley et al., 2001). It would seem that college students still have high levels of conflict with authority figures in the family and college and fairly high functional impairments with significant others.

In a personality study (May \& Bos, 2000) 104 individuals were divided into groups of $\mathrm{AD} / \mathrm{HD}$ individuals, $\mathrm{AD} / \mathrm{HD}$ individuals with co-morbidity, $\mathrm{AD} / \mathrm{HD}-\mathrm{ODD}$ (Oppositional Defiant Disorder) individuals and AD/HD-ODD-co-morbid individuals. With tests of the MCMI-II, clinical interviews with the adult participant and a significant other, DSM-III-R check list, Gordon Diagnostic System, Conner's Continuous Performance and Millon Multiaxial Inventory conclusions of the research were that the $\mathrm{AD} / \mathrm{HD}$ group sought out stimulation, excitement and attention in their relationships. They were charming and colorful at social gatherings, but loud 
and exhibitionistic with demanding behavior. They have intense emotional moments in friendships but those friendships do not last. The AD/HD co-morbid group individuals were detached and isolated from others with few friends. Those individuals with AD/HD-ODD had difficulty with anger, difficulty in relationships, resent authority and sabotage directives. They saw relationships in terms of power and in terms of winners and losers. The AD/HD-ODD comorbid group rejects social norms and is angry and without warm emotions, which is considered a weakness and they avoid and blame others (May and Bos, 2000). Within the qualitative study there was a higher rate of relationship impairment with authority figures in both the university setting as well as with authority figures in the family (parents and adult relatives) and with significant others (partners, boyfriends, girlfriends), but not as much with peers (only half of the peers), which is not the case with May and Bos' (2000) study. Therefore, I would conclude that the literature review does support the fact that there are significant problems in relationships with individuals with $\mathrm{AD} / \mathrm{HD}$ with authority, but not so much with peers. The individuals in the qualitative research showed less difficulty with peers. Only half of the interviewees indicated peer difficulties. This may be due to the fact that support services put a lot of effort into social outlet programs that focus on developing friendships. Most of the peers' friends come from the student services support program. The literature did not really specifically address work relationships impairments and made general statements about this. Further research is needed in this area. 


\section{Academic Functional Impairments}

For reading, 6 out of 10 interviewees had impairments in reading in cognitive and organizational issues and needing extra time. Four out of 10 interviewees said that they needed extra time to read.

For math, 3 out of 10 interviewees were determined to have impairments in math in cognitive and organizational issues and needing extra time. One of 10 interviewees said that they needed extra time to complete math problems. The self-report of interviewees concerning math impairment appears to be much lower than the actual number of courses in math and science that had grades of D or F. There were 12 Ds and 2 Fs (see Table 5 Academic Functional Impairments, page 107).

From the interviewees and significant other interviews 4 out of 10 reported issues currently with writing with organizational impairments including content issues, comprehension as in topic development and details, grammatical and mechanical issues. However, in the writing samples 9 out of 10 interviewees had functional impairments in writing with high errors in grammar and mechanics (see Table 5 Academic Functional Impairments, page107 and Table 6 Writing Sample Analysis, page 108.)

Two out of three freshmen students received Ds and Fs. However, the overall GPA for undergraduates is 3.09. This may suggest that student support services are beneficial to these students. Those graduate students who have a history of accommodations from student support services are doing well with an overall GPA of 3.64 (see Table 5 Academic Functional Impairments, page 107). Other factors such as requirements to get into a graduate program and the fact that a 3.0 or above is required may affect the data. The literature review did not 
specifically address impact of $\mathrm{AD} / \mathrm{HD}$ on academic performance, which is one of the reasons for the qualitative study.

Of the 5 out of 10 interviewees who have Ds and Fs all of the students received their Ds and Fs in their freshman year except for one student. This suggests that the student support services program may be having a powerful impact on academic success.

The American Disabilities Act of 1990 requires that students with disabilities be afforded accommodations to learn. Academic programs must provide services so that students can achieve academically to develop successful individuals for the work place. Student support services programs have the abilities to provide diagnostic services and academic services of tutoring to students. They can also act as a link to the community to obtain professional services of medication and counseling services.

\section{Work Functional Impairments}

Of the 10 interviewees, 7 out of 10 reported impairments in work function. Six out of 10 individuals reported impairments in concentration. There were 2 interviewees of 10 who had issues with organizational impairments. One interviewee out of 10 had a time related issue. There were 3 interviewees out of 10 that had hyperactive responses that affected work function. (Please see Table 7 Work Functional Impairments, page 116). There were no literature review studies that specifically addressed work functional impairments as a result of having AD/HD. However, one can conclude that if 6 of 10 interviewees had impairments in concentration such as distraction, lack of focus etc., if left untreated would create delays in task completion and increased error rates. 
This research study suggests that functional impairments for $\mathrm{AD} / \mathrm{HD}$ individuals continue well into the young adult years. The qualitative research suggests that overall functional impairments continue in the areas of concentration, organization, time-related issues and hyperactive responses for university students $18-25$ years old. These issues impact in negative ways relationships with higher levels of conflict; academic functioning with lower GPAs; work functioning with conflict with supervisors and peers; work performance in the areas of time management/scheduling; and the need for extra time to complete tasks. Successful accommodations and interventions that teach learning and coping strategies are necessary to help students with $\mathrm{AD} / \mathrm{HD}$ succeed academically and transition into the work world.

In summary the preliminary data appears to confirm the existence of functional impairments in adults that would affect relationships, academics and careers in the quantitative research studies, which supports confirmability of existing theory. A large majority of the symptoms manifest themselves in the communication realm in almost all of the instances. Implications for Education

The following recommendations address the second major purpose of this qualitative study: What changes, modifications or continued academic strategies or treatment services are needed for college age students with $\mathrm{AD} / \mathrm{HD}$ ? The implications for education also answer research question four of the research: What resources, teaching methods, and other professional resources need to be continued, modified, or changed due to functional impairments of college age students with $\mathrm{AD} / \mathrm{HD}$ ? They also answer research question five: What information from individuals with $\mathrm{AD} / \mathrm{HD}$ could be incorporated into an academic setting to ensure long-term success of students with $\mathrm{AD} / \mathrm{HD}$ ? 
Recommendations are as follows: Academic support services of tutoring that focus on organizational and time management issues with an emphasis on daily planning and adherence to schedules; diagnostic services to assess and confirm the diagnoses of learning disabilities and mental health disorders as well as $\mathrm{AD} / \mathrm{HD}$; tutoring and suggestions to professors for teaching practices that are geared to the individual's learning style strengths and breaks learning down into smaller units; accommodations of distraction free environments and extended test times.

Brand et al. (2002) indicated that instead of focusing on symptoms of AD/HD we should be focused on learning styles and the teaching environment. He also, along with modifications in teaching, suggests teaching to individuals' strengths. He supported environmental changes such as afternoon learning and structured environments.

Technology of reading such as Kurzweil and writing programs, Naturally Speaking Dragon, could be helpful to assist those individuals with accompanying disabilities. Additionally, on-line classes should be available to students so they can work at their own pace and take frequent breaks.

I would add that many of the student's with reading or math disabilities expressed that their issues of distractibility caused them to lose their place. Devices or props that assist students with not losing their place need to be used. An example might be an extra pencil that keeps the student on their place, especially on tests that have the bubbles to mark answers. One could also use the bottom of the page or a sheet of paper to keep track of the place and to cover other material that is distracting to them.

There should be strong mentorship from tutors or successful individuals who have $\mathrm{AD} / \mathrm{HD}$ from the academic world who can serve as a source of family support. Social programs 
should be developed that offer opportunities to develop socially. This should occur both in social media outlets such as Face book and Twitter for professionals and paraprofessionals along with on-campus socialization functions. Students with $\mathrm{AD} / \mathrm{HD}$ put in a greater amount of time in studies limiting time to develop socially. Given this impact on social relationships and the impact that impairments in listening and distractibility have on relationships, educational skills building in communication might be part of an orientation seminar. One could also include workshops in the area of problem-solving skills to help individuals with $\mathrm{AD} / \mathrm{HD}$ with impulsive decision-making, which has a negative impact on learning and relationships.

Students overwhelmingly expressed concern that professors do not understand that $\mathrm{AD} / \mathrm{HD}$ does not have anything to do with intelligence. They felt that some professors are negative about their abilities to succeed. Therefore, they would like for professors to have training about $\mathrm{AD} / \mathrm{HD}$. They also noted that posting class notes on-line is helpful. All assignments should be clearly identified in written form with due dates in the syllabus with a calendar due to organizational time management/scheduling issues in students with AD/HD. I would add that audio taped discs or digital formats of lectures should be available to students online. This would allow them to revisit information that has been missed. Many students noted that the processing issues of $\mathrm{AD} / \mathrm{HD}$ causes them to require more time to learn due to distractibility but it does not impair their ability to retain information once they learn it.

Academic Advisors should encourage students to take the minimum full-time required course load for at least their freshman year or students should be encouraged to take part-time classes because of the time related issues as in needing more time to complete tasks. Most of the students who had a D or F earned a D or an F in their freshman year. Reducing the academic 
load may offset the number of Ds or Fs that students receive. Also, most students appear to function better in afternoon classes rather than morning classes.

Finally, university student support programs should serve as a link to the community for professional services. This could be done with marketing functions with community services programs in the form of brochures, workshops etc. Also information releases from students should be obtained so that students support services staff can refer and communicate problems to providers in the community.

In terms of community agency services most of the students are receiving medical services with medication for $\mathrm{AD} / \mathrm{HD}$ or other mental health disabilities. Medication helps students focus more clearly. Very few students are currently receiving diagnostic psychological services or psychological treatment. Given the lack of opportunities for social development, counseling services could focus on communication skills building as well as problem-solving skills building to deal with impulsivity. Lack of skills in these areas appears to produce shortterm or lacking relationships with significant others. Distraction and lack of ability to listen as well as needing more time to complete tasks can create levels of conflict that impair relationships with authority figures at school or work, family members, peers and co-workers. Students should also be encouraged to participate in fitness programs and recreational programs particularly if hyperactivity is or has been an issue as this improves the ability to focus.

There should be consideration given to non-medical ways of dealing with symptoms of $\mathrm{AD} / \mathrm{HD}$. There has been some suggestion that dietary habits may affect the severity of AD/HD. In addition consideration should be given to forms of spirituality that use meditation and deep breathing exercises that can assist those individuals with hyperactivity and focus issues. 


\section{Further Research}

For future reference, follow up studies should be done with students who are in skilled rather than unskilled work positions as the research did not suggest major impairments on their jobs. There was little opportunity to interview co-workers or employers concerning work performance. Since the information is based on self-report, which according to others in the field, tends not to be as accurate as significant others, there may be more functional impairments in work than interviewees are reporting. Also, it would seem that skilled positions would require more demands for timely task completion as well as be less tolerant of careless mistakes. It should be noted that all of the work of the interviewees is in unskilled part-time labor positions.

It was sometimes difficult to keep students on task with the semi-structured interview as these students rambled, jumped subjects and shifted back and forth in the history. This made it extremely difficult to follow the semi-structured interview process. This is very typical of individuals with AD/HD especially if they have hyperactivity. Some of the examples had to be looked at in the total context of the interview along with what the significant other reported as well as the observation memos, creating some subjectivity by the interviewer. From a counselor's viewpoint some of what clients report is open to interpretation.

I sometimes found myself wondering, did I cover all of the questions? Their disorganization can quickly impact your ability to follow their train of thought and you can quickly lose your place in the interview process. I would suggest checking off the questions as they are asked or answered in the future to insure dependability of the study.

A medical office and other Appalachian Universities agreed to participate initially, but only agreed to send letters to students or wanted me to interview an older population. None of 
their students participated in the study. The Appalachian University Support Services Program that referred students contacted students directly and encouraged them to participate. The Director was heavily involved in recruiting and scheduling students due to her interest in the field. Without building a strong relationship between this university with other college or university support services program managers this research would not happen. I feel strongly that $\mathrm{AD} / \mathrm{HD}$ students would not have an initial interest in this activity without a personal understanding in how it benefits them.

The acceptable manual for diagnosing individuals with $\mathrm{AD} / \mathrm{HD}$ is the DSM-IV-TR. I hope that the American Psychiatric Association, which sets the diagnostic criteria to determine $\mathrm{AD} / \mathrm{HD}$, will consider revising the criteria to reflect changes in adults with $\mathrm{AD} / \mathrm{HD}$. There is also a need to consider and reference the impact of functional impairments for AD/HD college students specifically in a higher education setting and the work setting as these are addressed with little detail.

Consideration should be given to a comparison study with students who do not have $\mathrm{AD} / \mathrm{HD}$ to address the concern that even students without $\mathrm{AD} / \mathrm{HD}$ may have similar issues. For example even students without AD/HD may not want to get up in the morning. In addition all of the interviewees were receiving student support services. What about students with AD/HD who have dropped out of the college setting or those who are coping with their AD/HD and are not receiving services and are doing well in an academic setting? Although there was a high percentage of students who have student support services with functional impairments, academic impairments, work impairments and relationship impairments this study, but this segment represents only a small segment of those students with $\mathrm{AD} / \mathrm{HD}$. 
This study served as a model of grounded theory, therefore theoretical saturation has not been reached and further studies are required for grounded theory until no new information is discovered. Credibility cannot be established unless further studies are replicated to generate multiple comparison groups. 


\section{References}

American Psychiatric Association. (2000). Diagnostic and statistical manual of mental disorders (text revision). Washington, DC: Author.

Americans With Disabilities Act of 1900, 42 U.S.C.A. § 12101 ST SEQ. (West 1993)

Allen, K. E., Henke, L. B., Harris, E. R., Baer, D.M., \& Reynolds, N.J. (1967). Control of hyperactivity by social reinforcement of attending behavior. Journal of Education Psychology, 58(4), 231-237. Retrieved April 17, 2011, from PsycARTICLES database. doi: 10.1037/h0024905

Drash, P. W., Soloman, E. M., Long, K. L., \& Stolberg, A. L. (1976, May). Hyperactivity in preschool children as non-compliance: A new conceptual basis for treatment. Paper presented at the $29^{\text {th }}$ annual meeting of the American Psychological Association, Clearwater, FL. (ERIC Document Reproduction Service No. ED 138000)

DuPual, G. J. \& Eckert, T. L. (1997). The effects of school-based interventions for attention deficit hyperactivity disorder: A meta-analysis. School Psychology Review 26, 527. Abstract retrieved April 15, 2011, from NICHCY Research Database of the National Dissemination Center for Children with Disabilities Website site: http://research.nichcy.org/MetaAnalysisPF.asp?

Barkley, R. A., Edwards, G., Laneri, M., Fletcher, K., \& Metevia, L. (2001, December 1). The efficacy of problem-solving communication alone, behavior management training alone, and their combination for parent-adolescent conflict in teenagers with 
ADHD and ODD. Journal of Consulting and Clinical Psychology, 69(6). Retrieved September 9, 2002, from EBSCOhost database.

Barkley, R. A., Fisher, M., Smallish, L., \& Fletcher, K. (2002, May 1). The persistence of attention deficit/hyperactivity disorder into young adulthood as a function of reporting source and definition of disorder. Journal of Abnormal Psychology, Vol. III, (2). Retrieved November 30, 2002 from EBSCOhost database.

Barkley, R. A., Murphy, K. R., \& Bush, T. (2001, July 1). Time perception and reproduction in young adults with attention deficit hyperactivity disorder. Neuropsychology 15(3). Retrieved November 30, 2002 from EBSCOhost database.

Bogdan, R. C., \& Bicklen, S.K. (1998). Qualitative research for education, an introduction to theory and methods. Needhamm Heights, MA: Allyn \& Bacon, Viacom.

Brand, S., Dunn, R., \& Greb, F. (2002, June). Learning styles of students with attention deficit/hyperactivity disorder: Who are they and how can we teach them? Clearing House 00098655, 75(5). Retrieved October 4, 2002 from EBSCOhost database.

Denzin, N. K., \& Lincoln V. S. (Eds.). (1998). Strategies of Qualitative Inquiry. New Delhi: Sage Publications Inc. Retrieved May 23, 2009 from www.socialresearchmethods.net.

Devers, K. J., Ph.D., \& Frankel, R. M., Ph.D. (2000, July) Study design in qualitative research-1: Developing questions and assessing resource needs. Education for health: Change in learning and practice. 13(2), 251-262. 
Devers, K. J., Ph.D., \& Frankel, R. M., Ph.D. (2000, July). Study design in qualitative research2: Sampling and data collection strategies. Education for health: Change in learning and practice. 13(2), 263-272.

Edwards, J. H. (2002, April). Evidenced Base Treatment for Child ADHD: (Real-World) (Practical Implications). Journal of Mental Health Counseling, 24(No. II), 110139.

Glaser, B. G., \& Strauss, A. L. (1967). The discovery of grounded theory: Strategies for qualitative research. University of California San Francisco Medical Center. Chicago: Aldine.

Hallowell, E.M., M.D., \& Ratey J. J., M.D. (1995). Driven to distraction. New York: Random House.

Lincoln, Y. S. \& Guba, E. G. (1985). Naturalistic Inquiry. Beverly Hills, CA: Sage. Retrieved April 15, 2011, from http://books.google.com/books?

May, B., \& Bos, J. (2000, October). Personality characteristics of ADHD adults assessed with the Million Clinical Multiaxial Inventory-II: Evidence of four distinct subtypes. Journal of Personality Assessment, 75(2).

McGoey, K. E., \& DuPaul, G. J. (2000). Token reinforcement and response cost procedures: Reducing the disruptive behavior of preschool children with ADHD. School Psychology Quarterly, pp 15, 330-343. Retrieved October 3, 2002 from EBSCOhost database.

McGoey, K. E., Eckert, T. L., \& DuPaul, G. J. (2002, Spring). Early intervention for preschool age children with ADHD: A literature review. Journal of Emotional and 
Behavioral Disorders, 10(I). Retrieved October 3, 2002 from EBSCOhost database.

Merriam, S. B. (1995). What can you tell from an $\mathrm{N}$ of 1: Issues of validity and reliability in qualitative research. PAACE Journal of lifelong learning. 4, 51-60.

Milberger, S., Sc. D. (1998, April). ADHD places teens at risk for substance use disorders. The Brown University Digest of Addiction Theory and Application, 17(4) 1-3.

Nigg, J. T., John, O. P., Blaskey, L.G., Huang-Pollock, C. L., Willcutt, E. G., Hinshaw, S. P., et al. (2002, August). Big five dimensions and ADHD Symptoms: Links between personality traits and clinical symptoms. Journal of Personality and Social Psychology, 83(2). Retrieved November 30, 2002 from EBSCOhost database.

Pisterman, S., McGrath, P., Firestone, P., Goodman, J. T., Webster, I., Mallory, R. (1989). Outcome of parent-mediated treatment of preschoolers with attention deficit disorder with hyperactivity. Journal of Consulting and Clinical Pschology, 57(5), 628-635. Retrieved April 17, 2011, from PsycARTICLES database. doi: 10.1037/0022-006X.57.5.628

Reeve, W. V., \& Schandler, S. L. (2001, Winter). Frontal lobe functioning in adolescents with attention deficit hyperactivity disorder. Adolescence, 36(144). Retrieved September 9, 2002 from EBSCOhost database.

Robin, A. L., Foster, S. L. (1989). Negotiating parent-adolescent conflict: A behavioral-family systems approach. New York: Guildford Press. Retrieved April 14, 2011, from http://books.google.com/books? 
Schensel, S., Schensel, J. J., \& LeComple, M. D. (1999). Essential ethnographic methods: observations, interviews, and questions (pp. 121-148). Lanham, MD: Altamira Press.

Stage, S. A. \& Quiroz, D. R. (1997). A meta-analysis of interventions to decrease disruptive classroom behavior in public education settings. School Psychology Review, 26(3), 333-368. Retrieved April 16, 2011, from EBSCHOST Psychology and Behavioral Sciences Collection database at http://teach.belmont.edu: 2585/ehost/detail?

Strauss, A., \& Corbin, J. (1998). Basics of qualitative research techniques and procedures for developing grounded theory. New Delhi: Sage Publications Inc.

Wasserstein, J. (2001). Adults with attention deficit hyperactivity disorder (ADHD) (Report No. ED-99-C0-0026) U S Department of Education (ERIC Document Reproduction Service No. ED461959). Retrieved November 30, 2002 from EBSCOhost database.

Zametkin, A. J., Liebenauer, L. L., Fritzgerald, G. A., King, A. C., Minkunas, D. V., Herscovitch, P. et al. (1993). Brain metabolism in teenagers with attention-deficit hyperactivity disorder. Archives General Psychiatry, 50(5), 333-340. Abstract retrieved April 17, 2011, from http://ncbi.nlm.nih.gov/pubmed/8489322 


\title{
Appendix A
}

\author{
Office of Research Compliance
}

\section{IRB Protocol Full Board Approval}

\begin{abstract}
To: $\quad$ Obenauf, Patricia
From: $\quad$ WVU Office of Research Compliance

Date: Wednesday, April 14, 2010

Subject: Approval Letter

Tracking* H-22110

Title: $\quad$ What Functional Impairments Occur in College Age Students with Attention Deficit/ Hyperactivity Disorder and What Changes, Modifications and Continued Treatment Interventions and Academic Strategies Are Necessary for College Age Students with Attention Deficit/ Hyperactivity Disorder?
\end{abstract}

The research study referenced above was reviewed by the West Virginia University Instituional Review Board (IRB) via full board review procedures and was approved.

This protocol was reviewed using the following:

Regulatory Criteria Checklist $(21 \mathrm{Oq})$

Expedited Review Checklist (210a)

Waiver of Consent Documentation Checklist (210k)

category 7

The following documents have been approved and validated for use in this study and are available in the BRAAN system:

Locations of Research Offsite Location

Details

Attachments - Other (e.g., community hospital, nursing home, long - term care facility, private residence, etc.)

Concord University Approval Letter.rtf Permission from External Institution 
Once you begin your human subject research, the following regulations apply:

1 Unanticipated or serious adverse events/side effects encountered in this research study must be reported to the IRB within five (5) days.

2. Any modifications to the study protocol or informed consent form must be reviewed and approved by the IRB prior to implementation.

3. You may not use a modified informed consent form until it has been approved and validated by the IRB. 


\title{
Appendix B
}

\author{
Cover Letter
}

\section{Department of Curriculum \& Instruction/Literacy Studies WestVrrginiaUniversity.}

College of Human Resources and Education

\section{Dear Student:}

Thank you for agreeing to participate in my research project to fulfill the requirements for my dissertation. This project is being conducted by Sylvia A. Wright, Ed. S., Licensed Professional Counselor, under Dr. Patricia Obenauf, Professor, for the Curriculum and Instruction Education Doctoral Program. The goal of the research with Attention Deficit/Hyperactivity Disorder $(\mathrm{AD} / \mathrm{HD})$ in college age students is to identify functional impairments that continue into the college age student's life affecting success in an academic setting; relationships with others, and careers. The information will be utilized to propose teaching interventions and classroom strategies that will assist individuals with $\mathrm{AD} / \mathrm{HD}$ in a college setting and identify other professional services that may assist individuals with $\mathrm{AD} / \mathrm{HD}$.

\section{Procedures}

College age students ages $18-25$ years with $\mathrm{AD} / \mathrm{HD}$ will be asked a series of semi-structured questions about functional impairments that they experienced in elementary, high school and college in the areas of school, home and work. They will also be asked semi-structured questions concerning their relationships with others in those settings. Finally, they will be asked a general question about professional services and teaching interventions received thus far and whether or not they were helpful. The information gathered will be used for my doctoral dissertation.

The college age student will also provide a typed response to two semi-structured interview questions, which will provide further information about the impact that $\mathrm{AD} / \mathrm{HD}$ has had on their life as well as provide suggestions about appropriate interventions/strategies from an academic or community treatment intervention's perspective.

A significant other (defined as someone who spends at least ten hours a week with the student), with the student's permission, will be asked similar questions related to functional impairments that they feel the college student with $\mathrm{AD} / \mathrm{HD}$ experiences in college.

The students will be asked to provide a copy of their college transcript to review subject grades and overall G. P. A.

The combined interviews, student and significant other, are expected to take about three hours.

The information gathered will be useful to provide suggestions to college professors or other service providers for continued or additional services to college age students with $\mathrm{AD} / \mathrm{HD}$ to deal with functional impairments that the college age student may be experiencing. The colleges and community treatment service providers who participated in assisting us with referrals will be

602 Allen Hall PO Box 6122 Morgantown, WV 26506-6122

Phone: 304-293-3441 Fax: 304-293-3802

Equal Opportunity / Affirmative Action Institution 
provided a summary of the final research with recommendations for academic and professional services for students with $\mathrm{AD} / \mathrm{HD}$.

I want to point out several things to you before we start. Your participation in this research is strictly voluntary. You may withdraw at any time and you do not have to respond to every item or question. You are not required to answer any questions with which you are uncomfortable.

Your responses will remain anonymous and confidential. To protect student confidentiality interviews will be audio taped, but not videotaped. A pseudo name will be given to both the student and the significant other. Academic transcripts will be referred to by the student's pseudo-name. No identifying information will be given that could provide student location or the specific colleges that are attended. Typed transcripts of audiotape interviews will only be referred to by a pseudo name with any identifying information such as residence or specific school changed or eliminated. Your permission to be interviewed will be secured on audiotape so that there are no identifying paper trails for others that would suggest you were a participant. Your interview will take place in a private setting. Once your taped interviews are transcribed, they will be destroyed. Only the typist and myself will have access to the original tape and the typist must agree to confidentiality guidelines.

Please be aware that under certain circumstances we are required by state law to report certain behaviors to the legal authorities such as child abuse, elder abuse, dangerous behavior to self or others, and criminal investigations when they are ordered by a judge.

There will be no penalty or loss of benefits to you if you choose to withdraw or refuse to participate in this study. This will in no way do not affect your grades, academic status, class standing, or your athletic standing. This will not affect your employment status.

WVU Institutional Review Board Acknowledgement of this project is on file.

Thank you for agreeing to participate in this study. 


\section{Appendix C}

Sample Student and Significant Other Qualitative Interviews

Qualitative Interview - Frank

Interviewer: You have read the West Virginia University student cover letter that defines procedures and confidentiality for students with $\mathrm{AD} / \mathrm{HD}$ who participate in this qualitative research?

Interviewee: Oh, Yes

Interviewer: You are giving your permission for me to tape this interview with the guidelines described in the cover letter?

Interviewee: Yeah.

Interviewer: Thank you. Frank, I want to start out by asking you when and how you became aware that you had $\mathrm{AD} / \mathrm{HD}$ ?

Interviewee: Umm I found out in between the second and the third grade. That's probably about (indiscernible) ... what it really meant to me is it made me feel I wasn't normal at first.

Interviewer: So did you receive any kind of psychological evaluations or testing for your $\mathrm{AD} / \mathrm{HD}$ ?

Interviewee: Yes, my mom actually had me tested here a couple of times actually by a woman named Gina Ruble. Sit by her and ... (indiscernible).

Interviewer: Of your years in school how did AD/HD affect you, and I'd like to start with your elementary years? What do you remember about elementary school? For example what kind of grades did you get?

Interviewee: I was mostly a $\mathrm{C}$ average student. Uh the areas that I really struggled in was Math and sometimes (indiscernible)... Math has always been a struggle for me, and it was really frustrating that I couldn't understand simple problems like (indiscernible). I would sit there and watch other people just fly through it, and I would have to spend more time. It was ...

Elementary was ... it was rough because I didn't have tutors or special education, and I actually had to switch schools at one point.

Interviewer: So when you switched schools how did the school situation change for you? 
Interviewee: It actually got better. My first teacher ... it happened in the middle of my fourth grade year at the start of (indiscernible). Understanding ... understood what I was going through (indiscernible). For the first time I didn't have all my friends there, so that actually helped me focus better and knowing that I wasn't ... (indiscernible). Meeting new people (indiscernible) ... (Indiscernible) ... didn't really say much. We had a multitude of ways. I think it was a new start. Uh people didn't know about my past. Well, if they did it was confidential they didn't (indiscernible) ... the students (indiscernible) ... It was probably one of the best things that happened.

Interviewer: So when you changed schools, it sounds like the teachers were more aware of your situation, and more willing to take into account the ability that you had?

Interviewee: (Indiscernible) When I went to ... (indiscernible). I didn't really have a problem until up in the fourth grade. Fourth grade was ... (indiscernible). A multitude of problems: focusing, getting work done, umm plus I had a ... mentally impaired ... (indiscernible). So, I had a bit of temper back in elementary school (indiscernible). (Indiscernible) and felt frustrated. (Indiscernible) Umm I decided that I needed a change of scenery. Umm I can honestly say that my favorite subject in elementary school was probably social studies. I don't know why and never really been sure why I liked history and stuff so much, but it seemed like when all else failed I was always great at social studies, and I uh was just eager to (indiscernible) everything about it. Other than that it'd probably be music-music courses. We would have choir.

Interviewer: What was difficult for you in grade school?

Interviewee: Definitely Math and sometimes (indiscernible). It has always been a struggle. (Indiscernible) ... ties in Math to very complex Math. It's always been hard.

Interviewer: So what were you good at in elementary school?

Interviewee: I did Social Studies. I was actually pretty into sports back then. So (indiscernible) ... good at music classes ... again anything artistic ... like I enjoyed art class. I enjoyed gym. I enjoyed music or choir. Umm I enjoyed social studies and sometimes Science to a certain extent.

Interviewer: Okay, so your grades were better in those subjects than the other subjects. What kind of grades did you get in like music, and art, or social studies?

Interviewee: They were pretty much A's ... A's or B's.

Interviewer: (Indiscernible) ... those were more difficult. How about your grades in high school? What did you get there? 
Interviewee: (Indiscernible). They weren't good. They got better as the years went along. Actually in high school I was always put into special classes where the environment was normal. I was with people I knew, but I always had a secondary teacher to help. They never said that it was just for me, but they kind of hinted at it that it was. (Indiscernible) ... to break down things that the main teacher would go over. They would kind of break it down. (Indiscernible) if one teacher couldn't keep my focus there was another one to. They helped out in English and uh I had a literature course I think my sophomore year that both of my teachers were excellent. They always kept me interested and stuff, so ....

Interviewer: So your grades in English and Literature improved when you became more interested in the subject matter?

Interviewee: Uh huh.

Interviewer: And uh so what kind of grades did you get in those type courses did you get in high school?

Interviewee: Usually in English it was either ... I think in my freshman year I think it was a C. (Indiscernible) low B (indiscernible) for junior low Bs. In my senior year I had this teacher that I didn't communicate with very well. I also had another teacher in that class that I didn't relate too.

(Indiscernible) Uh Math ... it was always a C or D. A ... C or a D because of ... (indiscernible). It would start out pretty good then we would get into the more advanced stuff (indiscernible) Algebra. At the beginning, whenever the semester would start, I'd be fine. Make a good grade on something. Then whenever we would start on like chapter two or chapter three that's when I wouldn't understand things. I wouldn't just pay attention. I'd just ...

Interviewer: So when the concept became difficult you just kind of stopped?

Interviewee: Yeah I didn’t really ask for help, which uh I was frustrated. (Indiscernible) ... to ask for help. It's like I didn't want to tell anybody.

Interviewer: Did you feel some embarrassment?

Interviewee: A little bit, umm not so much in high school, but when I was younger, yes. In high school it seemed like I didn't care. I actually took some (indiscernible). (Indiscernible) in with my parents ... (indiscernible) while I was in college or I probably would have tried harder.

Interviewer: So it sounds like you got low C's and D's in math? Any other subjects that you had problems with in high school or the rest of them fairly easy for you? 
Interviewee: Uh I took a Spanish class that I didn't do well on. It was also like Math. I started out strong and then I kind of went totally downhill like I just stopped. I would bring sports magazines and read them. In high school we didn't have smart phones. I mean we still had a phone at one point in time that I had a poker game on that I would play sometimes.

Then there was some Science that I didn't understand ... uh not a whole lot of Science. My last Science class was an Environmental Earth Science. There were some things that I didn't remember, but my teacher was always helpful, and he always ... he knew if I was trying that he' $\mathrm{d}$ be more willing to help. Umm my sophomore and freshman year ... my freshman year teacher ... I think I got a $\mathrm{C}$ in all the six weeks that I had him for. My sophomore year ... I ... that was the first time I really struggled in Science. I can't remember what the name of the science class was, but our teacher was a real lecturer, and there weren't any windows in the room, so I found it very hard, well actually all it really made me want to do was sleep because it was early in the morning. I'd already had breakfast, so it would be about eight-thirty or nine in the morning, and I just (indiscernible) ... He kind of had a monotone voice, and the student ... the other teacher I had in there ... we didn't get along, so that course was kind of hard, but I ended up making ... I think a B on his final.

Interviewer: What did you like to do in high school and why?

Interviewee: I was in band all four years-marching band. I also played ...uh I did some small roles in ... (indiscernible). I liked music. Music was ... (indiscernible) and stuff. Whenever I play music I just don't ... I'm with friends. We always have a good time, and it introduced me to friends that (indiscernible) I have to this day. Uh it was always good for me. I still liked to play sports, but I wasn't as active in sports as I really was in (indiscernible) school. When I first started band I started drifting away from more playing sports to just watching. Then in high school I really solidified that which wasn't a bad thing at all. It just ... I just wasn't as ... when marching season ended we did concert band during the wintertime. I wasn't physically ... (indiscernible).

Interviewer: You discussed some of the difficulties with academic clients ... uh classes, I'm sorry, which uh were hard for you in some subjects and not (indiscernible). Also heard you talk a little bit about professors that made it difficult for you that ... that maybe were monotone or not interesting. (Indiscernible) ... who really didn't understand maybe what was going on with ... (indiscernible) ... that saw you ... (indiscernible).

Interviewee: Until I told them that I had a learning disability they probably thought I was just lazy and uninterested that I didn't care one way or the other what they said, so they basically didn't want to help me. Sometimes they knew, but they could just be kind of jerks.

(Indiscernible) uh I really enjoyed marching band. Uh my head band director ... uh she's actually had a problem with multitudes of students, but we didn't see eye to eye. Uh she didn't understand my learning disability that much. (Indiscernible) actually it was high school in 
general because my friends started going their separate ways. We started making new friends. I lost touch with a lot of old friends and then uh in band I was just defiant and didn't want to do what she told me to. (Indiscernible) that continued until the summer between my freshman and sophomore year. I kind of had a maturing 'cause I didn't have very many friends and I wanted to have friends, so I learned to be a ... (indiscernible).

Interviewer: (Indiscernible) saying exactly what you were thinking?

Interviewee: Yeah, I did a lot more thinking before I spoke. I made new friends. I actually ... friends that I still have to this day. You know people didn't say, "Hey there's Frank" when ... (indiscernible). That was probably honestly the best year of my high school career ... career. Though, I still hadn't quite mastered the academic side of it I was doing pretty well in school.

Interviewer: So you are talking about the social aspects with the teachers?

Interviewee: Yeah, I wasn't getting in trouble. Umm (indiscernible) ... socially I just felt better all around.

Interviewer: So your relationship with the band instructor improved?

Interviewee: Actually yes, that year it improved greatly. Uh I won most improved that year at the band banquet. (Indiscernible) still didn't really see perfectly eye to eye, but whenever I knew that we weren't seeing eye to eye I didn't tell her, you know, unlike my freshman year. I was also getting more active in social activities like going to basketball games. I was in the band so we had to go to football games. I was just hanging out more.

Interviewer: What would you say you were good at in high school?

Interviewee: Uh the history ... I was still a history uh ... (indiscernible). Even in my junior (indiscernible) class (indiscernible) ... I was doing a little bit better at Math that year. I can't remember much about my junior year in Math. Can't remember who I had, but I was doing better in Math too. Umm Science ... I also did well in science that year 'cause I had a great teacher, and a great kind of Special Ed teacher to help with it too. Umm ... (indiscernible).

Interviewer: What was different about Science that year?

Interviewee: Uh the teacher, Mr. Lava, was great. Uh he would ... (indiscernible) still (indiscernible) about ... we were talking about volcanoes, so we watched a movie called Dante's Peak. He just ... I don' know ... he knew how to relate to us, and he knew that he didn't have to be Mr. Boring or just (indiscernible). (Indiscernible) ... school's more than ....

College, what's your GPA like? 
Interviewee: Umm really, really Math has still been a struggle. It's been kind of harder and kind of easier because honestly in high school I think I would have done a lot better in math if I would have had a tutor, or someone besides my mom to jump on my case, and make sure I was doing stuff. Like uh the tutor that I meet with everyday here if I don't do it they know I didn't do it. And I don't know why, but usually I don't like that feeling because they feel like, well, kind of like some of the teachers that didn't know I had a learning disability, "There's Frankie, he just doesn't care, and why should I help him?" You know ... I know that if I don't try I won't succeed or I won't get help, so ...

Interviewer: What do you like to do here and why?

Interviewee: Well, I'm in the last year of doing marching band here. I've been in it all four years that I have been in college. Uh I like that. I've met a whole bunch of new people. Uh it gives me something to do in the wintertime and in the fall. Mostly, I'm not really in the band in the wintertime, but I still like to go to the basketball games with some of the friends I made from band. Uh (indiscernible) ... stay busy. It's also uh ... band's always given me a little bit of discipline. You know, understand that sometimes you have to (indiscernible) you don't want to. (Indiscernible) ... know everything about them ... that they're maybe not such bad people. It also encourages me to kind of be the first one to talk when meeting new people. The band's director is a wonderful guy. Uh he cares about us. He ... he always does ... he always asks things that he wouldn't ask of us if he hadn't done them himself. He always tells us were great, responsible young adults where he's always proud to be our band director something I didn't always have in high school. I didn't have somebody to say they were proud of us. He's always encouraging, you know, he's very understanding if we can't make it to practice because we have a class to study for. He's very understanding. You know, again, the university or colleges in general could all use more people like him in every class. If every teacher was like him, and there are some that are like him, college would probably be fantastic.

Interviewer: Uh huh. Umm what's been the most difficult for you in college?

Interviewee: Probably ... probably I'd say knowing ... just staying on top of things ... knowing when I have to study ... just time management. Time management has been probably the most difficult thing umm to use your time wisely. Uh I found that I've always ... I had a real problem with that where in high school everything was kind of planned out for the day. In college, you know, you can say, well I'm going today. It's been very hard. It's a constant struggle really, you know, knowing wow that I need to get this done right now or I'm going to be freaking out about getting it done later. Or (indiscernible) a test, or I'm not going to learn anything ... I'll probably be in trouble. By far it's been the biggest struggle. And then always asking for help that's always been a problem. Like I don't really want to ask for (indiscernible).... When I talk to my tutors, you know, sometimes I don't tell them everything because it's kind of embarrassing for me. (Indiscernible) like I'm self sufficient, I guess. Yeah. Yeah, cause I've never missed. 
I never really stopped and thought about what I've been good at in college. I'd say there is really one good thing that I am great at besides band ...that's kind of ... I try to distribute evenly ... I try to put ... not always ... I try to put forth the same effort as I do in band to each of my classes. I have been ... this fall I've been having some sleeping issues, so I finally got them straightened out, so things have been going a little bit smoother (indiscernible). I'd say if I had to (pause) take one thing ... then I'm better at telling my professors or letting them know that I'm having trouble. In high school, I didn't really ... people either knew or they didn't knew. I didn't really want to tell them. In college, I'm kind of more eager to tell them.

Interviewer: I want to ask you about your relationships with others. When you were in grade school what kind of (indiscernible) teachers? (Indiscernible) a little bit of some of the problems getting along with other people in elementary school. I think you (indiscernible).

Interviewee: I did, I did. Uh I didn't really tell anybody that I had AD/HD or that ... (indiscernible). First to start ... started developing a temper and having trouble controlling it. That's when people found out that there's usually something wrong. Tried to be funny ... the funny guy in elementary and in middle school. I was trying to make up for something that I did wrong, but uh (Indiscernible) my relationship with my friends ... it was okay. I'm not really good friends with any those people anymore. I still talk to them, but I'm not really as good of a friend as I wish I was.

Interviewer: Also sounded like you had some difficulties with some teachers?

Interviewee: Yeah, I did uh (indiscernible) mom or dad would talk to them, you know. Sometimes they could tell that I was saying that that teacher wasn't understanding, but they actually were. Then there would be other times where I'd be like that person really doesn't understand. (Indiscernible) umm first elementary school I didn't really have any problems until the fourth grade. My fourth grade teacher actually knew me already 'cause she had my mom. (Indiscernible) I would get angry, and I'd say things that I didn't mean because I'd be angry. Some teachers realized that, but others didn't until they talked to my mom or my dad, or both.

Interviewer: What about the principal?

Interviewee: (Indiscernible) I never really ... I didn't see the principal. I saw her a couple of times. I would get ... I think they called them ... infractions or something like that, but I don't remember ever going into the principal's office. I went in there a couple of times, but most of the time they just sent me ... where did they send me? Office (indiscernible) ... Oh, in middle school I got sent to the office. I had a great relationship with one of the assistant principals, uh (indiscernible) and the head principal it changed.

(Indiscernible) when they first started noticing a problem, you know, they took me to see a doctor right away cause they wanted to try a .... My dad's always understood ... My dad's had a harder time understanding I think, when he got older, you know. When you get older your 
temper gets a little shorter, but never (indiscernible) ... He never ... I think he would get frustrated because he didn't know how to help me because he didn't understand himself. I think that when we would argue ... we didn't really argue until I got in high school ... I think what frustrated him the most was if he knew I wasn't trying. He didn't understand ... giving that (indiscernible) what not (indiscernible) you're understandable too. If you're not trying why would anyone have sympathy on you. Then see (indiscernible) I've always had a great relationship with my mom when it comes to (indiscernible). She understands ... she understands what to say ... what to say. I just need an ear sometimes, you know what I mean.

Interviewer: What about your brother and sister?

Interviewee: Uh (indiscernible) normal fights like brothers and sisters do, but uh there was ... we both really active when we were younger, so I want to say for the most part we got along pretty good. You know we had stupid fights over stupid things, and he had some friends that would ... like they'd get together and make fun of me sometime. (Indiscernible) standard brother stuff and I'd do things that would make him mad. (Indiscernible) We got ... I got along good with my cousins and my aunts and stuff. Uh my mom has two sisters, so they were kind of like her so they understood. Her twin sister actually ... (indiscernible) aunt and uncles were always nice. Never really (indiscernible). I had ... I had some problems with cousins, but usually it'd be after we'd spent a couple of days together.

Interviewer: At school, what kind of reaction did you get (indiscernible)?

Interviewee: It was kind of sometimes a shocked reaction when I told them that I had anxiety. Mostly it would be when I told them I had anxiety. They weren't really shocked when I had $\mathrm{AD} / \mathrm{HD}$ (indiscernible) and showed it more. (Indiscernible) about something I had done (indiscernible) paying attention. My teachers ... uh some of them were good; some of them ... weren't good. It was more good than bad for the most part. Umm (indiscernible) my principal my first two years, and then actually, you know, I didn't really see him a whole lot, so my freshman year was probably the most I have ever been in a principal's office in high school. Then after that (indiscernible).

Interviewer: (Indiscernible) ... about your brother and sister?

Interviewee: (Indiscernible) pretty good. (Indiscernible) and I argued some. That's when we started probably having like arguing matches (indiscernible). Umm my freshman year it was that I had an attitude problem for the most part, and by all means they were right, I did, uh that was basically (indiscernible). My brother ... my brother and I kind of had a good relationship. He hung out with people that I ... he was ... he's kind of ... he still is a social butterfly. It seems like he knows everyone. To this day, it would be like back in high school our first day; he would be like, "hey man, what's going on, blah, blah, blah." I was kind of like that my senior year after I had been there for three and one-half years, but at first I was just like gosh. I felt 
intimidated at first being his brother, you know. I didn't know what to say or what not to say. Uh I kind of did some things that embarrassed him a couple of times.

Interviewer: Like?

Interviewee: Uh he actually ... I can name one thing he did to embarrass me. He actually ... he was on the TV news-broadcast news, whatever they did in high school, and they did a segment on brothers and sisters. And he played football and we were out in the courtyard, and he asks me to come over real quick. And I saw a bunch of people standing by a door, but I didn't know what they were doing. All of a sudden he breaks off in a dead sprint and tackles me in front of everybody in the grass. That was kind of embarrassing, but I did things just (indiscernible). I didn't like her at first, but we grew into each other, so ....

Interviewer: (Indiscernible) school, any significant issues with other...?

Interviewee: The only part that was really rough was probably (indiscernible) second semester of my junior year and the first semester (indiscernible). (Indiscernible) lost both of his parents, and my grandma died naturally and then I think my grandpa (indiscernible). It was a rough time for everyone. Uh dad and I had some arguments over that time, but I think it was mostly because (indiscernible) without any parents, you know, (Indiscernible) there were some rough times with ... I wouldn't say with everybody. I think there was a little bit of frustration cause he has four brothers and sisters, so we were ... they were all trying to figure out what to do while still maintaining their daily lives with me going to high school, my brother was in college, umm (indiscernible). I think the only problem we ever had as a family was when (indiscernible) first moved out. He went a little crazy at first and spent some of his money unwisely, so that caused some tension back at the house. My parents would get mad sometimes at my brother and I just happen to be there, so they would be like, "Oh boy, there's Frank." (Indiscernible) “... Not here, so you're here." So that caused a little bit of tension, but I'd say the roughest time was when both my grandparents ... my dad's parents died within a month ... within a couple of months.

Interviewer: (Indiscernible) college...?

Interviewee: Mostly understanding, you know. Some people I'm friends with ... we've all grown up, you know, we're all eighteen and older, so we all have more of a mature outlook on, you know, when you tell people serious things. (Indiscernible) I'd say more than $85 \%$ of the time their reaction is good because (indiscernible) everybody's got more serious problem their dealing with now. Everybody's got more serious problems they're dealing with now-like real life situations; so we all know when to have good time ... we all know when to be serious too.

Interviewer: You talked about this a little bit (indiscernible).

Interviewee: (Indiscernible) good and some bad. Umm I've had teachers, who have been very unorganized, and you know, I'm not very organized myself, but I still know a little 
(indiscernible). (Indiscernible) 'Cause I feel like a ... I'm frustrated 'cause they're not trying or not doing their part of the relationship. The professors have been good. Some have been just jerks that I just act good so I want to get out of class ... just get it done with.

Interviewer: How do you get along with your family now, and also if you have a significant other, like a girlfriend, or partner, or ...?

Interviewee: Last girlfriend I had I got along pretty well with. Umm ... had a little bit of communication issues ... when we'd talk it would be kind of awkward silence moments sometimes. I would do most of the talking, but ...

Interviewer: How did you get along?

Interviewee: Umm very good for the most part. She always wanted ... if I was having a bad day she always wanted to be there. Uh if was having ... if I was arguing with one of my parents, you know, she wanted to listen. She never really told me much of her problems, so I didn't have to deal with a lot of them. Her parents ... her mom was a little bit strange though ...her mom was definitely (indiscernible). I actually ended it when I graduated high school. She was still in school-in high school, and I didn't know if I would have time to spend with her, so I kind of ended it. I thought it ended on a good note, but I guess she had a little bit of anger hidden somewhere, so ...

Interviewer: So how (indiscernible)? What kind of difficulties have you had with work?

Interviewee: Uh I guess a problem I have is staying focus. I work at the mall now, so if I see someone I know I got to ... I talk to them, but I also got to know when to quit talking to them and get back to work.

Interviewer: Uh huh.

Interviewee: Umm also some people that ... I don't have very good patience with some of my co-workers. One of them actually reminds me of when I was in middle school. (Indiscernible) says whatever is on her mind. I know from past experience that that doesn't go well, so she knows how to make me mad.

Interviewer: Umm how do you get along with your boss?

Interviewee: No we have a pretty good (indiscernible). He treats me like a son.

Interviewer: (Indiscernible) some successes with work related positions?

Interviewee: (Indiscernible) so would say I'm a supervisor where I work at now. One of the biggest things I know I can get accomplished there ... I worked a couple of jobs ... I know that 
the kids that we hire ... that's bad that I'm calling them kids I'm only 23. Some of the younger people we hire don't understand so, I actually have one guy that quit and came back, and he says I have so much patience. I deal with things again, but that's just another thing ... where I worked a couple of jobs I developed that I know. Some people that work with me there ... this is their first job, so they don't handle things as well.

Interviewer: That's a good attribute for you.

Interviewee: I'm patient I think to a certain extent, you know. Like the one girl I work with she just ... I'm grateful I don't work with her very much ... she just knows things ... she does things to make me mad ... she knows how to cut to my anger cord which I ... usually I'm just like ... I'm just like ....

Interviewer: What type of services have you had for your AD/HD? I know you see a psychologist. You've had some testing (indiscernible).

Interviewee: They put me on a new medication called Trazodone (indiscernible).

Interviewer: Umm what has not been helpful in the professional services that you've had, or what has been helpful?

Interviewee: For a while my mom would always go with me 'cause I didn't ... I didn't really tell. I was very shy when I (indiscernible). (Indiscernible) to have one psychologist at one point that (indiscernible) to go in there by myself because I felt comfortable talking to him.

(Indiscernible) for a while the person that actually prescribed my medication ... uh the doctor I was seeing ... my mom would have to tell him what was going on. You know, she would kind of encourage me to talk, but I'd still be shy. I go to him by myself now because I've developed a little bit of independence on talking to him. I know that if I don't talk I'm not going to get help (indiscernible).

Interviewer: What types of services or teaching interventions have been helpful to you here at college or at home like in terms of academics?

Interviewee: (Indiscernible) it helps that my mom works here at the Student Support Center. Uh she deals with people that have learning disabilities all day. Uh she knows ... she knows every trick in the book 'cause what I have pulled other kids have pulled. She's like a mom to some of the other kids here, so that's definitely been a big help, and the fact that she's on campus or near campus that I can talk to her face to face is definitely a plus. Sometimes we see a little bit too much of each other, but uh also having tutors has been a major help. Without them I probably wouldn't be ... I probably would not be in school.

Interviewer: (Indiscernible) with them? 
Interviewee: Anything that I have trouble with ... even though a teacher's breaking it down ... they break it down even further.

Interviewer: Okay.

Interviewee: Umm they also know that if I'm going through a rough time ... like these past couple of weeks ... having trouble sleeping ... they understand. They're also kind of like parents. You know if I'm not there ... they call. "How are you? You okay?" (Indiscernible) kind of like having extended family, you can say.

Interviewer: What would like college professors and/or employers to know about your AD/HD condition?

Interviewee: I would like them to know that even though I have AD/HD I consider myself a normal person. I just take longer to understand things. (Indiscernible) that a little reluctant at first sometimes depending on what I'm doing, but (indiscernible) ... I wish ... one thing I wish they would know is that, you know, you don't have to be rude and strict, and straight ... (Indiscernible) at home is the best way to go about it. (Indiscernible) a little more ... (indiscernible) seem like I'm not getting ... Hospitality Management and Hotel Lodging ...

Interviewer: Oh, okay.

Interviewee: (Indiscernible) other people (indiscernible) little bit, so ...

\section{Frances - Frank's Significant Other}

Frances - Frank's Mother

Interviewer: You have read the West Virginia University student cover letter that defines procedures and confidentiality for students with $\mathrm{AD} / \mathrm{HD}$ who participate in this qualitative research?

Interviewee: Yes.

Interviewer: You are giving your permission for me to tape this interview with the guidelines described in the cover letter?

Interviewee: Yes.

Interviewer: Thank you. Umm, what is your relationship with Frank?

Interviewee: He's my son and I'm his mother. 
Interviewer: What difficulties does this student experience at college, work, or home?

Interviewee: Umm he is extremely $\mathrm{AD} / \mathrm{HD}$ and also has generalized anxiety disorder which makes umm ... he's a worrywart both at home and at school. Umm and he is also ... as a result of being a worry wart ... he's a procrastinator about some things which causes the worry to be worse. Umm gosh ... long time things with him. Umm he just has a lot of difficulties associated with the ADD ... probably more than anything.

Interviewer: Can you give some examples of what specific things are?

Interviewee: Umm well he's ... you know, ADD individuals tend to be very stubborn. He's got that very strong stubborn streak. He's got umm ... umm disorganized to the T, although it's really kind of funny because although he's never been diagnosed with OCD-he has compulsions about certain things. Umm like at home he is a neat freak, and you would think that someone who is disorganized as much as he is when it comes to school work would be disorganized in their family life as well or their home life... His room is absolutely spotless-everything has a place. Umm the closet is neat as a pin. Umm he actually lives on the second floor in our house and has his own bathroom. It is spotless. Umm he almost obsesses about it being clean which again is so opposite of what you'd think about ADD. Everyone that thinks about ADD as oh messy, dirty, and umm he's just totally the opposite. Even obsesses about his car ... His car has to be immaculate on the inside. He can't stand if it has a dent.

Umm so he's kind of different when it comes to the ... and I don't know if the anxiety with it makes him different, but he's very different with the ADD issues verses what I typically see as a normal ADD student. Loves to read ... most ADD students do not like to read. I don't care what it is ... he loves to read. Umm and I mean my family jokes ... you know, his grandfather, my dad jokes about how he can take a sport magazine and read it from front to cover then recall facts from it like he memorized it as he read it. So he's very different.

Interviewer: So he has a good memory.

Interviewee: Umm yes, the ADD does not affect the memory at all, but his biggest deficit with ADD is his Math. The processing ... because of his processing issues umm he has difficulty with all Math processing ... he can't remember the steps for the process, so anything after long division ... I mean he can memorize multiplication facts and do those sorts of things, but to do like a long division ... extremely difficult.

Interviewer: So do you think it's that he loses his place?

Interviewee: He loses his place or he can't remember what the steps of the processes are.

Interviewer: Okay. 
Interviewee: So like if he is doing two or three digit division umm he'll get lost in the steps. He may know what the steps are, but if he's doing two or three digits he may remember it for the first digit, but then he gets to the second and third and the processes get messed up.

Interviewer: Okay umm what about any issues at home? I know you mentioned a little bit of compulsiveness and stubbornness. Any other issues with you ... behavioral or ...?

Interviewee: He ... he's never really had ... I mean ... he had extreme issues at school when he was in middle school and late elementary school like fourth and fifth grade umm and the school system didn't believe it, but we never saw those issues at home. And I think the reason we never saw those issues at home ... the only issues we ever had at home were because of issues at school, and umm I mean we got through those, and they were never any more issues at home as a result of that. But every time there was an issue at school of course that made an issue at home. But as far as his home life or anything causing issues from his home life ... he was probably the perfect child, as far as I was concerned ... growing up at home. I mean ...

Interviewer: What kind of issues did he have at school?

Interviewee: Well, as a result of being anxious , I think he becam e depressed. I thin $\mathrm{k}$ when he could not function in the capacity that the teac her felt like he should of, you know, pe rformed in umm he would get very frustrated with that and alm ost shut down. Umm so ... so $\mathrm{m}$ uch to the place that when he was in fift $\mathrm{h}$ grade I removed him from the sch ool he had been in $\mathrm{s}$ ince kindergarten and took him to another school ... just simply because I think he felt like there was no ... they just didn't understand him, and there was no way of getting them to understand. They even wanted to identify him as BD-Behavior Di sordered, and I wasn't a bout to let that happen because I knew that really wasn't the issue with him.

Interviewer: So he was having some behavioral problems at school?

Interviewee: Oh yeah because he would shut down. I mean, if he didn't understand, and I blame part of that on him, but I also blam e part of that on the instruction that he was receiving. If the people that were dealin g with him in elem entary school w ould have had any ideal what they needed to do with an individual that had the difficulties that he had he wouldn't have shut down. It would have been a totally differe nt ballgame, so I blame part of it on him and the fact th at he didn't know how to vocalize what he was feeling a nd the frustration he was feeling. But I also blame the school system and the teachers that were teaching him partly because they didn't know how to recognize what was going on with him and what he needed, so ....

Interviewer: So when you say that he shut down do you mean that he stopped trying to do his work?

Interviewee: He would ... If he had a book open or ... and he felt like he didn't understand what was going on and the teacher ... he could tell th e teacher was fr ustrated with him ... he would close the book ... put his head dow $\mathrm{n}$ on the desk and probably go to sleep 'cause that was his 
way of saying, "you're not getting it ... I don't know what's going on here, and I need help and you're not willing to give it to me." So I got called to school a lot.

Interviewer: When you changed schools how did that work for him?

Interviewee: Well, it worked out perfectly. I say all the tim e ... the lady that um $\mathrm{m}$... 'cause that happened when he had been probably half a sc hool year in the fifth grade classroom, then I switched him to another school and another fifth gr ade classroom. And to th is day he refers to the teacher that he had and I refe $r$ to her as our angel. I even made her an angel pillow and gave it to her 'cause it was just ... when we went in I said this is what we've been through. This is what ... I even met with the principal. Then I met with the principal and the teacher; I said this is what we've been through ... this is the kind of s upport we need, and I hope you can give it. And they said, "by all m eans." And it was lucky for me that the principal there had a son who was learning disabled just li ke, you know, my son, and so he had a $\mathrm{m}$ uch more open perception on how to deal with that type of child than the principal from where he came from prior.

Interviewer: So understanding the disability was everything?

Interviewee: Understanding and understanding how they act out when they're frustrated was the issue, and that doesn't mean that all the behav ior issues went away. It $m$ eans that the teache $r$ was able to work through those b ecause he had such a wall up in front of him from the ... break those walls down, so ... Umm and so eventually the behavior disorder totally went away until we got to middle school, and then we ran into the same issue again, so ....

Interviewer: Any difficulties with work, part-time jobs, or ...?

Interviewee: Umm yes, he had his very first part-time job ... he was a stock boy and a bagger in a grocery store, and he could never get his schedule straight. Umm never ... if he would hear something about his schedule he wouldn't write it down, so therefore if there was a change in schedule ... it ... umm he didn't get it. Umm and so he eventually lost his job due to not being able to keep his schedule straight and not showing up for work when they were expecting him. Interviewer: Okay.

Interviewee: And I understood that totally, but that was a learning experience for him.

Interviewer: So how did he work through that?

Interviewee: Umm you know, surprisingly, it didn't bother him at first. Uh it bothered his dad and I a lot more than it bothered him ... umm, but when he went on to his next job he was much more in tuned with his scheduling. Umm if he wrote it down and even if he ... umm ... wasn't sure of his schedule he would ... a day in advance would call and say, "now am I supposed to work tomorrow" which is what we told him to do if you weren't sure, or if he lost his paper where he wrote his schedule down ... umm ... because, you know, the very first time he had a 
job he was probably seventeen ... Umm and so I chalked a lot of that up to immaturity and the fact that he needed to learn how the workforce works. Umm but then once he found another job I said you know ... I think he was probably eighteen when he got his second job and I said, you know, you're an adult now and you need to be treated like an adult. And I'm not going to take responsibility for making sure you get to work when you're supposed to be there. You need to take charge and this is what you need to do, and so he did it and umm he's been there ever since.

Interviewer: How does your son get along with others at college, home, or work?

Interviewee: Umm he gets along a lot better now at his age at college and at home. He has an older brother who ... I want to tell you that the older brother ... everything he touches turns to gold, so and of course the younger one, Frank realizes that that you know, that brother has that golden touch about everything. Umm we've never had major fist fights umm screaming matches ... umm we just never had that type of relationship in our family with that. But umm as far as his peers ... he never really had a lot of friends in school because ... I mean in I'd say in late elementary and middle school he never had a lot of friends just simply because of how his behavior was at school and how it was perceived by the other children. But if he did have friends they were several years younger than he.

Interviewer: So how did others perceive him?

Interviewee: Well, when he would shut down in class they would perceive that as a behavior disorder and I think that was ... that wasn't only because of what he did in the classroom to make the other kids feel that way, but I think also the teacher's reaction to his behavior ...

Interviewer: So?

Interviewee: Precipitated probably some of their ...

Interviewer: They perceived him as not being cooperative?

Interviewee: Uh huh, uh huh.

Interviewer: Okay.

Interviewee: Because they would hear the teacher make comments, you know that sort of thing. When she handled it negatively they reacted to it negatively.

Interviewer: So it sounds like that the teacher's lack of understanding of the disability created a lot of anger and animosity toward him that the kids picked up on?

Interviewee: Uh huh exactly. Cause he ... I mean we lived in a neighborhood where there were lots of kids for him to play with and he never wanted for playmates. He always had a bunch of 
playmates in the neighborhood, but at school it wasn't that much. I mean it was just a very different atmosphere at school verses home.

Interviewer: So any thing else you want to share with $\mathrm{m}$ e about his relationships with anyone, umm such as a girlfriend, or ...?

Interviewee: Well, he's only had one major girlfriend since uh-high school. And he dated her for probably... I guess probably close to a year umm, but she had a lot of issues in her family that I think caused issues with them and then plus the fact that he had never really dated. Umm I know her mother used to call us and say, "Well, my daughter's really disappointed because, you know, he called and canceled something they were supposed to do. But you know that was him wanting to be with his guy friends and not really knowing what a relationship was all about. And we would have to say to her mother, "This is new for him too" because the girl he dated was several years younger than he, and I said, "This is a new relationship for him, and so he's trying to work out that process as he goes along," so ... And eventually when he came to college she was still a sophomore in high school umm and he broke it off with her. But after he broke it off with her, for probably a month or two, he realized that he had made a really big mistake. And he was really very anxious over the fact that he made a mistake like that and realized that was an impulsive decision. And of course, by the time he realized all that it was too late.

Interviewer: She had another boyfriend?

Interviewee: She had moved on. Yeah and was very angry at him. Umm and so I ... you know, that's really had an impact on him when it come to females. 'Cause he ... we just talked about it the other day and he reverted back to that, so it's had quite a bit of impact on him, and I don't know that's he is ready to deal with it yet again, and that's been four years ago probably ... three years ago.

Interviewer: So the impulsivity of the decision-making caused him to regret breaking up with her?

Interviewee: Uh huh, uh huh.

Interviewer: Umm what types of services do you feel that your son needs from the college or community? Or what's been helpful and what do you think is needed?

Interviewee: Well you know I don't know that he really needs much from the college 'cause he's in the Student Support Program. I don't think he needs much college services except that he always needs help with his Math ... anything that has Math ... umm, and umm ... of course through the years of having a mom that's very in tuned with what he needs, I mean he's learned how to stay organized and stuff with what he needs to do. But from the community, I think that probably falls mostly in his dad's and I lap because we saw to it that when he was young that he got counseling for behavior modification, and to learn yes, we understand there are points when 
you get frustrated and angry, but this is in how you don't react and this is how you do react. So he's learned to handle his anger and frustration in different ways, which I mean, he got that from ... I mean, we put him in counseling. He was in counseling all through late elementary when all this started and through middle school and high school. You know he doesn't require counseling now, I mean I don't feel he does. Sometimes I think he would like to have someone to talk to other than his parents.

But as far as the community goes I mean I just think they ... The people he works for now ... umm he has worked for about three years now, and they're very understanding, but he's also a very good employee. I mean he goes out of his way and if he gets called in he goes in. And he's always the over-achiever at the place where he works and they know that. They rely on him very heavily, so umm I guess he's really getting everything he needs from the community. But I think it hasn't been because the community's conformed. It's because he has learned to conform to the community and what the standards are of the community.

Interviewer: So it sounds like that early on that relationship counseling and behavior modification were important tools that helped him move though that difficult period?

Interviewee: Oh absolutely and people in the community that did ... I mean when he got to middle school we had a counselor that we became involved with, and I again I call her another angel in my life because to this day I have a relationship with her. And to this day ... I mean she from the very first time she met him ... she said, you can do this and you can be successful. And umm she had a very Christian counseling background and umm had a lot of the same values that my husband and I had so it just really, really worked out. And I mean he said all time when he left middle school ... he said its time for you to go to high school. You need to go with me to the high school. I mean he really missed her ... umm so she was another pivotal person in his life. But I always tried to put him with people that would understand him and know what to do for him. And so I mean from that aspect the community really, really helped, and the fact that he was always in a place where he had understanding people, and if he wasn't I moved him to where they would be.

Interviewer: What about medication?

Interviewee: He was diagnosed with ADD when he was five uh in kindergarten. But he was in preschool-three year old preschool when the teacher came to me and said I'm reading oneminute stories. He cannot sit still. I put ... you know in three year old preschool they put them all in a circle and they sit down and read a short book maybe a minute or two, and after a minute he was up over at the shelves where the toys were getting attention from something else cause he couldn't keep his attention. So we knew early on there were issues there ... umm, but it was about when he was in kindergarten that he became medicated which he still ... he took stimulant medication until he was twelve. So he was probably six when he was in kindergarten because I held him back for maturity reasons, and so he probably took stimulant medication from six until twelve. But if you know anything about stimulants ... stimulants make the anxiety issues that he 
had already been diagnosed with much worse, so at the age of twelve is when they introduced Strattera, which is more of an anti-depressant, and we started on that. Matter of fact, the doctor prescribed it here in Hometown and they didn't even have it in any of the pharmacies here. So he got it so new umm and he has been on that now for ten years, and that's made quite a difference not only in the ADD but also with the anxiety issues, so ... And he also takes medication for anxiety as well and has since he was ... let's say eleven probably ... so long time.

Interviewer: So I guess you would say then diagnosing and assessing is important, medication has been helpful to him, counseling services have been helpful, and then the two tutoring services particularly?

Interviewee: It's a combination you know. I mean I try to ... I talked to a lot of parents who have struggled through the same things that I've struggled through with him. But the key ... I tell them the key isn't to just give them a pill and think it's going to go away, or the symptoms or the characteristics are going to go away umm because he may have to take that pill or she may have to take that pill the rest of their life. But they also need to be responsible for their behavior as they get older. And so I think it's a combination of learning yes, you may still need a pill to keep you from being impulsive or to say on task or yes ... But you have to learn also that there's consequences, and there's certain things that you can't do and with that you learn that through behavior modification. I think it's a combination. And then I think it's a combination for having your children in the people that understand because even though, you know, we've got great teachers out there. There's a lot of new diagnoses and new procedures for things that maybe some teachers aren't quite umm into like they should be, I mean ...

Interviewer: So would you think educating educators about $\mathrm{ADD} / \mathrm{AD} / \mathrm{HD}$ is ...?

Interviewee: Oh, I speak to a lot of them all the time about that because to me that's half the battle ... that's half the ... that's half of how your children are going mature and how they are going to be when they get older. If they've had bad experiences they are going to have a chip on their shoulder. They're going to continue to have those bad experiences if they can get with people that have had ... that have made an impact on their life then it's going to give them hope for there's going to be people down the road that'll continue to help them, so ...

Interviewer: Okay. Anything else you want to comment about?

Interviewee: About my son? Umm he is a very sensitive and loving individual with issues that umm he's working through.

Interviewer: And how's he doing academically?

Interviewee: He's been on the Dean's List all but one semester.

Interviewer: Wow! 
Interviewee: When he was told he would never graduate from high school, so you know ...

Interviewer: That's pretty significant.

Interviewee: Yeah, our goal is to let those people know when he graduates from college, so ... Which I tell a lot of them that I work with, you know, tell that person who didn't think you could do it-that you're there, so ...

Interviewer: It sounds like being a supportive parent has been a big impact for him too.

Interviewee: Uh huh. He relies on me a lot. Umm I don't know if you talked to him ... he probably told you that. Umm and his dad doesn't probably have the same understanding that I have, but it's simply that his dad hasn't worked in this field as long as I have, so he's really dealt with it from a parent's perspective on the outside that knew nothing about it. He learned a lot. Praising him, but he probably didn't have the patience that I did, but we got through it. That's the important part.

Interviewer: Thank you so much.

Interviewee: You're welcome.

Interviewer: The information you have given me has been really helpful and I hope to have all the recommendations compiled, and to send them here so you all get a sense of the research ...

Interviewee: Oh I'd love that.

Interviewer: And maybe find something useful in it or at least confirm that what you're doing is the right thing.

Interviewee: Well I've been here going on eighteen years, so you know, and we keep getting them so something must be working. That's all I can say.

Interviewer: Yes.

Interviewee: But I think it's great that you are doing this, so ...

Interviewer: Thank you,

Interviewee: I went to JDU (John Doe University). JDU, I don't think has any kind of program like we have here. They could probably benefit from it ... and other colleges too.

Interviewer: Yes. Thank you so much. 
Interviewee: You're welcome. Not a problem. 
Appendix D

Writing Samples

Graduate Student Example

Written Student Interview Questions

Alfred

1. How do you feel that $\mathrm{AD} / \mathrm{HD}$ has impacted your life?

2. What teaching strategies or professional services would you like professors or treatment providers to continue or change?

DADA BD is a major factor in my life seeing as I do not know what Ht is like to live with out AD/ HD. I do not believe that my AD/AD has held me back or keep me from doing any thing.

2. I was never a big fan of the ADThD medications. The Dross only seemed to make me out of it. Tutoring services have been the most effictive for me,

182 


\section{Undergraduate Student Example}

Written Student Interview Questions

Jack 
I feel that $\mathrm{AD} / \mathrm{HD}$ has had a great impact on my life. I feel that it has impacted in all areas of my life from learning abilities, social abilities, to personal abilities. With learning disabilities I feel it has impacted my life in the since that it makes it difficult for me to pay attention with all the noise and various distractions that are going on around me. Also it makes it difficult to explain to the people trying to teach me to explain how to educate me because they do not understand the various difficulties that I must overcome to understand. The various difficulties that they don't understand is how you may not appear and always act hyper but inside you head it feels as if your mind is racing or like a ping pong ball is just bouncing all over very fast; in addition to that they don't understand just how easy it is to become distracted and how hard it is to focus with various things going on.

With social abilities I feel it has impacted my life in regards to people that I associate myself with; like friends, family, and my girlfriend. The way I feel it impacts with regards to how I associate with is, my abilities to communicate with them, being able to stay focus and finish task that they asked me to perform, and how they don't realize that just because I'm not looking at them or seem to be paying attention when I am it is just difficult for me to focus and always look at them the whole time. Also with communicate it is hard for them to always understand what I am saying and for me to understand what they are saying to me. For example when people text me or I text them just the way we both may word things and miss words, because I am always leaving words out where I will say it in my head and believe I wrote it when in actuality I never typed it so, it at times hard to always get our messages across.

With personal difficulties it is hard in the since that you feel different from people around you. Also from private issues it can also be hurtful that some people may think because you have something you can't control makes you ignorant and will make fun of you and but you down 
because of it. Also it makes it hard trying to explain things to people and them not understanding you and because of that it can be very frustrating; especially if the medicine that you have taken never helped and done anything to suppress the hyperactivity.

The types of teaching strategies that I would like to see implemented in colleges across the nation would be a center like the Student Support Program at John Doe University to where all people with disabilities can receive help in their area of study and have new ways of understanding and different strategies to improve the way they study and prepare themselves for test. Also I wish that professors would become more educated in people with $\mathrm{AD} / \mathrm{HD}$ and help figure out better ways to implement new teaching styles to help all people better understand and focus in their class. I think if people were more educated on the area of $\mathrm{AD} / \mathrm{HD}$ it could help clarify the everyday adversities that people with $\mathrm{AD} / \mathrm{HD}$ must overcome and also it would show them that $\mathrm{AD} / \mathrm{HD}$ can be a really difficult obstacle that makes what may appear easy to someone without $\mathrm{AD} / \mathrm{HD}$ very challenging to someone who has it. 


\section{Appendix E}

\section{Observation Memos}

October 6, 2010

\section{Interviewee Alfred and Significant Other Alexandria}

23-year-old Caucasian male graduate student

Interview took place around noon and was finished after lunch.

Interviewee dressed casually in blue jeans and a tee shirt with his school's logo and color.

Alfred displayed many symptoms of functional impairments that present in individuals with $\mathrm{AD} / \mathrm{HD}$. Alfred's interview suggested impairments in concentration. He discussed his issues of trying to pay attention, boredom, listening, and lack of interest. Also, he seemed to be constantly looking off to the side as though struggling to organize his thoughts. Alfred also indicated an environment free from distraction is an important need for him.

Alfred did not indicate any type of organization issues in his responses to the semi-structured interview questions.

Alfred appeared to be hyper in his responses to the semi-structured interview questions. He presented with some jumping in subject matter and talking with his hands. Additionally, Alfred appeared to squirm in his seat as if he couldn't wait to get up and move around.

There did not appear to be time related issues in Alfred's interview. He indicated a need for extensions of time to learn academic materials in a college setting.

Alfred did not present any familial, peer or significant other relationship issues in his interview. Moreover, there did not appear to be any co-morbidity issues such a learning disability or mental health diagnosis.

Alfred discussed that he has received services such as medication from a community agency, but no longer utilizes this service.

Alfred appeared to have used academic services in the past and indicated historically he has done better with hands on learning (doing activities). Alfred also mentioned historical use of helpful techniques such as coding for memorization and flashcards. Presently, he appears to utilize the services of the Student Support Center that provides him with a distraction free environment for learning and testing. 
Currently there appeared to be a need for medication from a community agency as Alfred presented with concentration problems and hyperactive responses. Perhaps medication would improve focus and control hyper responses.

Alfred proposed there is a need for educators and faculty to be familiar with AD/HD. He also suggested a continued need for a distraction free environment. A Learning Style Analysis may be important to his success.

October 7, 2010

\section{Significant Other}

Interview took place in mid afternoon between three and four o'clock.

Interviewee dressed casually in jeans and a long sleeved tee-shirt type shirt with sleeves pulled up to her elbows.

Alexandria is a significant other to Alfred and she also has ADD. They have been dating for almost two years. Alexandria is very understanding of Alfred's functional impairments because she experiences some of the same difficulties. Alexandra described their relationship with the following quote:

"I think, together it's a good match because we understand one another, and we understand exactly what someone's going through when they're really stressed about something, or a test, or not understanding what a professor really wants from you."

Alexandria mentioned in her interview that Alfred appears to have impairments in concentration as in difficulty concentrating and not comprehending information the first time it is presented.

Alfred's significant other did not indicate any organization issues; except the need for routines. She did not indicate hyperactivity.

Alexandria indicated there appears to be time-related issues. She suggested that Alfred needs more time to learn academic material and that he needs to break up information and learning into smaller units with a break between each learning unit.

Alexandra reported that there appears to be relationship issues with other people. She said that Alfred mixes up words and is often misinterpreted. In addition, she indicated that he thinks too fast and uses incorrect words that create a situation that makes it difficult for others to decipher him. Next, Alexandria described the dynamics of their relationship as "... pretty good because we're both very vocal about what we want ..."

There did not appear to be impairments presented in work history. 
Alexandria indicated that co-morbidity is present. She indicated that Alfred has a learning disability, dyslexia.

In conclusion, Alexandria suggested a need for services in extensions of time to learn academic material, and an extension of test-taking time as especially important. She also indicated a need for Alfred to continue breaking up things (academic material and information) into smaller units for learning. Finally, Alexandria discussed a continued need for routines to prevent organizational issues. Communication skill building may be necessary to improve Alfred's communication with others. 
October 20, 2010

\section{Interviewee Bella and Significant Other Brittany}

18-year-old Caucasian female college freshman

Interview took place in the mid- afternoon.

Subject was dressed very casually with holes in her jeans and a painted tee shirt.

Bella believed she has had AD/HD from an early age, but was not diagnosed until college. Student Support Services diagnosed her at her particular college and she is in the process of getting medication from a local physician. Bella was tearful as she recalled her elementary and high years because she had experienced a great amount of family conflict and issues. During her interview, Bella did not make good eye contact and displayed fidgeting, twisting, and movements of the hand.

There appeared to be impairments in concentration in Bella's interview. Bella used the term "distracted" more than once to describe her impairments with concentration. Bella presented a lack of motivation and a lack of interest as indicators of her impairments in concentration.

Bella appeared to have possible organizational issues that have created difficulty for her in spelling and writing papers.

Bella appeared to have hyperactive responses as indicated by her movements and speech, which includes fidgeting and rapid paced conversation, respectively. Additionally, there appeared to be hyperactive responses in her relationships as presented in her behaviors and impulses.

Bella indicated time-related issues as she discussed feeling a time church when taking an exam and staying after class to finish the last few questions.

There appeared to be numerous relationship issues present in Bella's interview. These relationship issues were indicated by a lack of family support, lots of trauma in the family, and significant illness. Bella also mentioned "sister fights" which indicate sibling conflicts and relationship issues. In addition, she discussed breaking up with a boyfriend due to "boredom" in the relationship. Moreover, Bella appeared to have relationship issues with authority figures as indicated by conflict with her high school principal involving use of her cell phone.

Co-morbidity did not appear to be an issue in Bella's interview.

Bella is currently utilizing a community agency to confirm her diagnosis of $\mathrm{AD} / \mathrm{HD}$ and to receive medication for her $\mathrm{AD} / \mathrm{HD}$. She did not indicate using community services in the past.

Bella's significant other mentioned a need for services such as study groups, visual reminders as in flashcards, a time management advisor and a need for extra test time. 
October 20, 2010

\section{Significant Other}

Interview took place after Bella's interview in the afternoon.

Interviewee was wearing business casual attire.

Brittany is the maternal aunt of Bella. During Brittany's interview she described some of Bella's conflict with her family. Brittany also stated that Bella is very responsible, but lacks good study habits and organizational skills. In addition, Brittany presented Bella as not being a selfadvocate with her professors. Bella tends to lose important things such as her out of state driver's permit, and she has time management issues.

There did not appear to be any concentration impairments indicated by Brittany.

Brittany reported that Bella lacks organization.

There did not appear be any hyperactivity reported by Brittany.

There appeared to be time related issues as in making time to study.

There seemed to be no impairments in relationships with peers at college, but family problems were extensive. The student was intimidated by her professors.

Bella's aunt Brittany suggested a need for services in development of study skills and time management, a support system, and tutoring. She suggested that counseling might help this student resolve trauma in the family and develop social skills with authority figures. 
October 6, 2010

\section{Interviewee Clarice and Significant Other Christy}

19-year-old Caucasian female college freshman

This interview took place in the early afternoon.

Interviewee was dressed casually in jeans and a pastel colored sweater.

This student was extremely difficult to interview and not very verbal. Maybe I was too leading at times.

Clarice seemed guarded, nervous and tense. She also displayed co-morbidity obsessivecompulsive tendencies. She experienced difficulty answering questions, concentration problems, and her responses to the semi-structured interview questions were very brief and short. Clarice just started medication and being over-medicated could be an issue for her.

There appeared to be impairments in concentration issues indicated during subject's interview. Interviewee mentioned getting frustrated when others came up and started talking to her when she was trying to study. Clarice also mentioned, " not knowing what the material is telling you." This suggested comprehension issues.

There were no indications of organization issues or hyperactive responses indicated by Clarice.

There appeared to be time related issues as Clarice indicates she can't keep up with homework.

There seemed to be relationship issues with Clarice's brother in elementary school, but she wouldn't say what the problem was. She was also angry with her aunt who doesn't understand her cousin's AD/HD. Clarice reported she had good friends in college. She also indicated there was conflict when her parents "bug" her about homework.

There were no mental health diagnoses or learning disabilities suggesting co-morbidity.

Community agency services were utilized for taking medication. Clarice indicated that past community agency services included services at Hopes Children's Hospital and a resulting diagnosis of $\mathrm{AD} / \mathrm{HD}$ by this agency.

Academic services that have helped include tutoring and she has had the same tutor since first grade in elementary school. Also, she has had parental support. Clarice still uses tutoring services. In addition, she would like understanding and acceptance by professors. Use of a different style of learning may be helpful. Clarice indicated she loves to draw and is good with the numerical part of math, but not theorems. There may be a need for counseling with family members 
October 13, 2010

Significant other interview took place mid-morning.

She was dressed in business casual attire with black slacks.

Christy was Clarice's tutor. She has tutored Clarice from the first grade to the present for a total of 13 years. Their relationship is similar to a mother-daughter type of relationship. In addition, Clarice meets with Christy everyday to plan her day and set up daily calendars to help with time management issues. Christy is very personable and she is an educational specialist at this particular student support center.

There seemed to be impairments in concentration as she described Clarice as distractible.

There appeared to be organization issues as in Christy suggested that Clarice needs structure.

There were no hyperactive responses reported by Christy.

There seemed to be time related issues as Christy helps Clarice to keep an agenda and daily calendars.

There appeared to be relationship issues. Issues with socialization of peers was evident. She was shy, quiet and withdrawn. Clarice has had speech therapy in the past. Currently, she is in a social club at the Student Support Services. Christy reports there are no family issues just normal sibling "stuff." Her parents are sometimes frustrated with her. Christy discussed Clarice's social impairments because Clarice thought it was wrong to kiss her boyfriend. Christy suggested that Clarice is immature.

There did not appear to be any work related issues. Christy indicated that Clarice worked in the family company and ADD did not impact her work. Christy also indicated that Clarice gave $150 \%$ to her work.

Co-morbidity appeared to be an issue as indicated by Christy. Christy discussed the possibly of an Asperger's type of disorder and Obsessive Compulsive Disorder.

Community services that appeared to be used in the past include counseling or medical services for anorexia.

Community services that are currently being utilized include medication.

Academic services that have been used in the past include tutoring and the Wilson Reading Program. 
Current academic services include tutoring and help with time management and study skills. Christy indicated that Clarice still has difficulty getting her thoughts on paper, staying on task, and she also mentioned that the processing disorder is more of an issue than retention in that it takes her longer. Christy also suggested a need for behavior modification along with medication. 
October 6, 2010

\section{Interviewee Dianna and Significant Other Denise}

25-year-old Caucasian female graduate student

Interview was last interview of the day in late afternoon.

Dianna was dressed casually in jeans.

Dianna is a graduate student at her particular university and doing well academically with a 3.28 G.P.A. for her graduate work. She is very personable and friendly. She is articulate and well spoken. She also takes medication that seems to be working because she said her friends know when she misses a dose. She stated: "I take Adderall. They're set to release or what ever it is, so it last all day. So I mean my friends can tell when I have not taken it. They say Dianne have you taken your medicine?"

*Interviewer: What do they observe in you that make them ask that question?

"I'm just off the wall and everywhere like talking about two different things, and doing one thing and having a conversation and then skipping to another part of the conversation and just everywhere, not so good. Dianna also was very active as a child and she played sports in high school."

There appeared to be issues relating to impairments in concentration as reported by Dianna. She recalled not being able to pay attention in elementary school. Dianna also mentioned that in high school she forgot to turn in a paper and she got a $\mathrm{C}$ in the class. She indicated forgetting to take the paper to class. Dianna also recalled writing down homework and getting reminders from her mom to do the homework. She explained that in college she does not have reminders to do homework or to get up and go to school. Lack of interest affects her responsibility to get to class and do her work. Dianna also indicated that if she is off her medication she skips around in conversation and talks about two things at once (focus issue). She also discusses being distracted by students clicking pens and tapping fingers in class. Dianna reported that she had academic problems with reading and spelling in elementary school. She also mentions she did not want to do these subjects in elementary school. Her strengths in elementary school included math, science and physical activities, and her strength in high school was sports.

There appeared to be job issues relating to impairments in concentration as indicated by losing interest in tasks, boredom when not busy enough, and distraction. Dianna liked multitasking a lot. No impairments were reported with boss or co-workers.

There appeared to be organization issues relating to time and Dianna's need for a schedule. There appeared to be hyperactive issues as indicated by Dianna that she didn't sit still or couldn't sit down in elementary school.

There does not appear to be impairments in relationships as indicated by Dianna.

There appeared to be co-morbidity present as Dianna has dyslexia. 
Dianna indicated she has used a community treatment center in obtaining medication her second year at her university. She also mentioned having parental support.

Dianna reported helpful academic services she received in the past were teacher prompts and reminders to get information. She also reported that her parents sued the school system because they did not provide needed services for her dyslexia.

Dianna mentioned that her undergraduate grades were above 2.0 and when she transferred to her current university she received Student Support Services. These services included: 1) structure 2) tutoring, mentoring, and organizing, and 3) reminders to go to class. Dianna indicated finding an interest in sports was key to her college success.

Dianna stated she would like lectures recorded on line. She also indicates employees and professors need to understand AD/HD. Dianna also discussed the need for private rooms to take tests in so she can get up and stretch in the private room.

October 13, 2010

Significant Other Interview took place in mid-morning. Interviewee was wearing casual business attire.

Denise is a co-worker and friend of Dianna's. She indicated they share about $90 \%$ of their coursework because they are in the same graduate classes. Denise pointed out that they are sorority sisters and they hang out together. Denise's major concern for Dianna is lack of understanding from professors. She takes offense to some attitudes displayed by professors. She said, "So when I do see her experience issues with professors that kind of take the well, this is not how it's going to be in real life attitude, umm I take issue with that as a friend, and as a coworker, and as someone who works with people that have different types of learning disorders and you know AD/HD. So it's kind of ... I see it as a branch for her, but she is very polite with it, you know, and she's just kind of whatever ... you know, moves on to her credit."

Denise indicated Dianna's impairments in concentration during her interview. She mentioned that Dianna has no retention problems once she gets the material. Denise presented Dianna's issue of focus by indicating that Dianna can't follow lectures that are "not engaging." She also suggested that Dianna is distracted and she has distractibility issues. The focus and distraction issues were present in conversation not related to topic. Denise stated that she will ask Dianna, "Where did that come from," when Dianna has random thoughts off topic.

There did not appear to be any work issues reported by Denise. She did mention that Dianna's co-workers and supervisors know she has AD/HD. Denise indicated they are co-workers at the Student Support Services. 
Denise discussed Dianna's need for services. She proposed that professors don't understand $\mathrm{AD} / \mathrm{HD}$ and that they need education about AD/HD. Denise also mentioned that some of Dianna's professors say she won't get accommodations such as test time extensions and privacy in the field. Denise indicated that Dianna is better at hands-on learning. She also suggested more use of the ADA law. Again, Denise discussed that it takes Dianna more time to learn and she emphasized that Dianna retains the information once she gets it. 
October 7, 2010

\section{Interviewee Ellen and Significant Other Emma}

19-year-old Caucasian female freshman

Interview took place in the early afternoon.

Interviewee was dressed in jeans and a tee shirt with her school's color and logo.

Interviewee made no sense at times.

Ellen was a pleasant and bubbly student; however, she was distractible and jumped from subject to subject. During her interview, Ellen seemed to be distracted by her cell phone. In addition, she mentioned that she has reading comprehension problems and a learning disability, which indicates co-morbidity.

There appeared to be impairments related to concentration as indicated by Ellen during her interview. She mentioned comprehension issues in elementary school, but indicated they improved over the years. Ellen mentioned that when growing up she had to have a quiet room, free from the distraction of her siblings.

There appeared to be academic issues when Ellen mentioned that her writing is not very good. Ellen indicated literature was difficult in high school and that she had problems with writing skills in high school. She also discussed that she is good with technology and worked at her high school radio station. Ellen also indicated that science and math were positive subjects for her in high school.

There appeared to be work-related issues. Ellen reported that she didn't like the company or the boss that she worked for. She indicates he was always changing her schedule.

Ellen does not indicate any organization issues or hyperactive in her interview.

There may be time-related issues as Ellen mentioned her boss was always changing her work schedule.

There does not appear to be impairments in relationships. Ellen reported she has positive friendships and a positive relationship with her roommate and her roommate's brother.

There appears to be co-morbidity as Ellen indicated she thinks she has a learning disability.

Ellen indicated she has received medication from a community agency. Currently she is taking Concerta.

Ellen reported she had helpful services in high school. These include positive family support and extra help from teachers. Ellen indicated that outlining is a helpful technique for her. She also 
discussed her needs for tutoring, a quiet area for testing, and a reminder sheet of what is needed for class.

October 7, 2010

Significant Other Interview took place in the afternoon. Interviewee dressed casually.

Emma is Ellen's friend and she is very soft spoken. Emma indicates that

Ellen doesn't have very many friends because they do not understand her. She tends to leave out words when describing things and people say she is weird because her conversation does not make sense. Emma gives an example of Ellen's conversation in the following quote:

Interviewee: Like she doesn't make sense in conversations because she skips words and leaves out information. She told someone, "I rescued a dog ... threw it in the car." They said, "She's weird. We don't understand her.”

In addition, Emma says Ellen would benefit from an extracurricular group such as Campus Crusade to help her make friends.

There appeared to be impairments in concentration as indicated by Emma when she is discussed Ellen's issues with focus.

There does not appear to be any organization issues.

There appeared to be impairments related to hyperactive responses. Emma indicated issues with cognitive restlessness. She also mentions that Ellen skips words, leaves out information, and is disconnected in conversation.

Emma did not report any time related issues in her interview.

There appears to be impairments in her relationships. Emma indicates she is her only friend and that others think she's weird.

Emma did not mention any community agency services that Ellen may have used in the past. She did not indicate any current community agency services that Ellen may be using. Emma said that Ellen needs groups like Campus Crusade to make friends.

Emma does not suggest any academic needs for Ellen. Counseling may be helpful for relationship issues especially with peer relationships 
October 7, 2010

\section{Interviewee Frank and his Significant Other Frances}

23-year-old Caucasian male undergraduate student

Interview took place in the mid-afternoon.

Interviewee appeared to be wearing jeans and a polo-type shirt.

Frank reported having some issues with sleeping, but indicated he is getting more rest and feels some better. Frank seemed to rely on the encouragement of his mother to help him deal with his $\mathrm{AD} / \mathrm{HD}$ and co-morbidity of Generalized Anxiety Disorder. In addition, Frank indicated that he enjoyed playing in the college marching band. He also enjoyed this activity in middle and high school.

There appeared to be impairments in concentration as reported by Frank in his interview. Frank discussed changing from one elementary school to another and mentioned getting away from friends. He indicated his focus got better. Frank's concentration impairment continued to high school and he presented problems with focusing and not getting his work done. He mentioned that he wouldn't pay attention in Math. Frank described a lack of interest or possibly he didn't want to try or maybe a fear of failure leading to not trying. He discussed reading sports magazines, playing poker on the phone, and wanting to sleep during boring lectures in high school.

Frank indicated academic problems in math during elementary. He also mentioned he enjoyed gym and sports as positive outlets. In high school, Frank described poor grades and getting help in English. He reports getting Bs and Cs in English and Cs and Ds in math. He mentioned having difficulty in Spanish, but he presented Music (Band) and History as positive subjects for him. Frank indicated he still struggles with math in college.

Franks also presented focus as a work related issue.

There appears to be impairments in organization.

There does not appear to be any hyperactive responses mentioned in Frank's interview.

There appears to be time related issues as indicated by Frank. He mentioned scheduling, "time management and staying on top of things."

There appeared to be impairments in relationships. Frank indicated not having patience with coworkers. He suggested he had poor relationships with teachers, high school band friends, conflicts with band director, and argued with his dad in high school (dad's parents died within one month of each other). Frank indicated his relationships improved in late high school because he started thinking before speaking. In college, he reported the Band Director "telling us we're are great responsible adults ... proud of us." Frank indicated that the Band Director is encouraging. 
Frank reported co-morbidity in his interview. He mentioned that in elementary school he was described as mentally impaired with a "temper." In high school, Frank discussed his comorbidity as anxiety.

Franks described community services of medication. He reported his medication is Trazadone and he indicated seeing a psychologist. Frank mentioned that his mother works at Student Support Services so he has positive support when needed. He indicated he had and currently has tutors to break things down. Franks indicated that he wants others to know it takes him longer to learn.

October 13, 2010

Significant Other Interview was approximately three o'clock in the afternoon. Interviewee was dressed in business casual attire.

Frances is Frank's mother. She is very supportive of Frank and has been his advocate since his diagnosis at five years of age. She is a tutor with specialized knowledge of disabilities. Frances believes that community support such as counseling is helpful for those with AD/HD.

Frank appeared to have impairments in concentration as indicated by Frances in her interview. She mentioned that he could not pay attention from age six to 12 years old. Frances suggested that Frank has academic issues such deficits in math. "He has difficulty with the steps in the process and he loses his place or he can't remember the steps of the process." She indicated that reading is a positive for him and he loves to read. Frances reports that Frank made the Dean's List all but one semester.

There appeared to be impairments in organization as described by Francis in her interview. She indicated Frank needs schedules. Frances mentioned that Frank is disorganized, but he compensates by keeping his room neat as a pin.

Frances indicated that impulsivity (as a hyperactive response) appeared to cause a relationship problem for him with a former girlfriend.

There also appeared to be impairments in time related issues. Frances reported that Frank procrastinates. She also discussed his first job and how he couldn't get his work schedule straight, and as a result, lost his job. Frances mentioned that Frank got better with his scheduling at his next job. She indicated he is a good employee and still works for this employer, and has worked there for three years while in college.

There appeared to be some impairment in relationships. Francis reported positively that there were never issues at home. She mentioned that school was the only issue for Frank. Frances also discussed the issue of changing schools in the fifth grade. She indicated the new principal understood Frank's impairments because he also has a disabled son. She also describes Frank's 
new teacher as great. Frances reported relationship and socialization issues in elementary school. She mentioned that Frank did not have many friends at school, but he had lots of playmates in the neighborhood. Frances indicated that Frank impulsively broke off his relationship with his $10^{\text {th }}$ grade, high school girlfriend when he went to college. She describes that he now feels it was a mistake and he hasn't dated since.

Frances indicated that Frank has had counseling from a community agency in the past. She mentioned he previously took stimulants from six to 12 years old, but he is now taking Strattera.

Frances suggested that Frank needs a supportive services program. She indicated that Frank needs to learn that there are consequences with behavior modifications.

Frances suggested academically that Frank requires tutoring in math. She also mentioned there is a need for educators to have an impact on students and give them hope. 
October 13,2010

\section{Interviewee Georgia and Significant Other Grace}

21-year-old African American female undergraduate student

Interview took place in the mid-afternoon.

Interviewee casually dressed in jeans and a tee shirt.

Georgia was a very shy young lady who has AD/HD and co-morbidity with a speech disability and possibly other learning disorders. She was distractible and had trouble organizing her thoughts. Georgia had difficulty speaking and looked away as though she trying to organize every response to the semi-structured interview questions. Also, occasionally she referred to herself as just a child. She may still view herself as a child instead of an adult.

There appeared to be impairments in concentration presented in Georgia's interview. Georgia indicated that she was not affected by AD/HD until high school then she mentioned middle school. She also mentioned that her grandmother argued with her about not doing schoolwork. Georgia describes herself in high school by saying, "I got a little rebel." Georgia also indicated that her grandmother wanted her to be in stage again, but she reported that she lost interest in this activity. In high school it appeared that Georgia had comprehension issues as she reported tests were difficult for her. Georgia also discussed that she blanks out during test. She indicated that in college they "put me in a curtain, so I won't get distracted."

Georgia appeared to have academic impairments. She reported that in high school she got As, Bs, Cs and sometimes Ds and Fs. She mentioned that she did poorly in Home Ec. Georgia also indicated she was doing poorly in Geometry, but after she received tutoring she did much better and was able to pass class. She also discussed that she enjoyed sports and especially soccer in high school. Georgia indicated that in middle school she helped with a stage production. She also discussed her interests in middle school, which included sports and music, but she could not play the flute. Georgia said in college she likes writing, music and reading.

There did not appear to be work related impairments. Georgia reported no problems with work, co-workers or supervisors.

There does not appear to be impairments in organization.

Georgia did not present any hyperactive responses in her interview.

There appeared to be time related issues in Georgia's interview. Georgia indicated her time issues are related to learning. She described this impairment by stating, "Learning takes me a long time to do because I'm slow."

There appeared to be relationships issues present in Georgia's interview. Georgia reported that her mom was into drugs early in her life, but got off them when she was in high school. She mentioned that her grandmother raised her and she called her "mom." Georgia indicated that 
they argued. She reported that her dad is not in her life, and grandmother divorced grandfather, but she still visited him. Georgia also reported that grandmother had kicked her out at times for getting on her nerves, not doing chores, and being lazy. She states that grandmother told her she was mental, dumb, and stupid. Georgia discussed a break-up with her boyfriend last week after one month of dating. She indicated he told her he was not attracted to her. Georgia mentioned that she has had previous on and off relationships.

There appeared to be co-morbidity present in Georgia's interview. Georgia indicated that she had a speech disability.

Georgia indicated using a community service when she saw a therapist (psychologist) in the past. Currently, she is not on medication for $\mathrm{AD} / \mathrm{HD}$, but that could be a community service need for her.

Academic services included use of the Student Support Services and an area free from distraction when testing.

October 20, 2010

Significant Other Interview took place approximately around 3: 00 p.m.

Interviewee dressed in olive green professional attire.

Grace is Director of the Student Support Center at Georgia's particular university. She stated Georgia had issues with relationships and had difficulty with her math classes. In addition, Grace pointed out that Georgia seemed a little needier than other students and she stopped by the office for frequent advice on relationships. Grace also indicated that immaturity might be an issue for Georgia.

Georgia appeared to have impairments in concentration as indicated by Grace. Grace referred to a conversation she had with Georgia, "I was talking to her about a situation, the way she saw it and the way I saw it, but she has hard time listening to what someone else is saying." Grace indicated that the root of the problem was focus.

Grace also discussed Georgia's academic problem related to her impairments. She revealed that Georgia has taken a developmental Math course three times and has not yet passed. She also has failed other classes.

There appeared to be impairments in organization. Grace indicated that Georgia needs structure and she was currently working with a learning specialist to help her get organized.

Georgia did not appear to have any hyperactive responses reported by Grace. 
There appeared to be time issues as reported in Grace's interview. Grace mentioned that Georgia has difficulty with the organizational issue of time management.

Grace indicated there appears to be relationship issues relating to Georgia's impairments. Grace mentions that Georgia is needier than most students and has lots of question about relationships. Grace indicated Georgia has difficulty with socialization issues and making friends. She reported that Georgia's friendships don't last and her relationships with boyfriends don't last very long as well. Grace mentioned that Georgia misunderstands others' feelings and misreads body language. She indicated that Georgia was almost overly sensitive and immature.

Grace did not mention any community services that Georgia had received in the past or is receiving now. She suggested counseling services for relationship issues and for Georgia to work on understanding herself. In addition, Grace suggested that an exercise program may help Georgia to focus. Currently, Georgia is not on medication, but she may need and benefit from medication.

Graces indicated that academically she receives tutoring, help with time management and setting goals, and she is receiving help on her reading skills. Georgia also participated in the Student Support Services social club for students. 
October 13, 2010

\section{Interviewee Hal and Significant Other Harold}

19-year-old Caucasian male undergraduate student

Interview took place late afternoon and was the last interview of the day. Interviewee was dressed casually.

Hal mentioned that he had great difficulty reading and was very slow at reading. He took considerable time to read the participant cover letter for this research. He also had some focusing issues and tended to look away. Hal reported being called stupid by his math teacher in elementary school and talked about getting a tutor. He states, "Well, eventually I was having problems in Math. It was actually Math class that they ... she called me stupid cause I was doing uh on the board, and I couldn't do it, so ... and it was during the times tables I think. I just couldn't memorize those things. And then eventually we got me a tutor. I think it was in middle school when I jumped three grade levels in a year."

There appeared to be impairments in concentration as indicated by Hal in his interview. Hal reported that in elementary school he wasn't paying attention and would zone out. He mentioned that he had a focus issue. Hal discussed his issue of skipping lines when reading in elementary school. He explained his concentration impairments in the following quote: "Yeah, I lost my place a lot of times, memorizing stuff, remember what the teacher said to do (instructions). I couldn't memorize the times tables" (order of them). He also reports in high school he had distraction issues with people turning pages, pencils scratching, and typing.

In addition, Hal reported academic issues caused by his impairments. He also mentioned some activities he enjoyed in elementary and high school. Hal indicated that he had issues with reading. He liked recess and he enjoyed imaginative fort battles in elementary school. Hal reports that in high school English was difficult and writing was hard, but he made mostly As in his subjects. He also reported playing football in high school. Hal indicated in middle school he jumped three grade levels in math because he had a tutor. Currently, in college he has a 4.0 this semester. He also mentioned that he can't play football because it's too time consuming. Hal reported he still has reading issues (i.e. keeping up with the reading). He indicated his writing is getting easier with outlines.

Hal indicated he has organization issues in college. He mentioned using outlines to help with his writing. Hal also reported he has to have a list for him to get things done (homework).

Hal also discussed that he has hyperactive issues. He mentioned that in high school football helped to get the restless energy out. He stated: "If I don't take medication hyperactivity comes out." 
Hal reported that he has time issues in that it took him double or triple time to read. He indicated in high school he still studied longer and harder and he retained the information. He also mentioned it took a long time for him to memorize football plays.

There appeared to be relationship issues indicated by Hal in his interview. He indicated that he did not have many friends in elementary school. He reported they described him as slow, and he didn't know if they understood him. In high school members of the football team were his peers. In college he has friends at the Student Support Center. He indicated that he does not have a girlfriend because he feels he couldn't the handle relationship.

Hal indicates he has had relationship issues with authority figures. He reports that teachers called him stupid in elementary school. In college, Hal feels that some professors are annoyed with students if they have AD/HD.

There does not appear to be any family relationship issues reported in Hal's interview. He mentioned that he and his parents have always been close. Hal indicated that there is a lot of $\mathrm{AD} / \mathrm{HD}$ in his family.

There does appear to be work related issues for Hal as in remembering to do his work. He recalled having reminders from his mom to do work tasks.

There was no mention of co-morbidity.

Hal mentioned using community agencies in the past when he saw a psychologist and received medication. He indicated he is taking Concerta.

Hal mentioned he did receive academic services in middle school. He reported having a tutor who used candy to modify behavior. Hal indicated that the tutor used flashcards and reminders to refocus him. In high school, he mentioned his mom helped gather information for research papers. Currently he uses the Student Support Services of tutoring to explain things in a different way. He indicated that he could have his test read to him, but states it's too distracting. For his reading difficulty, Hal discussed using the Kurzweil program that reads to you.

October 15,2010

Significant Other Interview took place in the morning. Interviewee was dressed in casual clothing.

Harold is Hal's older brother. They attend the same university and both have AD/HD. Harold and Hal share an apartment and Harold reported having to help organize his brother. Harold struggles with dyslexia and attended a boarding school in high school that specialized in dyslexia. He also talked about unsupportive faculty in dealing with disabilities. Both students 
are interested in attending medical school. They rely on the student support services quite a bit in helping to achieving their study goals:

*Interviewer: So you both use the tutoring center pretty extensively?

Interviewee: Probably more that other students do umm 'cause ... I don't know ... we both want to actually get into med school if we can.

Harold reported in his interview that $\mathrm{Hal}$ has $\mathrm{AD} / \mathrm{HD}$ and minor dyslexia, and he indicated he also has AD/HD and dyslexia.

Harold suggested that Hal has concentration issues because it takes him longer to do things. In addition, he indicated that Hal has organization issues because he has too many things to do at once.

There did not appear to be any hyperactive issues or responses reported in Harold's interview.

There appeared to be time related issues as indicated by Harold. Harold mentioned that he has to structure Hal's time. He reported that in high school Hal would study after football practice from six until midnight every night, and in college Hal studies from seven until midnight.

There appeared to be some relationship issues relating to professors, but no relationship issues with family or peers. Harold indicates he lives with his brother and goes to college with him, so he understands the AD/HD. He sees himself as a mentor to Hal. Harold mentioned that he has to limit social activities because there is not enough time. He discussed some of their activities as going to the gym from 4-6 p.m., participating in a Christian group from 7-8:30 p.m. on Mondays (have friends in the group), and going bowling or to the movies on Friday with a female friend. Harold described an issue he had with a professor. He indicated this professor discouraged him from taking the class. Harold suggested he needs support and encouragement from professors.

Harold discussed the academic services that he and Hal use. He mentiond that they get tutoring at the Student Support Center, scheduling to get homework done, taking tests in a distraction free environment at the support services. He suggested they have a need for extra time when taking tests. Harold also suggested that Hal needed to have a course on how to adjust to college and set up routines.

Lastly, Harold indicated they have used a community agency recently because they now take Straterra which is better than stimulants. He reported they are trying to eat better. 
October 15,2010

\section{Interviewee Isaac and Significant Other Israel}

22-year-old Caucasian male undergraduate student

Interview took place in late morning.

Interviewee was dressed in casual clothing.

Isaac seemed very focused on his studies, but had some issues with unsupportive faculty. He had trouble with reading and his parents enrolled him in a program called Fast Forward in which he went from a second grade reading level to an eighth grade reading level in one summer. Also Isaac talked about his aunt being an advocate for him because she has a background as a high school principal.

Interviewee: "I got along with them really well. Umm my aunt is the one that really helped me the most. Like she has really helped me and my mom a lot by telling me what I should do because she used to be a high school principal and she was really helpful."

In addition, he takes Adderall. He seems to do well with organizing his thoughts. Isaac made good eye contact, but talked a little fast and was short and to the point.

There appeared to be concentration impairments presented in Isaac's interview. In referring to high school he states: "I'd read I wouldn't comprehend it. Literature material ... would confuse me ... hard to understand." Isaac indicated in referring to college: "I have to push myself."

Isaac reported in his interview academic difficulties related to his impairments. He also discussed activities he participated in during elementary and high school. Isaac indicated in elementary school he made Bs in his academic subjects and he played sports. He explained that English and Writing were difficult for him, but History and Science were positive subjects for him and he made As in those subjects. Isaac reported that he never received a "C" grade in high school. He also mentioned that he always made the honor roll and maintained a 3.0 or higher G.P.A. while in high school. In addition, Isaac indicated that Literature continued to be difficult and writing was still a hard task for him. He also mentioned that he was good with computers and enjoyed playing golf. He reported winning a golf championship while in high school. Currently, in college he has a 3.19 G.P.A. and is majoring in marketing. He indicated that marketing is not a hard major and he continues to be good in science.

Isaac indicated in his interview that he does not have any issues with work. He explained that he first worked as a server then went to the kitchen, and finally he moved to food prep. He reported that his peers griped at him for forgetting to put a lobster fork on the plate.

There did not appear to be organization issues as reported by Isaac in his interview. He also did not report any hyperactive responses or time issues relating to his impairments. 
There appeared to be relationship issues with authority figures as reported in Isaac's interview. He indicated that in elementary school a teacher said he'd never make it to college. He reported positive relationships with friends, parents, and siblings in elementary school. Isaac mentioned that his aunt was a high school principal and she was his mentor because she would tell him he could do it. In addition, Isaac mentioned that he had positive relationships with family, teachers, and principles during high school. Currently in college, Isaac described how some professors seemed rude, nasty, unsupportive, and they don't like to help kids. He also reported that some professors say Student Support Services is stupid. Isaac indicated he has positive relationships with friends. He discussed his break-up with his significant other girlfriend, after two and onehalf years. He described how she said hurtful things to him including: "I should have never been with you" and she said, "I wasn't fun."

There was no co-morbidity reported in Isaac's interview.

It appeared that Isaac used community agency services in the past. Isaac reported that he was prescribed medication (Adderall) in elementary school and he reports having 15 years of counseling with a psychologist. Isaac may still use a community agency to obtain medication for his AD/HD.

Academic services were received. Isaac mentioned being enrolled in the Fast Forward reading program, receiving speech therapy, and having parental advocacy. At college, he is currently receiving tutoring, in which the tutors highlight important information in his books. Isaac indicated his study habits have improved. He also suggested that he wanted professors not to think he's stupid, but to realize that he's as smart as anyone else. In addition, he mentioned it would be helpful if all professors used Power Points to highlight key points.

October 20, 2010

Significant Other Interview took place late in the afternoon. Interviewee was wearing a black basketball jersey and jeans.

Israel is a good friend and former roommate of Isaac's. He stated in his interview that he learned good study skills from Isaac and that Isaac always makes good grades, but gets" hyped" sometimes. Israel also indicated that Isaac has relationship issues with friends and his girlfriend that he had at college.

Interviewee: " His study habits umm I remember I actually test him a little bit like he actually helped me with my study habits some. Umm he told me that umm there's nothing wrong with taking a break. Don't overwhelm yourself with stuff. I always learned that about him. He would go over something for a maybe good hour or 30 or 40 minutes close to an hour then he 
would take a break from it take some time and go do something else. He would say, "Israel lets play a game of madness" to get his mind off of it, and then he would get right back to it and see what he learned from that 30 minutes ago."

Interviewee: "Yes, he gets good grades. Definitely a 3.0 like I don't know how many times he's been called up for a 3.0, so he works very hard on his work. I do know that for sure."

"But like some of my friends would be like man Isaac he's just real hyped. I don't want to stay a while. Everything just so got to be so loud and the way he talks and things. And I was trying to explain to him that's just the way he is you know. I learned to accept that by being his roommate. That when he comes that's just the way Isaac's going to be. Like when he comes I say I know one thing that it's going to be loud. That's cool 'cause I'm used to that. And he's going to want his point to be across cause he wants to make sure you understand where he's coming from and what he's saying."

Israel suggested in his interview that Isaac has impairments in concentration. He reported that Isaac does not think things through he just reacts. He recalls a time when Isaac was overwhelmed with taking five classes and the amount of work involved. He described Isaac as being stressed and hyped. Israel indicated that Isaac was stressed about his grandmother being ill and he told him to stay focused on his schoolwork.

In addition, Israel reported that Isaac has at least a 3.0 G.P.A., but changed from a medical degree because it was too overwhelming. He indicates that Isaac switched to business and sports, and he mentioned that Isaac knows his "stuff" on the radio.

There did not appear to be any organization issues as reported by Israel.

On the other hand, Israel reported that Isaac had hyperactive responses. He states: A lot of people notice he's hyped ... the way he talks."

There does not appear to be any time issues relating to Isaac's impairments.

Israel did report relationship issues. Israel described his friends' reaction to Isaac while they were roommates. He mentioned that his friends would leave when things got loud. Israel indicated that his friends' thought Isaac was rude because "he interrupts, cutting me off, and not being respectful." In addition, Israel described how a lot of people would say that Isaac was pushy and he would explain that Isaac just wants to get his point across. Israel also reported family issues when his grandmother was ill. He described that Isaac was having significant other problems with his girlfriend at the same time. Israel also discussed that Isaac's impairments affect his peer relationships. He recalled that he was hurt when Isaac moved out because his girlfriend told him to. 
There appeared to be a need for community services as reported by Israel. Israel suggested that Isaac needs someone to talk to when he is overwhelmed. Israel discussed that Isaac's girlfriend always pushed him to work out and she told him he wasn't good. He reported that she pulled Isaac's self-esteem down and he felt used. He also felt that his friends in Nevada used him. Israel suggested counseling services for his friend to help him get a lot of ideas out.

Israel reported academic strategies that Isaac used while they were roommates. He recalled Isaac highlighting his notes and blasting music in his ears. He indicated that Isaac's papers were in the upper 90's, and suggested the strategy helped Isaac to focus more on his work. He also reported that Isaac would study 30-40 minutes, take a break, and play a game of madness. He mentioned that Isaac also received tutoring services. 
October 15,2010

\section{Interviewee Jack and Significant Other Jim}

20-year-old Caucasian male undergraduate student

Interview took place in the morning.

Interviewee was dressed casually.

Jack talked about having a hard time learning to read and his mother's frustration with him.

He also talked about being hyper in elementary school, but he says his friends were hyper too from drinking sugar-filled soda. He mentioned at his friends became frustrated with him because they were tired and he wanted to keep doing whatever activity they were doing. Jack also reported his father called him stupid and told him he would not make anything of himself. In addition, Jack was very hurt by his father's statements and he indicated that he has no use for him. Jack also has other disabilities such as dyslexia, a reading disorder and English language disorder, which indicate co-morbidity.

Interviewee: Yeah I think she just got ... I know she just got really, really frustrated trying to teach me how to read because I know for the longest time I think she really thought I was faking and that I really could read this. And because like the little teeny tiny like flip books like that probably take ... took most kids $10-15$ minutes it would take me like $2 \frac{1}{2}$ hours to three hours to read it. And I think she would just get really frustrated with me because I couldn't figure it and learn it, and she's like this is so easy.

There appeared to be impairments in concentration as indicated by Jack in his interview. He reported in elementary school it was "difficult to concentrate ... focus ... pay attention on what teacher was talking about ... and understand." Jack described his distractions in elementary school as: "tapping feet, pencils ... talking, and looking at the bright colored pictures. $\mathrm{He}$ indicated his distractions continued into high school as he mentioned he looked out the window, and he recalled people talking and tapping. Jack also reported he was not interested in what the teacher said. In college, he noted he is bothered by monotone professors and is distracted in class by monotone professors.

There appeared to be impairments in academics as indicated by Jack in his interview. He reported making A's and B's then all A's in elementary school. Jack mentioned he enjoyed sports in elementary school. He discussed having reading problems and writing issues with grammar and sentence structure. Jack described how it took him $2 \frac{1}{2}$ hours to read what others could read in 10-15 minutes. He also explained his confusion of the greater than and less than signs in Math. Jack reports Math and Science as his positive subjects in elementary school. In high school, Jack indicated making straight A's and was fifth in his graduating class. He still enjoyed sports, but again he mentioned difficulty with reading. In addition, Jack reported he was good at Science, History, and Math. Currently in college, he reported having a 3.7 G.P.A. Jack 
mentioned that he had difficulty with Organic Chemistry because he couldn't visualize the rotation of elements. He described having to relearn study habits and explained that reading is still slow for him in college. Jack mentioned that he received Student of the Year at the Student Support Services.

There appeared to be minor work issues relating to Jack's impairments as indicated in his interview. He described working at the Student Support Services and not being sure how to answer questions that are sometimes asked. He reported that he has good relationships with his co-workers and he described them as family away from family.

There does not appear to be any organization issues reported by Jack in his interview.

There appeared to be hyperactive responses relating to Jack impairments as indicated in his interview. He recalled having to "wear out a lot of energy" in elementary school. He described how playing sports in high allowed him to "release energy."

There did not appear to be any time related issues presented in Jack's Interview.

On the contrary, there appeared to be numerous relationship issues relating to his impairments. Jack mentioned that AD/HD didn't have an impact on his elementary school friends. He recalled his dad called him hurtful names such as stupid. He also reported that his parents divorced while he was in elementary school. Jack described how his teachers became frustrated with him and he was put in lower classes in $2^{\text {nd }}$ and $3^{\text {rd }}$ grade.

In addition, Jack reported his maternal grandfather was his mentor and they golfed together. He also mentioned that in high school his friends didn't know he had academic problems and they would say that was a dumb or stupid question. He indicated that he missed words or letters when communicating with his girlfriend and she didn't understand. Jack reported significant other problems when his friend told lies to his girlfriend. He also mentioned his dad was never there, but he was close to his grandfather.

In college, Jack indicated that most of his friends have $\mathrm{AD} / \mathrm{HD}$. Jack described that he realized he had AD/HD when he came to college. He also mentioned that his mom told him he took Ritalin when he was little. In addition, Jack reported he has communication issues with his current girlfriend. He indicated they understand what each other says.

There appeared to be relationship issues with his professors. He stated his Biochemistry teacher is a "complete jerk." Jack mentioned other professors are good and that they teach from different perspectives. Lastly, he described the Student Support Services as close family.

There appeared to be co-morbidity present in Jack's interview. He reported in addition to the $\mathrm{AD} / \mathrm{HD}$ he also has dyslexia, a reading disorder, and a written language disorder. He mentioned that he had testing last summer when he came to college. 
It appeared that Jack used community agency services in the past. He indicated he was on Ritalin when he was little. Currently, there does not appear to be any community agency services used because he does not receive counseling or use medication now.

There did not appear to be any academic services that were used in the past. At college, he received tutoring, help writing papers and studying for exams. He indicated when testing he gets lost with the bubbles so his tutor marks them for him. Jack suggested training professors to understand $\mathrm{AD} / \mathrm{HD}$. He also requested that professors not to be monotone during their entire talk.

October 20, 2010

Significant other interview took place around 11:00 a.m.

Interviewee is wearing a light blue dress shirt with dark slacks.

Jim is Jack's tutor in science classes. He mentioned that Jack has trouble with getting complete notes in his classes. On the other hand, he stated Jack is well organized and spends his time studying. Jim also mentioned that Jack gets along well with people probably better than he does. Interviewee: "He gets along with people a lot better than I do. He is much more sociable."

In addition, Jim indicated a more detailed Learning Analysis would benefit all students:

Interviewee: "I think a ... if there was a test design to measure like how do you learn things the best. I think that would help them a lot ... any student. Really would help them a lot like", "This is how you take notes very well. This is how you learn. This is what you should focus on. These things are more complicated for you. This is the strategy to help you deal with it."

*Interviewer: So are you talking more about like a learning style inventory?

Interviewee: Yeah.

*Interviewer: "Umm like whether people learn auditory, visually, kinetically ... those kinds of things?"

Interviewee: "Uh huh. Yeah and better information on how to utilize those because we are ... like here at Student Support Program we are ... Those are mentioned to us and this is how you can do this, but I think there's more ways to do it and more like looking forward (indiscernible). There's more variations on how to do it than just the way they teach us."

*Interviewer: "Okay so you would like more information about catering to people's individual learning styles."

Interviewee: "Yes."

*Interviewer: "So that you can base your tutoring on that student's learning style."

Interviewee: "Uh huh. And be able to do it a lot quicker because as it stands now the first semester with the student you're still feeling each other out and gathering how each like ... This is how they learn ... This how I need to adapt our sessions to help facilitate that." 
There appeared to be difficulty in concentration for Jack as reported by his tutor, Jim. Jim indicated that Jack's teacher goes too fast and Jack can't get everything down in his notes.

There did not appear to be any work issues related to Jack's impairments as Jim mentions, work tasks "just fine and everybody likes him."

There did not appear to be any organization issues reported by Jim in his interview. Also Jim does not report any hyperactive responses.

There appeared to be time issues relating to Jack's impairments as indicated by Jim in his interview. He described the teacher going too fast and Jack can't get everything written down.

Jim indicated in his interview there could be relationship issues with professors in that certain professors don't work for some students.

Jim does not report any co-morbidity for Jack in his interview.

In addition, Jim reported that academic professors need to post notes on line for Jack and other students. He also suggested Student Support Services using a Learning Style Assessment to determine "how you learn best."

In summary, it appears there are functional impairments in concentration and organization. There seems to be a need for extra time to get things accomplished for many students. There was a lot of co-morbidity.

Words that might be search for concentration could be distraction, focus, and memory. Maybe forgetting? Organization issues are noted for most of the students with things like scheduling. Hyperactivity was evident with restlessness and fast paced conversation. Words are skipped as though the person is in a great hurry.

Many students seem to have relationship impairments especially with authority figures, parents and professors. There's considerable impairments in significant other relationships such as girlfriends or an absence of any dating relationships or multiple short-term relationships.

There seems to be a need to search for more indicators of these general ideas. 


\section{Appendix F}

Vita

\section{SYLVIA A. WRIGHT, Ed. S., M.Ed., LPC, ALPS}

OBJECTIVE

SUMMARY OF PROFESSIONAL EXPERIENCE
Administrative or clinical position in a mental health area or professional teaching position.

Management Experience: I have held the following administrative positions: Program Director of out patient substance program; Chairman of two Boards of Directors for substance abuse programs; Director of Community Me ntal Health Services for a three county area; Clinic Administrator for a county mental health center; Crisis Intervention Coordinator providin $\mathrm{g}$ on call em ergency mental health services for six counties. Develope $d$ and implemented two mental health partial hospitalization programs. All positions required leadership skills in areas of program development, day-to-day clinical supervision and operations, recruitment and training of staff.

Clinical Experience: I have provide d therapy to child ren, adolescents, adults, and families in m ental health and substance abuse in outpatien t, day treatment, and residential settings for both private and for profit settings. Currently, Director/Owner of Sunrise Counseling Services in Princeton, West Virginia practicing as a Licensed Professional Counselor for ten years in the areas of mental health and substance abuse.

Consultation Experience: I have ta ught as guest or adjunct faculty at several colleges and univ ersities in the areas of psychology, counseling and human relations management at Bluefield College, Indiana University SE, University of Louisville, Sullivan Jr. College of Business; provided supervision for graduate counse ling internships for colleges and universities and supervised individuals for licensure for the West Virginia Board of Exam iners in Counseling; provided statewide and agency workshops, and written several gran ts or Medicaid approved programs. I have developed prevention educati on programs in subs tance abuse and parenting.

Marketing Experience: Provided televised presentations, provided community workshops, and develope d marketing materials such as brochures, and business cards. 
Strengths: Excelled in the areas of supervision and therapeutic interventions. Excellent teaching abilities. High creativity resulting in the development and im plementation of innovative program $\mathrm{s}$ in the $\mathrm{m}$ ental health field, such as day treatm ent programming for chronically m entally ill patients.

Credentials: 1) Completed Education Specialist Degree at Marsh all University with a $\mathrm{m}$ ajor in Counseling. Dissertation study on functional impairments of college age adults w ith Attention Deficit/Hyperactivity Disorder through West Virginia Univer sity to com plete a Doctorate in Education with a $\mathrm{m}$ ajor in Curr iculum and Instruction and a $\mathrm{m}$ inor in Counseling. Completed the required doctoral level course work to become an Approved Licensed Professional Supe rvisor for the W . Va. Board of Examiners in Counseling. Obtained an M. Ed. from Indiana University $\mathrm{SE}$, with a specialization in counseling. Internships: Community agency counseling (substance abuse field) while at Indiana University Southeast. School counseling internship, grades 5-12, through the WV College of Graduate Studies. Licensures: Previously was a Licensed Mental Health Professional state of Florida 1985 - 1988; Provisionally Certified school counselor 1992, grades 5-12, Stat e of WV; Currently Licensed Professional Counselor in W V, effective December 1996. Currently an Approved Licensed Professional Superv isor through the West Virginia Board of Examiners in Counseling.

Professional Associations: AMHCA (Am erican Mental Health Counselors Association WVLPCA ( West Virginia Licensed Professional Counselors Association).

VOLUNTARY WORK EXPERIENCE MAY 1997NOV 1999.
West Virginia Licensed Professional Counselors Association

1) Secretary of Board of Directors '97 - '99 and again in 2011

2) Editor of Newsline for WVLPCA' 97 - 2001

3) Co-Chairperson of committee to explore/define requirements for the licensing of addiction counselors as licensed professional counselors '98 - '99 